\title{
"LITTLE PEOPLE CAN LEARN ABOUT RACE": THINKING WITH THE WAKE IN A FIRST-GRADE CLASSROOM
}

\author{
A Dissertation \\ presented to
}

the Faculty of the Graduate School

at the University of Missouri

In Partial Fulfillment

of the Requirements for the Degree

Doctor of Philosophy

by

OONA R. FONTANELLA-NOTHOM

Dr. Candace R. Kuby, Dissertation Supervisor

May 2019 
The undersigned, appointed by the dean of the Graduate School, have examined the dissertation entitled

“LITTLE PEOPLE CAN LEARN ABOUT RACE”: THINKING WITH THE WAKE IN

\section{A FIRST GRADE CLASSROOM}

presented by Oona Fontanella-Nothom,

a candidate for the degree of doctor of philosophy,

and hereby certify that, in their opinion, it is worthy of acceptance.

Professor Candace R. Kuby

Professor Amalia Dache

Professor LaGarrett J. King

Professor Angie Zapata 


\section{Dedication}

For my dad.

Thank you for your trust, love, courage, and humor.

I miss you every day and I am so grateful for the time we had together.

This song has new meaning for me now... thank you for sharing it, and so much more music with me.

"The moment we said goodbye

Silence tore across the sky...

Gone before its time

There goes your shadow down the highway

Out on that road I couldn't find

While I crawl like a scorpion

Slowly to the new word

Across these miles of prairie

Full of melancholy time"

Jennifer Warnes, "Prairie Melancholy,” (2001) 


\section{ACKNOWLEDGEMENTS}

First, I would like to express my heartfelt gratitude to both Ms. Rotter and her students. Although I cannot name them all here, this dissertation would not be possible without all of you. Ms. Rotter, you are truly a caring, risk-taking, and amazing educator. I have learned so much from and with you over these past two years. I am proud to call you my friend. I am excited to see how we continue to collaborate in the future and looking forward to all the great opportunities that await you as you finish your own dissertation project!

I am so grateful for the strength, support, kindness, and scholarly knowledge from everyone on my dissertation committee. I regularly tell everyone I know what a powerhouse committee I have. You all continue to push me to think, read, question, and write in ways that only make me better. Dr. Amalia Dache, the first time I heard you talk about theory, I was blown away and thought "I need to get to know her!" I am so grateful for your time and expertise-Each time we talk I walk away with new literature to read, new questions to ask, and excited about the possibilities ahead. Thank you for your mentorship. Dr. LaGarrett King, thank you for sharing your deep expertise and knowledge regarding race and racism with me. You always push me read and know more and I am so grateful. You also help me think critically about the language I usewhenever I write or think about new or newness, I always hear you in my head saying, “is anything really new?” Thank you for your feedback and support. Dr. Angie Zapata, you showed me kindness before I even officially met you! You offered up your home to me and my family not knowing who we were, and we are all so grateful for your generosity and trust. I have learned so much from you throughout my $\mathrm{PhD}$ program- 
about selecting children's literature and approaches to sharing the wonder and joy of books, building teacher-researcher collaborations, and developing myself as a researcher. There have been countless moments where I doubted myself and my process, but you were always there with positive support. Thank you for believing in me. Dr. Candace Kuby, the phrase 'thank you' will never be enough to contain my tremendous gratitude for your mentorship, support, generosity, and patience over the past four years. I have to imagine that I was not the easiest advisee to work with, and I am grateful for the time you spent, working to support me in the ways I needed most in that particular moment (which often changed!). I have learned so much from you, as well as the experiences you have provided and facilitated. Being a student your classes has provided me space to think through the questions and wonderings I had about being a researcher with young children and teachers. Your thoughtfulness and intentionality about how to work and think-with teachers has been instrumental for me. Thank you for providing permission to explore ways of thinking, writing, and (re)presenting that were most helpful to me! Writing and researching with you allowed me to see the joy in embarking upon unknown and uncertain paths. Thank you to you, Nick, and Carlann for taking us in and caring for us when our start in Columbia was unstable. It helped us to feel like we supposed to be here (when everything else seemed to say we should leave!). Your support has helped to make me a better person and scholar - thank you for accepting me as I am.

My journey as a doctoral program has been a rollercoaster. Filled lots of highs and lows that I do not believe I could have survived without the support of fellow doctoral students. There are so many people I have met, talked, and learned with over these four years. Thank you all. I would like to highlight three specific people that have 
significantly shifted my growth, learning, and belief in myself in positive ways. The first is Tamara Hancock. Tamara, thank you for your friendship. Without your desk positioned directly across from mine, I'm not sure I would have made it. For the conversations, laughs, tears, and writing — I felt sustained by our friendship throughout my time as a doctoral student. Christy Goldsmith, you were one of the first friends I made here at Mizzou. Thank you for being willing to share a hotel room with me (now that I know you so well, I recognize that choice was a big deal!). Thank you for carrying my suitcase across the country when you barely knew me! I appreciate your support throughout the years - the constant words of encouragement, validating the questions and frustrations I had/have, and for your kindness. I am so appreciative of the time you took to read over my dissertation and provide feedback that I know have only made my writing stronger. Traci Wilson-Kleekamp, teaching, talking, and learning with you has been a highlight of my doctoral program. I have enjoyed our conversations about Black Feminisms, antiblackness, and racism. You are a philosopher and have so much to share with the world through your thinking, writing, and activism. I can't wait to read your book one day soon.

I wouldn't have been able to complete this dissertation without the love and support of my family. My dad repeatedly shared with me that I am seem to be born with a strong sense of justice. My parents were bold and unafraid in their choices to talk about injustice, social issues, and have difficult conversations with me. Both of them were passionate about their work and provided great exemplars of what deep engagement in your professional practice looks like. Duke, our dog, has been my dissertation companion. Sitting with me as I continue to write at all hours of the day and night has 
reminded me that I am not alone. Jack, thank you for your patience as I have been consumed by this project over the last year. Your creativity, silliness, questions, and hugs kept me going when I felt like I would never finish. Thank you for reading over parts of it and reminding me about the importance of ongoing consent. You are the best son anyone could ever hope for. I'm excited to read your dissertation one day. I love you so much! Josh, there is no way this could happen without your trust, faith, partnership, and love. Who would have thought we would spend four years of our lives in Missouri?! Thank you for supporting my dreams and desires as they took us in different directions. This last year has been a tough one — but you were there every step of the way. From providing lots of edits, holding my hand during tearful conversations, listening when I needed to vent, finding a way to navigate a home filled with endless piles of books and papers, and reminding me that what I had to say was worthwhile—-thank you. I'm so glad and grateful to be your partner in life. I love you all the manies, always. 
ACKNOWLEDGEMENTS .........................................................................................................................ii

LIST OF FIGURES ................................................................................................................................... ix

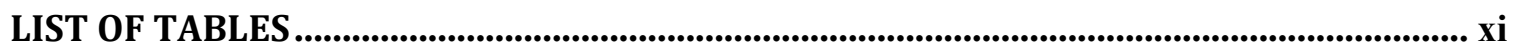

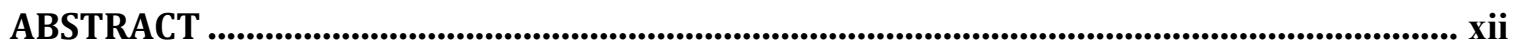

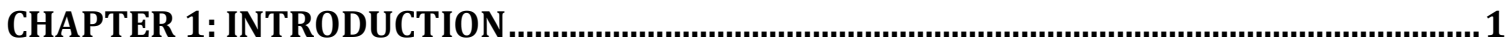

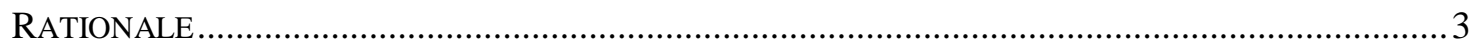

Why Should We Teach About Race and Racism With Young Children? ................................. 3

Are Race and Racism Appropriate Topics for Young Children?.......................................... 8

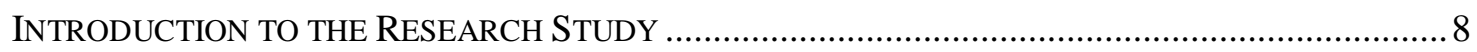

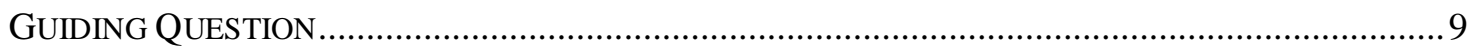

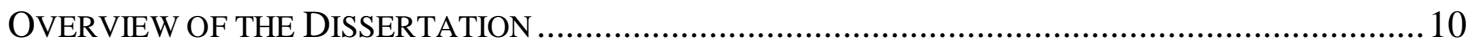

A Guide for the Reader ................................................................................................ 10

CHAPTER 2: REVIEW OF THE LITERATURE ………….....................................................11

HISTORICAL PERSPECTIVES OF CHILDREN'S UNDERSTANDING AND/OR THINKING ABOUT RACE

R

Learning About Race With Children's Literature ………………………………………...... 16

Critical Literacy Approaches to Teaching About Race and Racism .....................................24

Transforming Race Talk in Classrooms .......................................................................2

Reconceptualizing Early Childhood Education............................................................... 31

Exploring Antiblackness and the Protection of Whiteness in Early Childhood Education ... 37

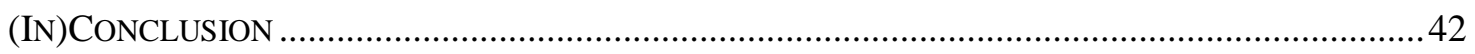

CHAPTER 3: RACE CONCEPTUALIZATIONS AND THEORETICAL UNDERPINNINGS....... 44

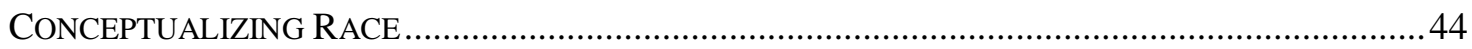

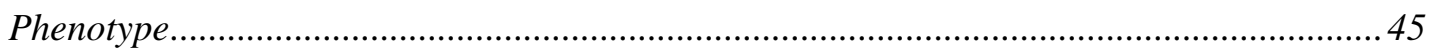

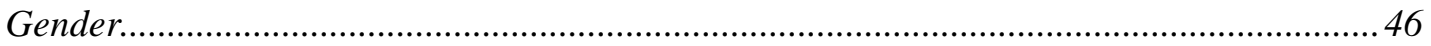

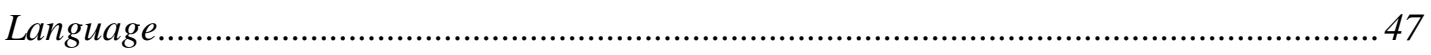

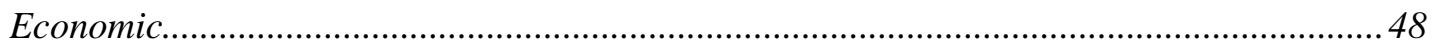

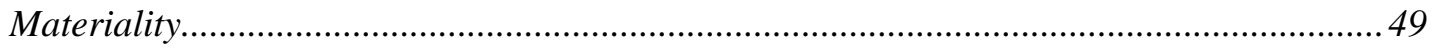

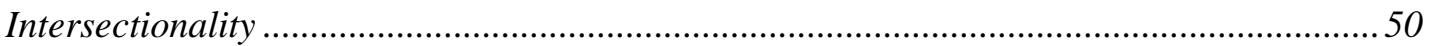

THINKING ABOUT RACE IN THIS DISSERTATION STUDY: ANTIBLACKNESS AND AFRO-

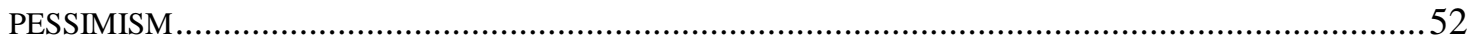

Afro-pessimism and Antiblackness ............................................................................52

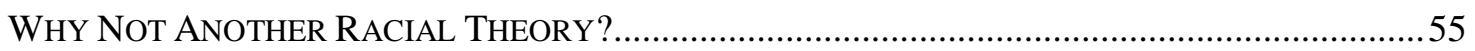

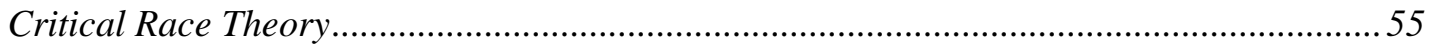

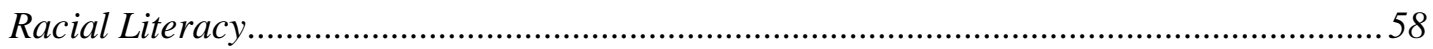




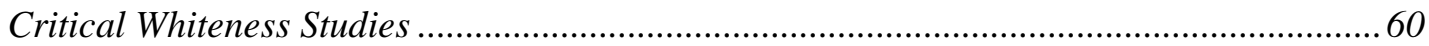

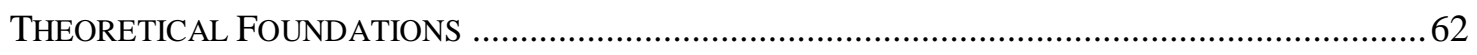

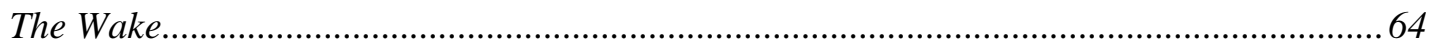

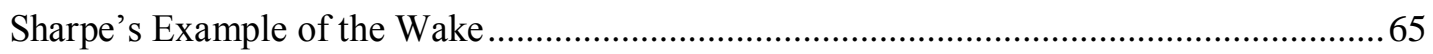

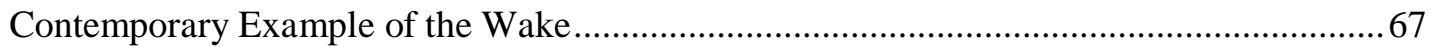

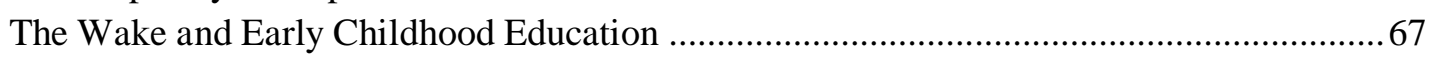

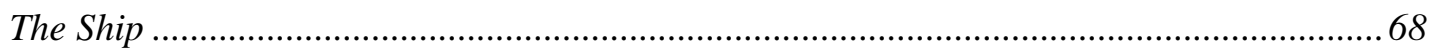

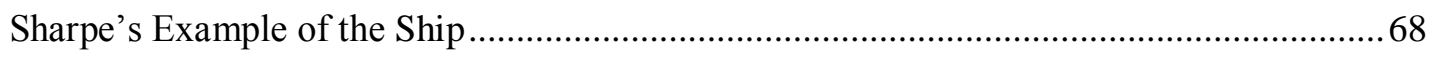

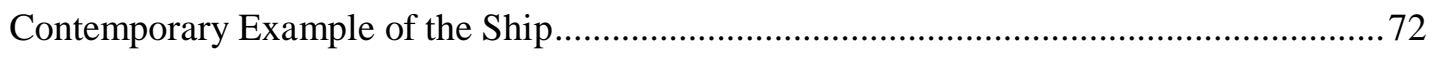

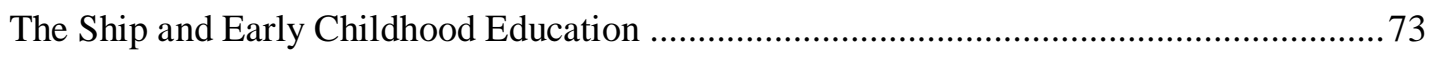

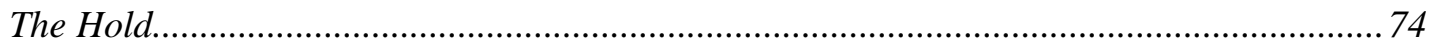

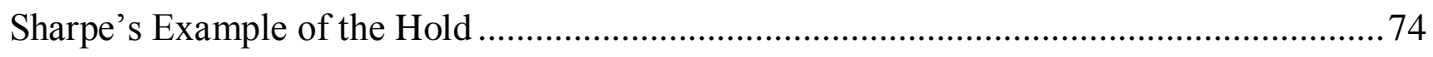

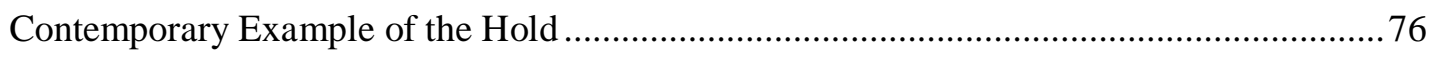

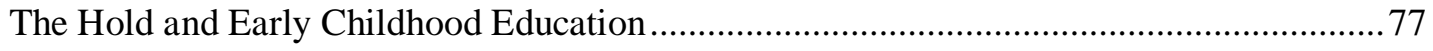

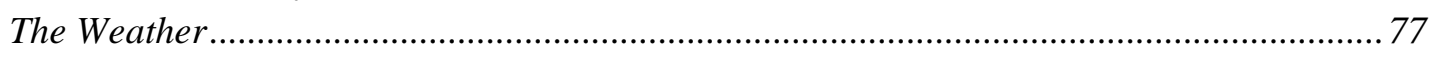

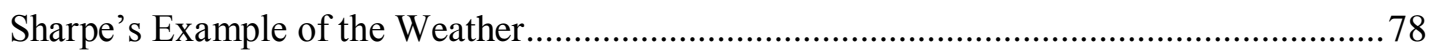

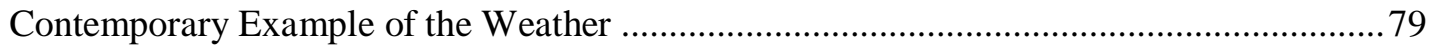

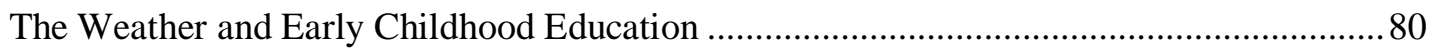

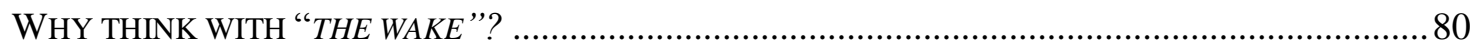

Ethical Considerations of Thinking with Antiblackness ...................................................... 81

How Ms. ROTTER's STUDENTS CONCEPTUALIZED RACE ................................................... 82

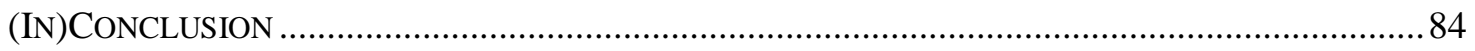

CHAPTER 4: CONTEXT, METHODOLOGY, AND RELATIONAL CONSIDERATIONS ........... 86

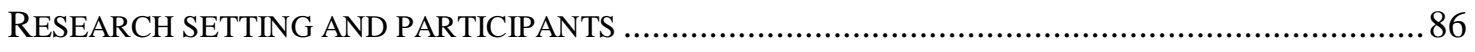

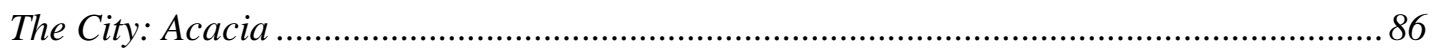

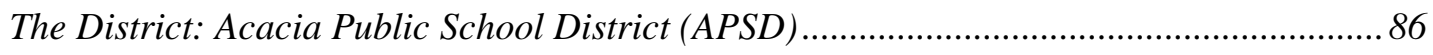

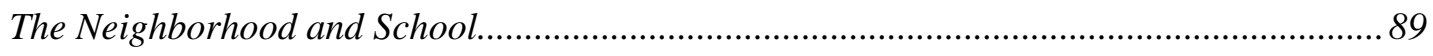

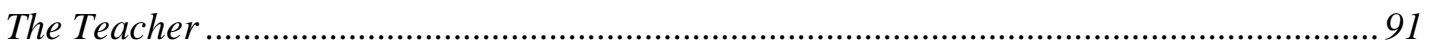

Photos of Ms. Rotter's Diverse Literature Rich Classroom .................................................. 95

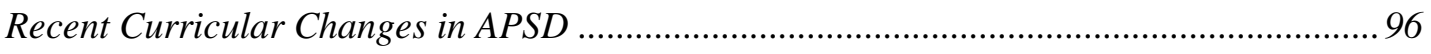

Developing a Research(ing) Relationship .................................................................... 97

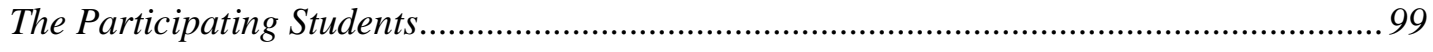

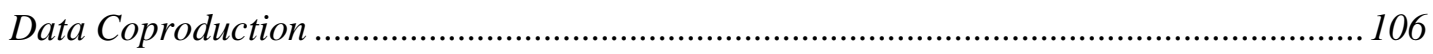

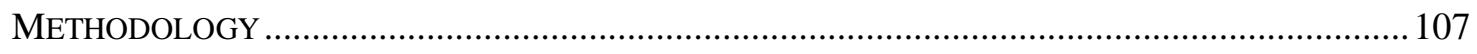

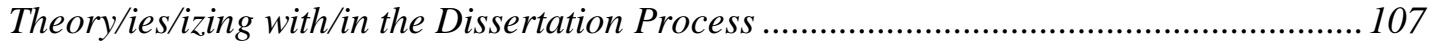

Thinking with Theory ................................................................................................ 107

Methodological Considerations When Thinking, Working, and Researching with Ms. Rotter

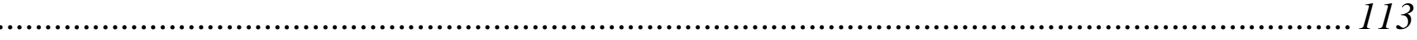

Ethics and Positionality: In Other Words, "Why This? Why Me? Why Now?” (Patel, 2016)

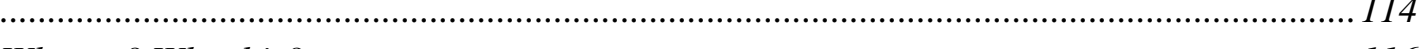

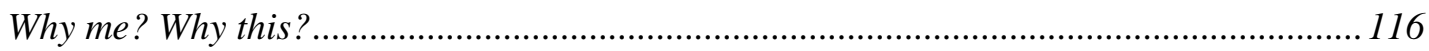

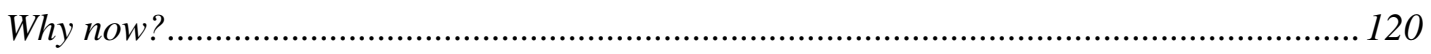

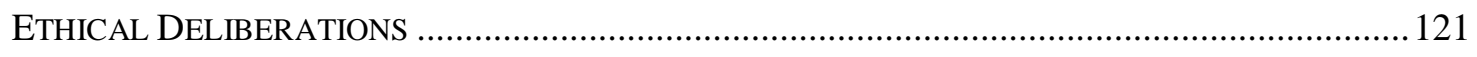

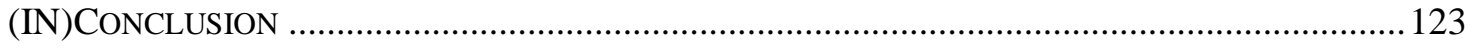




\section{CHAPTER 5: THINKING WITH/IN MOMENTS FROM MS. ROTTER'S CLASSROOM ........125}

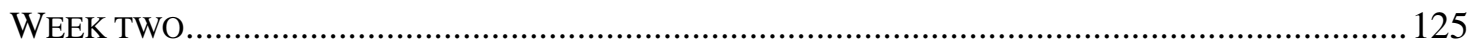

Whole Group Discussion: So what is race? What is racism? ............................................ 125

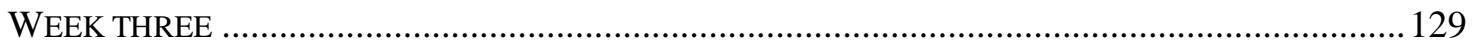

The Case for Loving: The Fight for Interracial Marriage ……........................................... 129

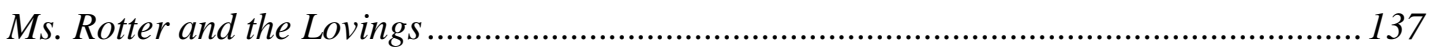

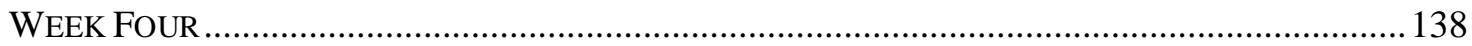

Through My Eyes: 'The Wall' as a Solution? .................................................................. 138

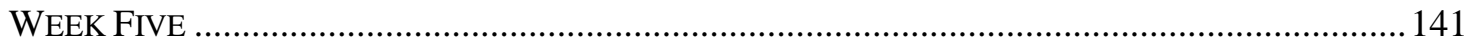

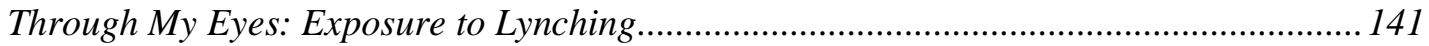

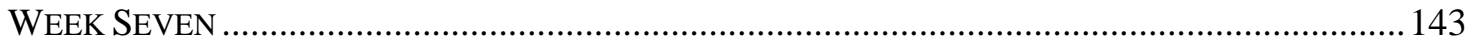

Separate is Never Equal: Sylvia Mendez and Her Family's Fight For Freedom ............... 143

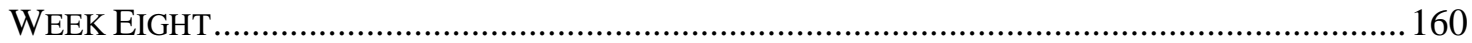

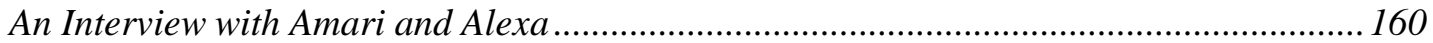

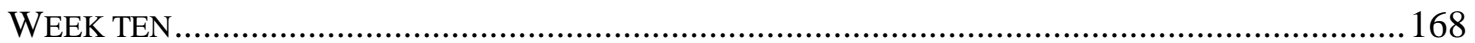

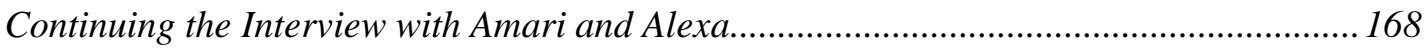

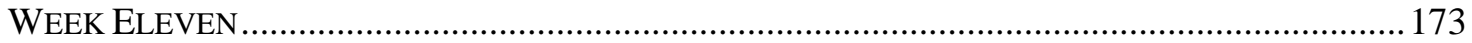

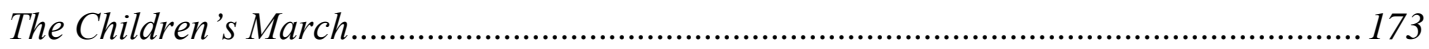

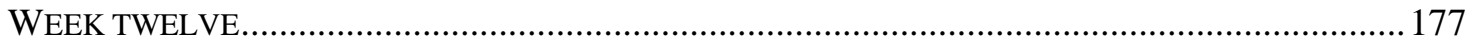

A Conversation with Penny: "Where are the books about Black people and white people?"

Strange Fruit: Billie Holiday and the Power of a Protest Song

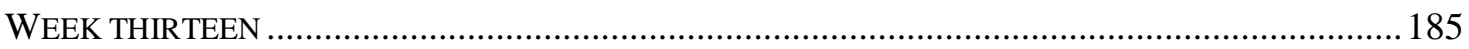

Opinion Writing: Should We Read Books About People of Different Races? ...................... 185

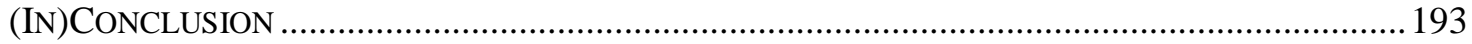

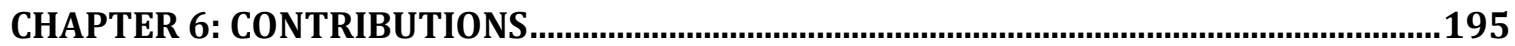

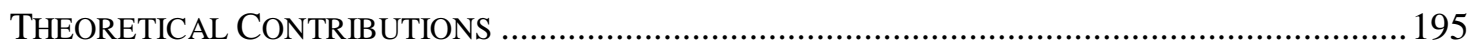

Challenging Our Relationships With and To The Past..................................................... 196

(Re)Thinking Orientations When Learning About Race and Racism ................................ 199

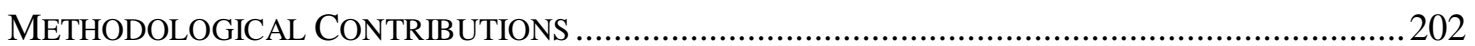

The Choices we Make with Children Matter .........................................................................2202

How we Work-With and Conceptualize Teachers Matters ....................................................205

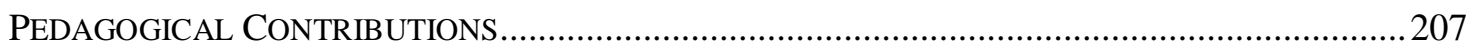

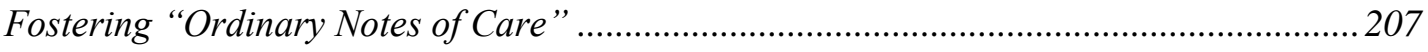

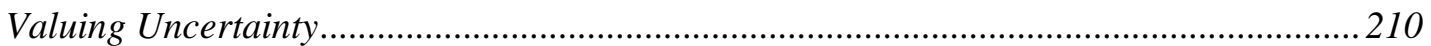

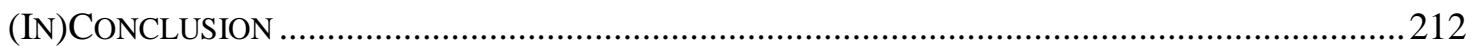

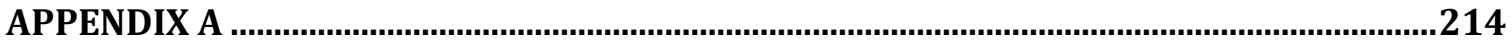

APPENDIX B

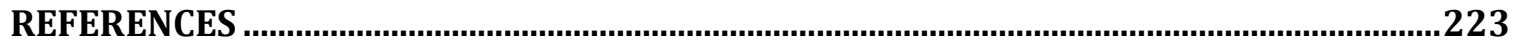

VITA 


\section{LIST OF FIGURES}

Figure 1: Walkway under Moving Chains with mechanized chains overhead ..................71

Figure 2: Installation adjacent to St. Louis arch with view of chains from top................71

Figure 3: Note to Jonathan Brown's family to cut his locs..........................................73

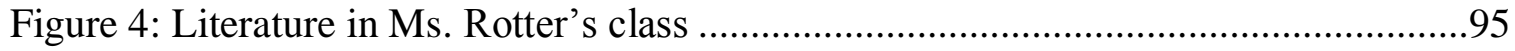

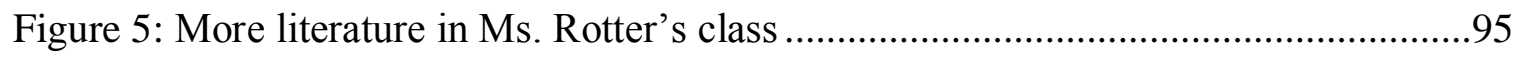

Figure 6: Literature display in Ms. Rotter's class .................................................95

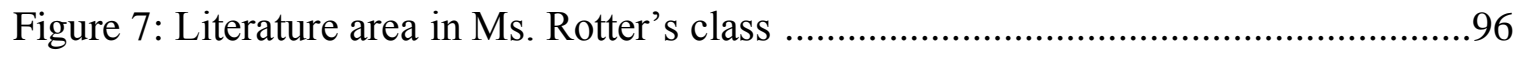

Figure 8: Diverse literature poster in Ms. Rotter's class ........................................96

Figure 9: Illustrations demonstrating the differences in segregated water fountains .....131

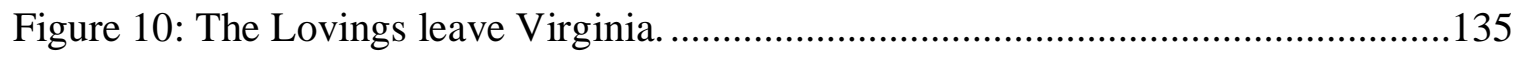

Figure 11: Illustration demonstrating the segregation in public pools ..........................149

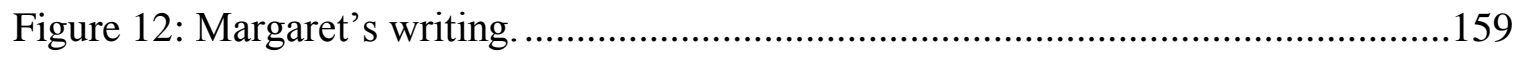

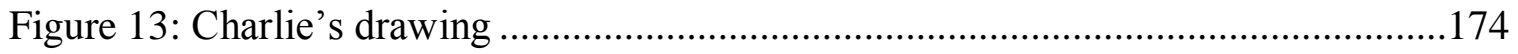

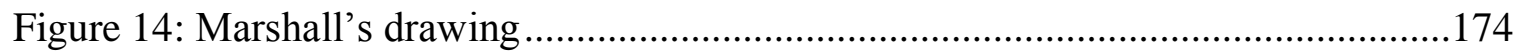

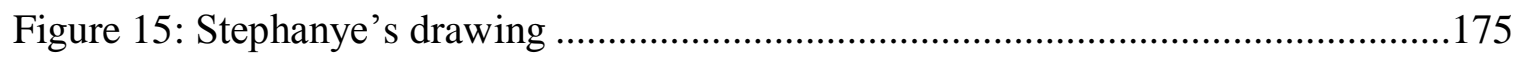

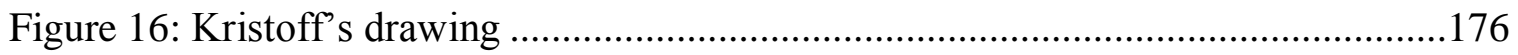

Figure 17: Illustration depicting child marchers being water hosed by the police .........177

Figure 18: Audience members listening to "Strange Fruit" being performed .................184

Figure 19: Ms. Rotter's question prompt for writing your opinion about reading books

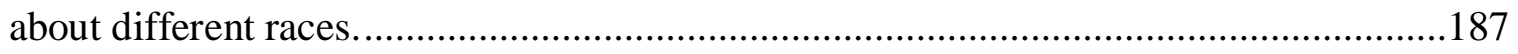

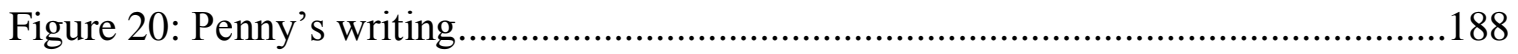




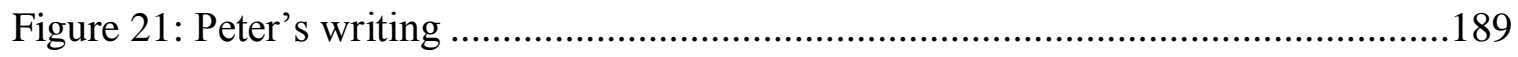

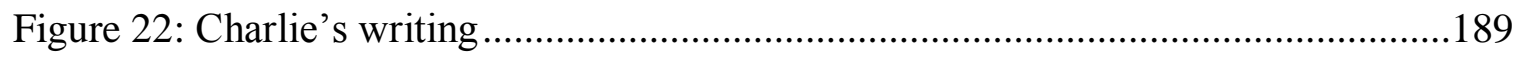

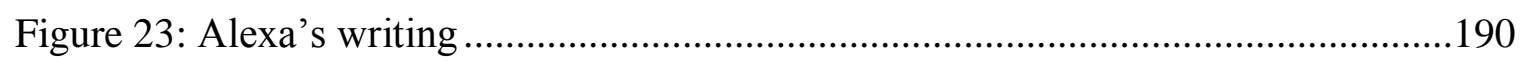




\section{LIST OF TABLES}

Table 1: Demographics of Acacia Public School District During the 2018-2019 School

Year

Table 2: Demographics of RB Elementary During the 2018-2019 School Year ..............90

Table 3: Demographics of the Students in Ms. Rotter's Class During the 2018-2019

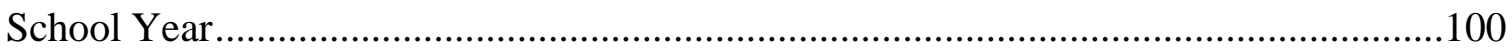




\title{
"LITTLE PEOPLE CAN LEARN ABOUT RACE": THINKING WITH THE WAKE IN A FIRST-GRADE CLASSROOM
}

\author{
Oona R. Fontanella-Nothom
}

Dr. Candace R. Kuby, Dissertation Supervisor

\begin{abstract}
This dissertation sought to explore the processes and actions that unfolded in a first-grade classroom when teaching and learning about topics of race and racism. I developed a research(ing) relationship with the classroom teacher, where we collaborated and worked together. The theory of the wake, which is grounded in antiblackness and Afro-pessimism, and the four theoretical concepts within, was engaged to inquire how these theoretical processes can be recognized when teaching and learning with young children. A thinking with theory methodology were engaged to bring about valuable questions and implications during the classroom research. A discussion of contributions related to theory, methodology, and pedagogy are described.
\end{abstract}




\section{Chapter 1: Introduction to the Study}

Before introducing this research study, I provide a vignette of an experience when I was a preschool classroom teacher. This moment grounds my thinking and engagement in this research study.

I was in my classroom getting ready for the school day when a parent of a student walked in and asked me, "What did you all talk about yesterday?" My practice as a teacher was always to display classroom materials (such as: read aloud literature, questions that were guiding student inquiry, and/or individual or student group work). I looked over to where the materials were from yesterday and saw the book Remember: The Journey to School Integration by Toni Morrison (2004). We had read this book the previous day and so I shared the book with the parent, explaining what we had read, learned, and talked about. I inquired if her daughter was okay and asked if she had talked about the book. The parent told me that her daughter had not mentioned reading the book, but had broken down in tears in the parking lot of a supermarket after school. When I asked why, she shared (I am paraphrasing):

She noticed a homeless person outside of the supermarket and began crying. When I asked her what was wrong, she mentioned the homeless person. She told 
me, "Mom, all the homeless people I see have brown skin. I don't think they are treated right and it is just not fair." I just didn't know what to say to her. Did you talk about homeless people?

I answered no. I returned to the book, and shared the illustrations from the pages we had read the previous day. I pulled out my clipboard with my anecdotal notes from the day that included the questions her daughter had asked about segregation and the connections she made. "Perhaps she made this connection on her own?" I suggested. "Hmm, maybe" the parent responded, looking over the pages of the book. "But she was just so sad," she shared with me. She continued, "I want her to learn about these things, but does she need to be so sad?"

This story occurred seven years ago, but it was a critical event in my teaching career, and I think about it often. I am haunted by the question the parent asked me: "I want her to learn about these things, but does she need to be so sad?" I honestly cannot remember if or how I answered the question. I remember getting the impression that this parent wanted her child to develop an awareness of social injustice but at the same time wanted to shield her child from hurt and pain. I continue to think about this story and wonder: Is hurt and pain part of the process of learning about racism? What does the process of learning about racism look like for young children? Furthermore, I still think about how this student made a connection, perhaps after learning about school segregation and integration from the book, to seeing and identifying the social 
stratification in her own community. I was reminded how brilliant, perceptive, and honest children are and why I valued my teaching and learning with them.

Although I share this moment in my teaching career, I do not aim to pinpoint one exact moment where my thinking shifted and this teaching/learning became so important to me. Years of experiences, learning, reading, and thinking have led me to the place I am in. Coming to a consciousness of working and teaching for racial justice takes time to develop. As Tuck and Yang (2018) write, our "impulse to dream and work toward justice... shape[d] your education in and out of schooling, your day jobs and your night shifts, your relationships, your breakups, your sense of home and of movement” (p. 1). The memory I share is one moment of many that propels me toward this work- the teaching and learning of topics of race and racism in the early childhood classroom.

\section{Rationale}

\section{Why Should We Teach About Race and Racism with Young Children?}

In thinking about my rationale for this research, I am inspired by James Baldwin's Talk to Teachers (1963). Baldwin cautions that society itself has power over what children believe about their world. Education, he claims "is designed to perpetuate the aims of society" (para. 2), but yet society is need of revolutionary change rather than just replication. Baldwin (1963) warns that if we continue along this path, there is danger ahead:

What societies really, ideally, want is a citizenry which will simply obey the rules of society. If a society succeeds in this, that society is about to perish. The obligation of anyone who thinks of himself as responsible is to examine society 
and try to change it and to fight it - at no matter what risk. This is the only hope society has. This is the only way societies change. (para. 2)

As an educator committed to social change and social justice who sees themselves as responsible and response-able ${ }^{1}$, this stance saturates the un/intentional choices made. Tuck and Yang (2018) advise that education is a social justice endeavor, as they compose:

Social justice is not the other field of education, it $i s$ the field. There is no future of the field of education without the contributions of people who are doing their work under the rising sun of social justice. There is no legitimacy to the field of education if it cannot meaningfully attend to social contexts, historical and contemporary structures of settler colonialism, white supremacy, and antiblackness (emphasis in original, p. 5).

I unapologetically adopt that education is for transformation, change, and social justice. This stance informs every decision and move within this research study. I am concerned about the world we are creating with and for children.

Baldwin warns that the views, actions, and attitudes of society are how children come to see and understand the world. Unfortunately, for children in the United States, society is rife with racism and antiblackness ${ }^{2}$. For example, the rhetoric of the current

\footnotetext{
${ }^{1}$ I borrow this term from Haraway (2008) who writes about understanding ourselves as both causative and conducive in relating with Others which Haraway names "sharing suffering." When we recognize that the suffering of Others (often non-human others) is intimately connected to the ways that we experience the world, it changes how we relationally connect and respond.

${ }^{2}$ In this dissertation, I make deliberate choices in capitalization. I capitalize Black, but do not capitalize white to call attention to the unearned privileges of people who identify as white in the United States. Yet, antiblackness is not capitalized because the term does not refer to Black people, but instead a harmful social construct and action.
} 
$\left(45^{\text {th }}\right)$ United States President is plentiful with racist, homophobic, sexist, xenophobic, divisive, and intolerant messages and action. To be clear, I am not pinpointing the current President as the "cause" of this rhetoric or to hypothesize this person or their supporters as a new or unique problem. Indeed, white supremacy and antiblackness are the bedrock of this place we refer to as the United States. On the other hand, the racist rhetoric and practices enacted each day through and by this administration leave no doubt that exhibiting these behaviors and discourses does not preclude one from obtaining the position of public office, creating and influencing policy, and holding positions of leadership.

Some might ask, "but what does this have to do with children?" I argue that the world adults live in is the same world that children live in, and as such children are also affected by hate, intolerance, and racism. To provide illustration of this point, I offer a few examples. First is an example from experiences my son Jack had in his elementary school. The day after the November 2016 election, a student in the class shared during the morning meeting that they felt scared and afraid as a Muslim person. The teacher responded with "we are not going to talk about the election at school." Jack was concerned about this and shared with me that he and his friends (including the student mentioned above) took their concerns about the new President to the playground at recess where they would be safe from the teacher's ears. Further, these students decided to make a club where students needed to share their view on the president in order to join, culminating in a safe place to discuss concerns. In another example, which reprises later in the dissertation, the students in this research study brought the rhetoric and notion of 'the wall' as proposed by the President into their conversations. The students in 
classroom described the wall as a way to separate people of different races in a conversation about school integration. The notion of 'the wall' was present throughout classroom conversations for several weeks. Finally, in a recent release, Teaching Tolerance reported that in February 2019 the United States experienced the highest recorded number of media reported hate acts in K-12 schools since they started tracking hate acts two years ago. (Dillard, 2019). Of all of the reported incidents, close to $70 \%$ of those hate acts were racist.

Within these examples, although different, demonstrates that racism present in current events seeps into the porous nature of children's lives. Derman-Sparks and Ramsey (2011) agree, writing:

a key influence on children's ideas about others comes from the ideas and messages surrounding them in the larger society, as well as those they absorb from their families. Either these influences teach racism and other divisive beliefs, or they support connection and social justice for all. (p. 7)

School classrooms are microcosms of larger society and so, how might our classrooms be places where racism can be named, discussed, and interrogated? How might teachers and educators support children in their different in/experiences with racism and racist structures? A return to Baldwin (1963) provides caution:

All this [racism] enters the child's consciousness much sooner than we as adults would like to think it does. As adults, we are easily fooled because we are so anxious to be fooled. But children are very different. Children, not yet aware that it is dangerous to look too deeply at anything, look at everything, look at each other, and draw their own conclusions. They don't have the vocabulary to express 
what they see, and we, their elders, know how to intimidate them very easily and very soon. But a black child, looking at the world around him, though he cannot know quite what to make of it, is aware that there is a reason why his mother works so hard, why his father is always on edge... And it isn't long - in fact it begins when he is in school - before he discovers the shape of his oppression (para. 4).

Here, Baldwin describes what makes children such important people to learn from. They "look at everything" and draw new and different conclusions and ways of seeing that we can learn from. I disagree with Baldwin's hypothesis that children “don't have the vocabulary to express what they see." While children's language around race and racism might sound and look different than adults, they still possess knowledge to advance understandings of how racism operates. It is important to not only listen to children, but respect and value their contributions. I build this research study learning from researchers who value and listen to young children's thoughts about race and racism. Boutte, LopezRobertson, and Powers-Costello (2011) engaged in classroom research which centers and values first graders classroom discussions and responses about literature and racism. Further, Kuby (2013) while listening and valuing five and six year old's questions and ideas about race and racism, also noted the influence of educators' identity and perspectives in shaping how we teach. Garlen (2018) names the claiming of childhood as a time of innocence as protecting whiteness. Instead, Garlen advocates for reconsidering childhood as a project of justice, considering both the rights of children and responsibilities of educators. Baldwin informs us that children can and do recognize how oppression is a force within their lives. Perhaps we can provide classroom spaces that 
assist children with ways they can transform and change oppressive structures, for themselves and others in the world.

\section{Are Race and Racism Appropriate Topics for Young Children?}

Researchers, contemplating if and/or when young children recognize and understand race, have presented that children as young as three years old recognize and discuss race (Derman-Sparks, 1989; Tatum, 2017; Van Ausdale \& Feagin, 2003). However, many researchers and educators are still concerned that children are too young to discuss topics of race and racism (Husband, 2010). Therefore, many early educators employ a figurative color-blind approach, claiming that they do not see or notice racial differences and therefore do not need to address race or racism within their teaching with young children (Derman-Sparks \& Ramsey, 2011).

Husband $(2012 ; 2016)$ has argued that employing this figurative color-blind approach, or what Leonardo (2016) has named "selective seeing", is harmful. A selective seeing stance is detrimental because it advocates for a falsehood where children may believe that racism is not a significant problem within society. Consequently, demonstrating that social action is unnecessary. Additionally, for children who already recognize, understand, and/or experience racism this stance dismisses their knowledge and lives. Boutte et al. (2011) expound upon the hurt involved in not allowing young students a place to discuss race and racism and the distress caused works against an educators' oath and commitment to do no harm. Thus, continuing to advocate for children's engagement with these topics is important.

\section{Introduction to the Research Study}


In order to learn from children and the practices that they engage in during the teaching and learning of race and racism, I thought it wise to develop a relationship with a first-grade teacher, Ms. Rotter (a pseudonym). My role was transparent: to provide support and learn from Ms. Rotter and her students about how topics of race and racism were taught in her classroom. Ms. Rotter had 21 students in her classroom, and of those students, 18 of the parents provided consent for classroom participation in this study. Data was produced from four months of classroom research ${ }^{3}$.

In this research study, I think with the theoretical contribution of the wake (Sharpe, 2016). The wake is a theory grounded in Afro-pessimism and antiblackness, ways of theorizing and understanding the world which explains how Black people and Black life exists within a synonymous relationship with and to slavery (Dumas, 2016; Hartman, 2007; Wilderson, 2010). The theorizing of the wake, embracing an antiblackness perspective, impels one to engage with what seems to be our past (e.g., slavery, segregation laws) as ongoing in our present-day lives, thereby altering the future we are creating. The wake rejects notions of antiblackness residing solely in the past, rather "encountering a past that is not past" (Sharpe, 2016, p. 13). In undertaking this research study, I aim to more carefully examine the way that wake processes unfold in an early childhood classroom.

\section{Guiding Question}

The analytical and methodological framework guiding this project is thinking with theory (Jackson \& Mazzei, 2012, 2017). As I describe more fully in Chapter 4,

${ }^{3}$ As I discuss further in the dissertation, although I focus in on four months of data production in Ms. Rotter's classroom, I have been working and researching in her classroom since August 2017. 
thinking with theory is a process oriented approach where the focus is bringing data and theory together to examine how things work and processes unfold. To that end, the guiding question of this research study is: How do early childhood students and their teacher navigate the wake while teaching and learning about race and racism?

\section{Overview of the Dissertation}

In Chapter 2 I provide an overview of relevant literature regarding the teaching and learning of topics of race and racism in early childhood education. Chapter 3 contains conceptualizations of race including a detailed description of the racial theory I think with in this dissertation. In Chapter 4 I discuss the context of the research study, methodological choices, and research relationships. In Chapter 5 I bring the moments from teaching in Ms. Rotter's classroom together with theory to provide an analysis and insights related to the research question. Finally, Chapter 6 includes contributions from this study to theory, methodology, and pedagogy.

\section{A Guide For the Reader}

Throughout the dissertation you may notice certain disruptive elements such as use of different font or italics, and an engagement with deliberate questions, sometimes posed at the end of a section or paragraph (hanging questions). These moves are intentional to shake things up. I pose them to cause the reader to dislodge a firm grasp from one idea or one solution and to invite the reader to think along with me. 


\section{Chapter 2: Review of Literature}

In this chapter, I first describe the historical perspectives of children's understandings and conceptualizations of race. Then I provide an overview of research that has been accomplished regarding the teaching and learning of topics of race and racism in the early childhood classroom. This includes studies which center children's literature as a vehicle for learning about topics of race and racism, critical literacy approaches, investigations that center young children's talk, researchers who are attempting to reconceptualize our notions of children and school structures, and lastly, scholars who are researching and theorizing about antiblackness and the protection of whiteness in childhood. Finally, I conclude with how this literature informs the work completed in this research study.

\section{Historical Perspectives of Children's Understanding and/or Thinking About Race}

Much of the way that educators and researchers conceptualize young children's (age 8 and younger) understanding and recognition of race is from the fields of developmental and cognitive psychologies (MacNaughton \& Davis, 2009). Unfortunately, these learners are often dismissed as incapable of engaging in conversations about race with some claiming they are too young (Williams \& Norton, 2008), too innocent (Robinson \& Jones Díaz, 2006), and too immature (Fass, 2007). Yet, studies that seek to discover and understand how children recognize race have been tackled by researchers for many years. I describe this work below.

According to MacNaughton and Davis (2009), Bruno Lasker's book, Race Attitudes in Young Children (1929) was one of the first to challenge notions of innocence 
and colorblindness in young children. Lasker utilized and studied adults' memories and recollections of their childhood experiences and knowledge of race. As a result, Lasker argued about the importance of social context in young children's racial learning. Three points underlined his description of social context: depictions and descriptions of people in curricular materials, surrounding adults' racial attitudes, and children's experiences with racially segregated spaces and places. Although some (at the time) dismissed Lasker's research as subjective, and therefore unscientific, Lasker's contributions of the role of social context in how children make sense of race continue to have value (MacNaughton \& Davis, 2009).

Well known due to use in the Brown v. Board of Education case, psychologists Clark and Clark (1939), completed a research study with the aim of understanding children's racial awareness and connection to their own identities as well as pinpointing an age or developmental stage when this occurs. This study has been replicated by various psychologists over years, all with similar results. Using markers of race as connected to skin tone, hair type, and facial structure with dolls and/or images, the Clarks explored these aims by following young children's answers to two questions: (1) Who do you look most like? and (2) Who do they [the dolls] look most like? Within the study, when children correctly matched dolls and people via physical characteristics, the researchers concluded the children were aware of racial differences and similarities. Clark and Clark (1939) concluded that around the age of three years old, children are able to consistently match the prior attributes with the person. This study and its replications, then, connect children's understanding and recognition of race to be largely physical and brush aside social, political, linguistic, and other implications and connections. 
Goodman (1964) built on this research, connecting the ages and stages when young children develop perceptions of race with their attitudes about sharing their racial knowledge with others. This research was completed in an effort to understand when and how racial prejudices form. In alignment with Clark and Clark (1939), Goodman argued that between two and three years of age young children begin to notice and name racial differences. In the next stage, between four and five years of age, Goodman claimed that children begin to express opinions, beliefs, and attitudes towards racial groups. Goodman claimed that in the next stage, between seven and nine years old, children have developed and express prejudices and stereotypes around race.

Cognitive psychology researchers built upon Goodman's (1964) work, putting it in conversation with Piaget's stages of cognitive development. This has led to conclusions that young children's racial knowledge, beliefs, and attitudes regarding race follow a linear path. This path means that there are pervasive beliefs and theories that young children are not yet capable of being racially tolerant or open minded (Bigler \& Liben, 1993; Katz, 1973; 1987; Levy, West, Ramirez, \& Pachankis, 2004).

Conceptualizations of children's racial knowledge trajectory, drawn from cognitive psychology and cognitive developmental theories, have particular implications for our conceptualizations of young children and their understandings and relationships to and with race. As MacNaughton and Davis (2009) describe, Cognitive Developmental Theorists, following Piaget, believe that young children have an innate need to understand their world and that to do so, they sort and classify items in their surroundings...Children sort and classify people into groups in the same way that they sort and classify other items into groups: they search for 
similarities and differences between people and sort them into categories...

Cognitive Developmental Theorists, following Piaget, emphasize that sorting and classifying people (as with other objects) is an innate, natural, and therefore, universal activity (pp. 21-22).

The assumption that a child's desire to sort and classify informs how they think about and analyze race is troubling. First, race is more than what can be seen (e.g., skin color) so simply sorting by attributes does not necessarily mean sorting by race. Second, this premise assumes a universality about children and their ways of learning and being in the world. Do all children need to sort and classify in order to understand? The complex and socially connected ways of navigating race are important to consider and should not be ignored. As a result, other researchers which I discuss below, have sought to understand why some children remain silent or non-responsive when asked about race, since according to earlier research, as children grow and develop along a continuum, their racial knowledge and understanding should deepen.

Killen, Margie, and Sinno (2006) and van Ausdale (2004) have written about the social implications of race and how children's silence may have more to do with their internalization of social norms and values, rather than children's understanding or recognition. In fact, Apfelbaum, Pauker, Ambady, Sommers, and Norton (2008) researched why children, as they increase in the primary grades, seem to become more silent about race and racial identification. According to MacNaughton and Davis (2009), Apfelbaum et al. (2008) concluded that older children's silence may show their greater capacity to internalize 
social norms such as the unacceptability of racial privilege... in other words, children's silence on race is not necessarily evidence that they lack knowledge of race or see it as irrelevant when sorting and classifying people. Instead, it may demonstrate their growing understanding that race and what is said or not said about it matters in their specific context; and so children's silence on racial issues may be linked to their maturing social cognition. (p. 23)

Research on young children's refusal to talk or silence about race is valuable in order to complicate simple notions of how children understand race. Understanding, recognizing, and naming race is a complex venture for someone of any age. What many of these research studies fail to recognize is one's own identity in racial sense making. How does a child's own racial identity impact the way that child sees others? Additionally, many of these research studies are conducted in the United States. What does this look like globally or transnationally with students who see themselves and their loved ones blurring and reshaping our static ideas of racial identity?

The social and political ways of influencing how we see and recognize racial identities are important and are crucial to consider when thinking about young children. Children do not develop their racial understandings in a vacuum. There are social, political, and economic forces that influence how racial groups are perceived and which racial groups are considered most desirable. Children may live in the same worlds that adults do, but they are not adults. They are not just a miniature version of adults. They are people in their own right, and we still have a great deal of work ahead of us to try and understand them. There remains some uncertainty in regards to how children understand, recognize, and talk about race. 


\section{Relevant Research on Race and/or Racism in the ECE Classroom}

Within the broad and loosely defined early childhood community, many practitioners and researchers are taking up the important work of teaching and learning about topics of race and racism with young children. Tying all of this research together is difficult because there are diverse ways of entering and thinking about this work with young children. In this section, I provide a discussion of research that addresses the teaching and learning of race and racism with young children. The first part focuses on research that centers children's literature while the second part focuses on critical literacy approaches when teaching about race and racism. The third centers on pedagogical considerations of talk about race and racism while the fourth section describes research studies that reconceptualize notions of children and childhood. Ultimately, the last part provides a discussion on antiblackness and whiteness within early childhood.

\section{Learning About Race With Children's Literature}

Many approach the teaching and learning of race and racism topics through the sharing of children's literature (e.g., Husband, 2016; Lewison, Leland, Flint, \& Möller, 2002; Wood \& Jocius, 2013). Diverse children's literature provides an opportunity for readers to see themselves represented visually and to learn about others' lives. I am focusing on research that centers children's literature because literature has the ability to transcend our limits of time, space, location, and language. Additionally, we can "learn about an individual or group of people whose stories take place in a specific historical or physical setting" (Jenkins \& Austin, 1987, p. 6). Bishop (1990) wrote about the metaphors of windows and mirrors where books can be a mirror for children to see their lives reflected and a window to learn about the lives of others. Additionally, Bishop 
builds upon this with the metaphor of literature as a door, allowing a reader to step into another world of another while developing empathy. Indeed, Ms. Rotter and I often considered read alouds as an essential gateway to begin conversations with the students in class about topics of race and racism.

For example, Beneke and Cheatham (2017), interested in how talk about race happens during shared book readings, spent a small amount of time in two Head Start classrooms as classroom teachers read children's books with racially present themes. The study was framed using a critical literacy framework and discourse analysis with utterance counts as a method of analysis. The authors also indicated that they paid close attention to topic shifts in order to understand how they were negotiated.

Beneke and Cheatham (2017) wrote that they discovered the conversations about race in both of these classrooms moved more towards conversations about color concepts and identification that were detached from the socially and culturally negotiated concepts of race and/or racism. Additionally, teachers' words and voices seemed to dominate the discourse of these read alouds which limited, and in some cases prevented, children's questions and ideas from emerging and closed down possibilities for initiating new meaning making about topics of race or racism. The researchers shared that as a result, we cannot assume that because we are sharing children's literature that is inclusive of race and racism, that those topics will be taught, learned, or discussed. Instead, the sharing of children's literature with the intention of producing discourse about race and racism must be thoughtfully and intentionally mentored.

One of the limitations of this study (as written about by the researchers) is the small amount of time spent in the classroom as well as the lack of any teacher interviews. 
This limitation, put in conversation with the findings, brings about important questions about intentionality such as: Did these teachers have an interest in teaching about race and racism? What were the teachers' thoughts, intentions, and goals for these read alouds? Considering the pedagogical goals and intentions of the teachers is important.

In the work of Boutte, Lopez-Robertson, and Powers-Costello (2011), children's discussions about race and racism were one of the intentional topics within weekly literature discussions/pláticas literarias in a second-grade classroom. In this research, the researchers advocate for the inclusion of discussions on race and racism in early childhood classrooms. Boutte et al. (2011) confirm that early childhood-aged children are indeed aware of racism, evidenced in their research when they inquired to the students, "what is racism?" and the children responded to them through imagery and verbal responses. The perceptive response of one student was "I think that racism is people that want Mexicans to leave" (p. 338). This response is simply one example of the young students included in this research that perceive racism through their everyday experiences.

Boutte et al. (2011) advocate for integrating the teaching of topics of race and racism into classroom curriculum. They suggest the sharing of children's literature, allowing students to respond in visual and verbal ways, as well as class discussions as a way to provide opportunities for this learning to happen. These steps provide opportunities for students to have a space for their thoughts to be heard and get feedback from their peers as well as their teachers.

Boutte et al. (2011) recognize the discomfort of most early childhood educators lies in doing what they name "anti-racism work". As such, they include a table of 
suggestions that includes stimulating questions for teachers to use to start conversations with children. They emphasized the importance of teachers continuing to engage in this anti-racist teaching on regular basis. By maintaining a commitment to teaching as ongoing, it becomes the norm rather than exception and in doing so these educators will grasp "that the process becomes easier with practice [and] will hopefully encourage and inspire educators to inch out of their comfort zones on behalf of the children whose care is entrusted to them" (p. 335).

Finally, Boutte et al. (2011) connected the imperative for teachers to engage with young children regarding race and racism as an ethical and moral issue, as part of a teacher's sworn duty to do no harm. The researchers advise that when teachers do not create time in their classroom curriculum for conversations about race and racism it "threatens the full humanity of all" (p. 341). There is harm involved in not allowing young students a place to discuss race and racism and the distress that it causes. Boutte et al. (2011) argued that "silence in early childhood classrooms on issues of racism prevents preparation for active and informed participation in our democratic society which includes multiple (even dissenting) perspectives" (p. 339). Avoiding issues of race and racism in early childhood classrooms teaches students that being disengaged from race and racism is a goal to which they should aspire.

Boutte et al. (2011) have constructed a compelling case for the importance of teaching about race and racism in the early childhood classroom. Their suggestions for how to get started and examples of books that should be read are helpful for educators not knowing where to begin. However, beyond the literature shared by Boutte et al. (2011), how might one know the best literature for engaging in these topics? How might we 
make sure that the literature, in an effort to educate about racism, does not reinforce stereotypes, misconceptions, and/or deficit perspectives?

In a research study drawing on children's literature to teach about race Boutte, Johnson, Wynter-Hoyte, and Uyoata (2017) explored how to support and emphasize the important contributions of people from the African diaspora with young children through literature. The researchers built upon on the 10 principles for Black education and socialization created by the Commission on Research in Black Education (CORIBE) task force from the American Educational Research Association (AERA) headed by Joyce King. Boutte et. al (2017) emphasized that the use of an African Diaspora literacy approach to teaching moves away from a monolithic approach to African people (which is typical in contemporary education). As the authors write "Blackness can be viewed as an ontological symbol that is the quintessential signifier of oppression" (p. 66). Instead they advocate for literature that demonstrates a commonality in history while understanding the diverse sociopolitical nature of what it means to be a person identifying as having African heritage.

In the study, Boutte et al. (2017) provide examples of teachers engaging with texts that they consider to be high quality African Diaspora literature. The authors inform that "it is problematic to ground Black history in the conceptual framework that begins with slavery" (p. 75). To make sure this does not occur, they recommend that we look to African history as of equal importance and value in our classrooms. Too often, educators ground their teaching of Black people and Black histories from the point of view of oppression. Instead, the authors urge educators to utilize children's literature that shows a more complex and diverse view of the day-to-day lives and histories of Black people. 
The researchers demonstrate ways to be attentive to children's literature we share with students as being purposeful and intentional, including titles that show a diversity in what it means to be from the African Diaspora. They also advocate for the importance of moving beyond shallow narratives of race topics as simply about oppression.

Husband (2018) argued that multicultural picturebooks can and should be utilized in early childhood classrooms to advocate for racial awareness and racial justice. Husband provides examples of multicultural children's literature to share with young children. Building upon Bishop's (1990) metaphor of mirrors, windows, and doors he points to the value in not only seeing your own experiences reflected, but also learning about the experiences of others.

Husband (2018) stressed that this work, engaging in teaching for racial justice, is important and should not be undertaken lightly. He recommends that all educators pursuing these pedagogical endeavors explore their own understandings of race, racism, and injustice as well as their motivations for engaging in this challenging yet rewarding endeavor. Husband (2018) acknowledged that educators in this pursuit must "first be willing to critically reflect on the ways in which race, racism, and racial privilege exist and operate in larger society and within their own personal lives" (pp. 19-20).

Husband concluded his article with important implications for early childhood educators to consider. When educators engage multicultural picturebooks with the aim of working for racial justice, there are many difficult consequences to consider. This includes political, social, personal, and/or emotional risks and vulnerabilities that come along with engaging these pedagogies. However, Husband also named working for racial justice as "courageous" and early childhood educators who carry out this work need to 
remember the worthwhile cause they are pursuing. Husband reminds us that teaching is personal and for educators to stay close to their critical and reflective rationales for working towards racial justice. Husband ends with an important point for educators; just because you are working with children's literature does not mean your voice, ideas, and meanings are not included. He notes that often educators may feel because the narrative is coming from the text, their perspective does not matter. Instead, Husband (2018) informs that teachers' selection, ways of sharing, and talking about books is not neutral. Thinking carefully about what teachers ask of students to do with literature and how they represent their own voice and perceptions matters.

Similarly, within my research study picturebooks were shared in Ms. Rotter's classroom as one way to engage the learning about topics of race and racism. Rosenblatt's $(1978,1982)$ transactional theory provides the framework for how Ms. Rotter's first-grade readers made meaning from literature. Rosenblatt wrote about efferent and aesthetic reading of texts. Efferent reading focuses on retention of concepts and ideas that a reader can retain and use, while aesthetic reading focuses not just solely on concepts but also feelings, emotions, and connections for the reader as a result of engaging with literary works.

Rosenblatt posited that literary work does not reside independent from the reader. Instead, it is the coming together of reader and text in aesthetic reading where meaning, or "the poem," is created. Rosenblatt (1982) advised that it is through literature where we can "understand ourselves and others...widening our horizons to include temperaments and cultures different than our own, for helping us to clarify our conflicts in values, [and] for illuminating our world" (p. 276). 
Therefore, not only is meaning derived from text, but as a result of the sharing of children's picturebooks in this study, careful attention was made to the role of the visual narratives present in these picturebooks. Visual narratives can include (but are not limited to) color, lines, position, and texture. Picturebooks, with their contribution of both text and picture working together, offers something special. Sipe (1998) named this contribution as synergy, where images and text work together. Sipe informs, "Synergy between words and pictures adds up to something greater than the sum of its parts" (1998, p. 238). In fact, Sipe (2008) distinctly notes that the intentional use of the term picturebook - placing "picture" and "book" together to create a compound wordemphasizes the unique contribution of bringing these two art forms together to forge an inextricable connection. Within my research study, the synergy of picturebooks had an impact with how students made connections, asked questions, and engaged with the learning of topics of race and racism.

Across these different research studies, the role of children's literature in teaching about topics and events of race and racism are emphasized and highlighted. These researchers and their work have informed the design of this study by helping me to think carefully about the literature selected and shared with children. When choosing books to assist one with teaching about race and racism, we must consider and include a range of perspectives, being careful to not continue to perpetuate deficit narratives. Additionally, our pedagogical intentions are important. What do we aim or hope for children to gain from our sharing of children's literature? These implications have assisted me, as I worked with the teacher, Ms. Rotter, in this research study, to plan carefully and thoughtfully about children's literature selection and read alouds. 


\section{Critical Literacy Approaches to Teaching About Race and Racism}

A critical literacy approach is generally guided by four tenets: disrupting commonly held ideas and assumptions, engaging multiple perspectives, focusing on relevant sociopolitical concerns, and moving towards social action (Janks, 2010). Early childhood educators who engage in critical literacy practices use resources such as picturebooks, other forms of texts, and additional tools to focus on injustice in their world and move towards social action. A critical literacy approach, then, seems a natural fit for the teaching and learning of race and racism and how to move towards dismantling it. Several researchers and/or practitioners have engaged critical literacy in work with young children about topics of race and racism.

Kuby (2013) wrote about her experiences engaging in a critical literacy approach to teaching as an educator of five and six year old students. Prompted by an issue of fairness and unequal treatment occurring within the school, Kuby used narratives, picturebooks, and histories of racial injustice to assist young learners in developing connections. Over the course of a couple months, Kuby was able to engage the young children she was teaching in difficult large and small group conversations about racism and encouraged students to create multimodal responses about racism.

Kuby's critical literacy work with students is enmeshed with authoethnography, as she heeded the writing of Vasquez (2004) to see critical literacy as lived. Kuby explores how her identities, perspectives, and experiences have shaped and continue to shape her teaching experiences. For example, Kuby spent a great deal of time wrestling with ways that her whiteness impacted her pedagogical choices and how those choices unfolded in the moment. Kuby's pedagogical practices with young children reminds one 
that the ways in which we teach must be intentional as our beliefs, experiences, and ideologies are imbued in the methods and topics we engage with.

Kuby's (2013) work is an important contribution that reminds those who teach and learn with young children of the difficulty of teaching for social justice and social action. It is important to understand how our lived realities influence our work with young children. Kuby shared,

Teaching from points of uncertainty is a constant state of reflections and tensions. These ambiguities are productive. I do not believe one can ever know exactly how to teach from a critical perspective; there is no script for this type of work. It comes from relationships, embedded in a particular context in space and time, in an attempt to truly know someone else and their experiences. (p. 113)

Embracing uncertainty and ambiguity is difficult. Remaining in the moment with difficult topics like race and racism when we do not know where they will lead or what will happen is a challenge. However, focusing on the learning that happens when people come together in effort to learn, grow, and change is important. Kuby's reflexive work about critical literacy teaching is important to learn from.

Labadie, Wetzel, and Rogers (2012) also explored critical literacy practices. However, they had a more explicit focus on expanding students' understandings of racial injustices with the goal of moving students toward a social justice orientation. The researchers selected texts with the teacher that focused on slavery and moved in the direction of the civil rights movement. The books that were purposefully selected included the topic, but also included familiar vocabulary for students and illustrations the researchers found helpful in bringing the content to life. 
Labadie et al. (2012) discovered when books had informative illustrations, students were better able to fully comprehend the severity of the events they were reading about. The researchers found that to move students to recognize injustice, lengthy talk about social justice from the teacher was not the answer. Rather, purposeful prompts and providing students with longer wait time was more effective. These two pedagogical moves led students to share more information, disagree with one another, and debate social issues. This research causes one to consider how we ask and expect children to respond to literature with serious narratives like slavery and the civil rights movement. Labadie et al. advocate for creating spaces for open-ended and diverse reader responses and limiting teacher talk and intervention. Considering Kuby's research from earlier, it seems important to also consider students' connection and relationship to the texts in this study. How might only including books with stories and narratives of slavery encourage students relationships with and to Blackness as deficit oriented? How might we include more complex and rich narratives of people's lives that expand the oppressed/oppressor binary?

Nash, Howard, Miller, Boutte, Johnson, and Reid (2018) wrote about their work of critical racial literacy with diverse and varied ethnographic data that was brought together through the research process. Nash et al. (2018) describe critical racial literacy, specifically for young children as having three main components: a reflective engagement with a focus on re-membering of Afrocentric histories and narratives, developing cross community relationships and partnerships where one has the opportunity to learn from people different than themselves, and a willingness to identify 
and engage with "blind spots" such as bias, profiling, and privilege in an effort to work for social change.

In their research, Nash et al. (2018) provide examples of ways that young children were encouraged to work through these three processes of critical racial literacy. Like Kuby, they indicate that this approach cannot become a one size fits all model. It varies by people, relationships, needs, and time and space. The main point is to continue to work on the process as they importantly note "racism is like a shape-shifter-just when we think we have identified its presence, it is remolded, recreated into something new, evading our ability to completely capture and dismantle it" (p. 269). Because racism works in this slippery and evasive way, we too must evolve our methods of working against it. That includes paying close attention to the way language shifts around race and racism both inside and outside of classroom spaces.

Critical literacy and critical racial literacy practices demonstrate that teaching is political and personal. Our beliefs, experiences, and ideologies inform how and what we teach. When choosing to embed topics of race and racism in teaching, we also must examine the language we use in our descriptions. Critical racial literacy focuses on working to dismantle racism for social change. These research studies informed how I considered the personal and intentional pedagogical practices within this research study.

\section{Transforming Race Talk in Classrooms}

Talk and dialogue are a large portion of the work in engaging young children in conversations about race both inside and outside of classrooms. The kind of talk we engage in, the terms we use, and the transformational ability of talk can contribute to social change. 
Copenhaver-Johnson (2006) explored and discussed the importance that silence has on conversations about race. Copenhaver-Johnson begins with a story about a conversation with her daughter. She noticed her daughter's classroom did not have literature that centered the experiences and visuals of People of Color and/or included bilingual stories/characters. When asking her daughter if they could donate some books to the class, her daughter asked her not to in the moment, but to instead wait until the end of the school year. When Copenhaver-Johnson inquired as to why, her daughter said that they had never talked about race in her classroom and so she didn't know her teacher's stance on the topic. Copenhaver-Johnson shared this anecdotal story to question how the absence of a conversation about race still teaches.

In her further exploration of K-2 classrooms, Copenhaver-Johnson (2006) noted that even when teachers were purposeful about creating racially and ethnically diverse working groups of children, as well as when children were free to choose groups for themselves, children still grouped themselves along racial lines. Copenhaver-Johnson detected racial tensions within these groupings as she wrote, "The children in this class played out variations on adult race relations even though they did not explicitly speak of race" (p. 17). Copenhaver-Johnson wrote about how she remains curious how race continues to dominate classroom spaces, even when we do not engage in overt conversations about it or even make sure it is removed from classroom conversations to be purportedly 'fair' or 'neutral'.

Copenhaver-Johnson (2006) drew important next steps at the conclusion of the article and suggested: "We need to talk to our children because children notice the messages our silences send" (p. 18) and "talking with children about race is also helpful 
because we need to learn how to do it, and our children need to observe us actively trying to learn...the benefits outweigh the risks of comfortable silence" (p. 20). The research as well as implications shared by Copenhaver-Johnson are hopeful future directions of where this work might go. It is important for one to consider our responsibility as educators, but we must also engage in reflexive practices regarding intentionality to have meaningful and respectful conversations with children about race.

Also engaging young people in dialogue about race, Jordan and Hernandez-Reif's (2009) research study sought to build on the Clark doll studies of the 1930s and 1940s. In this updated version, more shades of skin color were provided as a choice for the preschool children (rather than just Black or white as in the original). Additionally, the researchers did not use physical dolls as in the original Clark study, instead, images of people-like dolls were presented via computer and designed digitally. One final way that this research design differed from the original Clark study was that the researchers attempted to provide an intervention. After asking the children about which skin color they preferred, the researchers then either read a story that either highlighted a Black child as having exceptional merit or read a story where the child's race was not mentioned.

In the results, Jordan and Hernandez-Reif discussed that the story seemed to only positively affect the Black children who participated in the study. After hearing the positive merit-based story about the Black child, the Black children (there were only children identified as "Black" or "White" in the study) had a more positive connection with the images of Black children while the white children's responses stayed the same. In this research study, the "interventions" did not have an impact on all children. Are 
there ways to think more carefully about our research designs in order to reach all children, holistically, about topics of race and racism? Additionally, in classrooms, how can we be conscious of how the ways in which we teach about race and racism might not effect students of different races in the same way?

In a second-grade classroom made up almost entirely of white students, Rogers and Mosley (2006) engaged in a research study that used a racial literacy framework to explore students' willingness to engage in conversations to interrogate their own whiteness. According to Rogers and Mosley, a racial literacy framework has three main tenets: a recognition of racism as a structural phenomenon, engaging a more critical analysis of discourses to directly name racism, and then the persons who become racially literate gain these tools to solve social problems. Within their analysis, Rogers and Mosley shared that the students' progress and ability to critically analyze whiteness in relation to themselves and others over the course of the one year study was mixed. Many times students were observed to recognize racism and white privilege as a "thing of the past," adding to the "color-blind" rhetoric that exists in a society dominated by whiteness (e.g., "Martin Luther King changed everything") (Rogers \& Mosley, 2006, p. 484).

However, there were instances throughout the study where students did recognize white privilege and identify it as problematic. Rogers and Mosley (2006) concluded that the second-grade, as positioned within a young person's education, serves as a crossroads for students' identities and discourses. They believe that second-grade students are at a point where many of the stable, dominant discourses to which they had been socialized could either be solidified or disrupted. Even with this potential for change, Rogers and Mosley predicted that the new discourses about race and whiteness that were learned in 
this second-grade classroom were unlikely to continue. They felt because teachers and students alike are socialized to avoid conversations about race, racism, and what it means to be anti-racist as students' progress through the education system, they are unlikely to participate in a classroom community where these topics are discussed or interrogated. Rogers and Mosley recognized the positive impact critical literacy has, especially with white students, to interrogate power and privilege. However, without consistency, dominant discourses and disregard for structural and institutional racism will likely quickly return.

Looking across these research studies, the importance of talk within classrooms when teaching about race and racism is important. In classrooms, whether we deliberately engage in talk or remain silent, we continue to send messages about race and racism. These research studies provide an important reminder that teaching is never neutral. A racial literacy framework, for example, demonstrates how to assist children with directly locating and naming racism and working towards justice. Combined with the critical literacy studies discussed earlier, these are strong and powerful examples of how to develop children's racial knowledge and actions.

\section{Reconceptualizing Early Childhood Education}

A group of scholars formed the reconceptualizing early childhood education (RECE) group in the early 1990s. This group consists of mostly researchers and educators involved in ECE and elementary teaching and learning. Many of the researchers came from diverse backgrounds such as: child development, developmental psychology, sociology, anthropology, women and gender studies, and psychology. The group formed because of a two-fold concern: the universal 'truths' held about children 
because of the dominance of developmental/Developmentally Appropriate Practice (DAP) theory and the largely quantitative and/or positivist dominance in research methodologies in early childhood studies. Those who identify within this umbrella tend to focus on whose knowledge counts and whose knowledge is excluded/marginalized (Bloch, 2014). Additionally, these scholars often embrace and think with postcolonial, decolonizing, critical, feminist, poststructural, and posthuman theories and ways of seeing and thinking about children.

Often in education, when thinking about the teaching and learning of topics of race and racism with young children, we turn to a focus on multicultural education or critical multiculturalism (Derman-Sparks \& Ramsey, 2011; Souto-Manning, 2013). Pacini-Ketchabaw (2007) critiqued the dominant discourses of multiculturalism in early childhood and child care centers. Pacini-Ketchabaw stated that we often think about multiculturalism as a positive approach to the teaching of young children as it has a focus on acceptance, tolerance, and sensitivity. Using Foucault's theorizing on power as not only restrictive but also productive as well as normative practices of neoliberalism, Pacini-Ketchabaw (2007) showed that the way that we and educators think about multiculturalism is problematic. Pacini-Ketchabaw noted that our thoughts of openness to difference in multiculturalism is actually a response "to the needs of global markets... and [for children and their families] to compete and play in the game of global capitalism" (2007, p. 229). Pacini-Ketchabaw argued that globally capitalist informed multiculturalism has one believe that they are working to remain open to difference, but in fact have a preformed idea of a final goal or destination for students and their families. 
Pacini-Ketchabaw's (2007) indicated that ideas of supposed “openness" within a neoliberal approach to multicultural education has an appearance of embracing of difference(s) but really has a goal of guiding or steering children and families towards a specific goal - similar to the global project of neoliberalism. Pacini-Ketchabaw connected goals of tolerance and flexibility in multicultural early childhood education to two main goals espoused through neoliberalism - deregulation and freedom. Tolerance and flexibility at first glance seem to be welcoming of difference, but Pacini-Ketchabaw took a more critical stance determining that in fact the control and monitoring through tolerance and flexibility she witnessed within early childhood centers more closely mirrored the aspects of global control which is becoming more and more common throughout the world.

In a rejection of these common sense views of multiculturalism, PaciniKetchabaw asked if it is possible to remain open to difference without a predetermined outcome of what that difference could and should be. She built upon the work of Lenz Taguchi (2006) who writes about an "ethics of resistance" as a way to consider how we can resist the normative, norming, and 'common sense' approaches to multiculturalism. So, when thinking specifically about the teaching and learning of race and racism in the early childhood classroom, I wonder how we can remain open to ways of teaching and learning about this topic while refusing a specific end goal? I wonder, is that possibility considering the 'problem' has already been identified (racism)?

Moving to a more micro level thinking than multiculturalism, Clarke and Watson (2014) explored and discussed how whiteness was performed, constructed, and deconstructed in a child care center in the UK by teachers, students, and families. Clarke 
and Watson explain that their focus on whiteness, rather than People of Color or a multicultural focus, is a result of a lack or gap in the research of how whiteness effects young children and operates in their school spaces. As they wrote, "From a critical whiteness perspective, studies have tended to focus on minority racial and ethnic groups, thereby ignoring whiteness...we explore how a critical engagement with whiteness can open up spaces for emancipatory interventions with young children and families" (p. 70). They also noticed that while researching and specifically analyzing, notions of whiteness were shaping how participants and researchers conceptualized race and ethnicity. As a result, they decided to shift their focus.

Clarke and Watson discussed the term "postmodern thinking" (2014, p. 70) citing Foucault and how this allowed them to see race, ethnicity, and whiteness as constantly changing and shifting. This perspective allowed them to consider more fluid way of seeing race. Additionally, Clarke and Watson's added that "ethnically diverse toys" such as dolls, toys, etc. did not make a difference in how whiteness operated within children's identities and beliefs. Instead, they stated that we need to engage historical and political perspectives to engage historical change. Clarke and Watson also engaged an "ethics of resistance" from Lenz Taguchi (in line with Pacini-Ketchabaw, 2007) as a way to participate in a deconstructive approach, citing Derrida, towards thinking about race and whiteness as it opens up new possibilities of seeing, knowing and experiencing. Clarke and Watson's (2014) call for future work was particularly important:

Future anti-racist strategies in multi-ethnic settings need to find ways of helping staff, parents and children to explore... multiple aspects of whiteness. Both white 
and black people need support to discover how whiteness can be oppressive, but also how it can be anti-racist. (p. 77)

If one takes this stance, what might anti-racism look in a first-grade classroom? Also, can whiteness be anti-racist? Is it possible that whiteness might just re-center white people and not dismantle racism? It is important in our work of teaching and learning topics of race and racism that we work for action and change, not to just learn oppressive histories.

A book written by Robinson and Jones Diaz, Diversity and Difference in Early Childhood Education (2006), provides an in-depth discussion on various theories and perspectives regarding how they may provide new thinking about early childhood education. Some of the theories/perspectives discussed are poststructuralism (drawing on Foucault), feminist poststructuralism (drawing on Davies), cultural studies (drawing on Hall and Bhaba), postcolonialism (drawing on Ashcroft and Cannella \& Viruru), critical theory (drawing on Bourdieu) and queer theory (drawing on Morris). These multiple, overlapping, and divergent theories allow Robinson and Jones Diaz to explore early childhood education in new ways and ask different questions. They spend several of the chapters using these theories to think in new ways about such topics as globalization, racism, immigration and refugees, and homophobia in young children's lives.

A major goal of this book is to dispel many of our taken for granted assumptions and/or truths about children and childhood. They also aim to make social justice education vital and important to young children's education. They believe we must center this type of teaching rather than consider it as an additive or specialized approach. Robinson and Jones Diaz make an important point that many early childhood educators do not see racism and bigotry from children and/or within classrooms as part of a larger 
systemic issue. Instead, they see these interactions as operating at a more micro level. Over 10 years later, it seems that this might continue to be a problem as well. In their suggestion for next steps, the authors call for further research as well as professional development and education for current and future teachers. Specifically connected to this research study, Robinson and Jones Diaz (2006) recommend:

There are a number of specific areas of diversity in which further study would be useful. In particular, research investigating children's voices as they negotiate aspects of identity and power relations in everyday social practices in early childhood settings would provide significant insights into the different ways in which children locate themselves in various mainstream discourses of diversity and difference. (p. 178)

Working to listen to and value children's voices important. If we are able to provide new methods and modes of listening to children's insights, perhaps we can learn new practices for the teaching and learning of race and racism in early childhood classrooms.

By reconceptualizing childhood and the practices within the field of early childhood education, one questions 'taken for granted' assumptions about children, childhood, and the common sense practices that dominate classrooms. Scholars who are reconceptualizing ideas of children and childhoods are often thinking with critical, feminist, as well as postmodern, poststructural, postcolonial, and posthuman theories. These theoretical underpinnings closely examine power, knowledge, gender, place, materiality, and race. Across this area of research and within these studies, I am encouraged to recognize that there is no one way of knowing, being, and thinking. Additionally, there is not one way of understanding and working to dismantle racism. 
Research that reconceptualizes children and childhood provides different ways of listening, studying, and being with children—ways that consider children's equal rights in democracy.

\section{Exploring Antiblackness and the Protection of Whiteness in Early Childhood}

\section{Education}

While antiblackness has not quite made its way into the field of early childhood education, some scholars are writing about antiblackness and white supremacy and how they are part of childhood. Antiblackness, described in further detail later, exists within the domain of Afro-pessimism. Afro-pessimist scholars theorize that Black people and Black life exists within a synonymous relationship with and to slavery (Dumas, 2016; Hartman, 2007; Wilderson, 2010). According to Afro-pessimist thinkers and scholars, to be Black is to never be fully considered human. Hartman (2007) names this as "the afterlife of slavery" (p. 6) where Black people are considered not only less than human, but not human at all. Therefore, antiblackness is a practice which permits Black people's abilities, talents, contributions, and accomplishments to be ignored, dismissed, and even erased. Additionally, antiblackness serves as a way to dismiss and dehumanize darker-skinned people (Dumas, 2016). In the studies discussed below, researchers encourage us to look critically at discourses and practices of childhood and how we normalize one way of being white and dismiss and other ways of being as not child-like or belonging to innocence of childhood.

Dumas and Nelson (2016), drawing on critical childhood and reconceptualist childhood studies, argue that Black boyhood is an unimaginable impossibility. They argue that the intersection of Blackness and maleness renders childhood - a time of 
freedom, joy, and play — an impossibility. They provide several examples, and one of those is Tamir Rice. A young Black boy who was not allowed the carefree and imaginative play of a childhood, because he was always already conceptualized as an older and dangerous 'man' of at least 20 (he was 12 years old). Dumas and Nelson write about how the deficit notions of Blackness have contributed to our thinking and acting in schools and in larger society around and upon Black boys in this way.

Unfortunately, our inability or unwillingness to see Black boys as children leads us to blame them rather than ask what we can do to address the pain and isolation they feel. To the extent that Black childhood is unimagined-and worse, unimaginable_-Black children become responsible for their own school failures, regardless of maldistribution of economic and educational resources. (Dumas \& Nelson, 2016, p. 35)

Dumas and Nelson encourage one to rethink and reimagine how we provide spaces for Blackness to be in childhood. Specifically, they encourage educational researchers, those involved in normalizing everyday school practices, and educational policymakers to create spaces for Black boys to just "be" as they are now, allowing them to be "silly" and "worthy" of their diverse ways of being. Although my research study does not specifically focus in on Black boys, it does in fact focus in on antiblackness, which is a part of creating the impossibility of Black boyhoods that Dumas and Nelson write about. What if early childhood educators, and the field of early childhood education as a whole, faced the ways in which they have contributed and enforced the impossibility of Black boyhoods? What would it look like for educators and administrators to recognize how they are complicit in antiblackness? Would that shift our pedagogical practices? Could 
we then consider Black boys and Black children as capable of having a carefree and fun childhood?

Bryan (2018) has also written about Black boys, specifically how Black boys’ play is criminalized in childhood. This criminalization leads to what Bryan names the "school playground-to-prison pipeline" (STPP, p. 3) for Black boys because of the way their play is assumed to be violent and more serious by their white peers and teachers. Bryan provides many examples of this, including recent data about how Black boys are more likely to be suspended and expelled from preschool than their white counterparts for engaging in the same behavior. Bryan cautions that schools view play as something mostly for white children, and that Black children are seen in need of remedial help and not deserving of play, which research has demonstrated to benefit all children.

Bryan (2018) provides several recommendations for the field of early childhood education, to begin to shift this mindset. Several of these recommendations are for the field of teacher education. These recommendations provide opportunities for preservice teacher candidates to learn about and discuss critical whiteness and white supremacy as well as the restructuring of how play is taught. Bryan points out that much of the theory and examples of play described and read about in teacher education is based upon the play of white middle class children. What if, instead, they were more curious about and took an interest in the unique ways that Black boys play? Seeing Blackness as a part of a childhood is an important step. Last, Bryan encourages talking about race and racism in early childhood classrooms, using intentional teaching strategies and approaches to assist young children with a more complex understanding of their peers in school and in other community and neighborhood contexts. Bryan's work reminds how Blackness is 
criminalized in society and even in schools, where students are supposed to be learning, growing, and thriving. We have a responsibility to counter this antiblackness and work against it. In this research study, the focus is how race and racism is talked about and learned in a first-grade classroom and how we might understand these pedagogical and curricular choices through the lens of antiblackness.

Garlen (2018) has written about childhood and how it has been conceptualized as a period of innocence. Garlen describes how these concepts of innocence are a way to preserve and maintain whiteness. In the article, Garlen takes the reader through the historical trajectory of how childhood has been constructed over time and how innocence has been conflated with childhood, but only for some children. As such "children born to circumstances of poverty, abuse, or discrimination are always already excluded from innocence. From its inception, childhood innocence in this country was raced White" (Garlen, 2018, p. 10). As Garlen further elucidated, “Thus, 'childhood' was constituted through the repetition of whiteness and practiced as exclusion concealed as universal truth" (pp. 10-11). If we understand childhood innocence as raced white and imbued with whiteness, how can we view this as a desirable experience for any child?

Garlen described important points for interrupting and disrupting current thinking of childhood. This includes the talk and teaching we do with young children and the topics we consider appropriate for early childhood curriculum. If we view children as not ready to engage in these topics, who or what are we protecting? Additionally, how do we view the experiences children have already had in the world? Do we believe they have not viewed racism and/or experienced racism? Garlen adds, 
In the everyday lives of children in the United States, ignorance operates as silence not only by concealing the raced property of innocence, but also by excluding human experiences that fall outside the boundaries of innocence from the realm of childhood. The doctrine of innocence stands in the way of social justice work with children, which necessarily involves "difficult knowledge" (Britzman, 1998). In early childhood classrooms, the ideal of innocence manifests at the macro level of official curricula and the micro level of individual instructional decisions as the avoidance of potentially "controversial" topics. Thus, children who, for example, experience racism, question traditional gender roles, witness violence, or suffer abuse, are afforded no opportunities to acknowledge the experiences that are shaping how they are learning to understand themselves and their roles in the larger social world. In elevating childhood innocence to essence, we have constructed silence as safety, believing that as long as children are oblivious to the depravity of the adult world, they are protected from it. But, in the face of social injustice, silence is not protection. It is complicity. (2018, p. 11-12)

Garlen is advocating for interrupting these silences to reconceptualize our ideas of childhood. This serves as a rejection for notions of inclusion, for example, expanding current assumptions of childhood to be more inclusive of children who do not fit in current the vision (for example, expanding notions of childhood to be inclusive of Black children). Instead, Garlen advocates for seeing childhood as a project of justice, considering rights and responsibilities. If we reconceptualize childhood as a project of justice, rather than a project of protecting innocence (and whiteness), how might children 
rights be considered? Children's rights as citizens are to fully participate and be heard in society.

These research studies focus on antiblackness and the protection of whiteness in early childhood education. As such, they interrogate contemporary conceptualizations of childhood as maintaining white supremacy and Black exclusion. This emerging intersection of research foci has caused me to recognize the way that institutions of education are complicit in being anti-Black and engaging in antiblackness.

\section{(In)Conclusion ${ }^{4}$}

This literature review draws on recent research on the teaching and learning of race and racism in the early childhood classroom. It describes what the recent conversation about this kind of work has looked like. Based upon this literature, there are many important points that I am thinking about through this research study. First, children's literature can serve as a powerful tool to teach about topics of race and racism, but needs to be selected and shared thoughtfully and carefully — moving beyond shallow narratives of race topics as simply about oppression. The goals and consideration of critical literacy are an important entry point in order to think carefully about the goals and relationships when teaching and learning with young children, as well as moving towards social action. Another important component is an attentiveness to the language we use in

4 I borrow this title for ending this chapter and the remaining chapters from Davies (2014) as a conclusion. This way of phrasing conclusion signifies the opening up of new possibilities and "listening without knowing the meaning" (p. 19) to resist tidy and neat conclusions. Throughout the dissertating process, I struggled with the way that completing a dissertation creates the illusion of research(ing) as trim and orderly when I experienced it as messy and often illegible at times. (In)Conclusion is one way I am (re)presenting this tension. 
our work with youth about race and racism as well as exploring the way teacher silences of race 'speak.'

Last, much of this research affirms my intentionality in forming a relational ethics of working with teachers and students. Although it can be tempting to critique educators and their practices, I aim to support educators in taking risks, challenging the status quo, and working for social and educational change. My research offers up a reconceptualization of childhood and children as they learn about and discuss race and racism, while working to maintain a relational ethic of working with both teachers and students. Additionally, it is important to see how antiblackness influences views and conceptions of childhood. I work to bring in theory/ies that are new to this topic of study with young children, which I discuss in the next chapter. As a result, this dissertation study offers new thinking and contributions for the field of early childhood education.

In the next chapter, I tie the previously covered review of literature together with a rich description and discussion of the scholarship I build upon to conceptualize race. My conceptualizations of race are drawn from a diverse group of scholars and research, many of which are reflected as frameworks within the studies previously discussed. Additionally, I draw out and expound the theory of the wake by discussing the four theoretical concepts Sharpe (2016) writes of. I also make connections from Sharpe's theory to the field of early childhood education. 


\section{Chapter 3: Race Conceptualizations and Theoretical Underpinnings}

In this chapter, I begin by naming and describing the different theories and components that I draw from in thinking about and conceptualizing race. After, I detail theories of Afro-pessimism and antiblackness which the wake, the theory I thought with in this study, is grounded in. Next, I describe additional racial theories often used in educational research and the affordances and limitations of these frameworks. I discuss how these theories are similar to or different from the wake and include a rationale for why they are not used within this study. I conclude with a detailed description of the wake (Sharpe, 2016), and the four theoretical concepts within. Additionally, a rationale of why this theory was chosen and is useful for this research study is included. In conclusion, I consider how the understandings of race from students' in this research study might differ from the way I have discussed and conceptualized race.

\section{Conceptualizing Race}

The way that I conceptualize race draws from a variety of theories and perspectives. Chong-Soon Lee (1995) understands this explaining, “Abandoning one set of definitions entirely may deprive us of useful tools in the struggle against racism" (p. 447). This is my rationale for the diversity of theories and scholars I draw from in conceptualizing race. While some may caution drawing from theories with differing views of what race is, what it does, and how it acts upon us, I embrace these differences. I find myself agreeing with and finding support in Lee once again who suggests:

Instead of referring to a single definition of race, we can refer to multiple definitions of race; instead of talking about racism, we can talk about racisms. 
Instead of abandoning certain definitions of race, we can employ each of them when necessary. (1995, p. 447)

In these multiples of meanings, definitions, ways of thinking, and being is where we can embrace newness and possibility. A diverse focus encourages me to concentrate on what race(s) and racism(s) do in society, rather than what race or racism is. What are the affects and effects of the racing of people on their lives, the environment, and our larger world?

Generally, I see race as a socially constructed identity through which power and privilege are assigned. Yet, that definition seems flat when I think of the complex ways that racial identities are performed, ascribed, and claimed. I see race as a constantly shifting and evolving way of identifying people that can be empowering, oppressive, or both. Some components of racial identity can include the following resources and components: phenotype, material, linguistic, gender, and economic. Additionally, I see these components as intersectional.

\section{Phenotype}

Phenotype is a person's observable characteristics or traits. Some examples of phenotype include skin color, facial features, hair color and textures, and a person's height and weight or body shape and size. Often, people are racially classified by these traits either by themselves or others. However, looking at phenotypical traits alone are not enough. For example, Rachel Dolezal, a white woman who claimed to be Black for years, did so by changing her hair texture and tanning her skin. She claimed that she "felt Black” and changed her outward appearance to match (Dolezal, 2015). Yet, Rachel Dolezal is not a Black woman and never will be. Relying on observable characteristics is 
not an adequate or accurate measure of someone's race. However, it seems that most often we use phenotype as a measure of race. If we look more broadly, beyond someone's skin color or facial features, it is possible to see how race and racial identity formation is much more complex.

\section{Gender}

Similar to race, gender identity is a social construction which is ascribed to others (and/or self-identified). It is so commonplace and pervasive to make assumptions and designations about gender, that we assume gender is bred in our DNA and genes. Instead, gender is constantly (re)created from our interactions, social life, and existing structures. This is similar to racial identity in that we assume there are biological ties to race, when in fact it is just the systems we have become complicit and comfortable with that encourage and allow us to make assumptions and then ascribe gender identities to people. Lorber (1994) shared that "gender signs and signals are so ubiquitous that we usually fail to note them-unless they are missing or ambiguous" (p. 13). There is no doubt that individuals in society have differences from each other. However, lumping people together in sameness based on social constructed definitions of labels like gender smooth over the nuanced and unique contributions and knowledge of people. For example, when thinking about concerns of women and concerns of feminism, scholars doing this work can often prioritize concerns about gender over other identity categories, thus, missing how for some, their gender identities cannot be detached from their racial identities. Lorde (1980/2010) explains why this is problematic: "Refusing to recognize difference makes it impossible to see the different problems and pitfalls facing us as women" (p. 666). Consequently, it is important to recognize the diverse parts of our identity that 
make us distinctive from one another and how those identities cannot necessarily be separated and ranked.

\section{Language}

Alim (2016) has written about raciolinguistics, a complex analysis of the interconnected and mutually constitutive processes and relationships between race, ethnicity, language, and power. Alim writes that this is "a process of socialization in and through language, as a continuous project of becoming as opposed to being” (2016, p. 2). How does our language expression and language interpretation lead us to racial categorization and identification? The focus within raciolinguistics on becoming rather than being demonstrates the fluidity of race and language, constantly changing and shifting through time and place. This is a more nuanced and complex approach to race, which can be challenging to see and understand. It is not a simple framework to engage, because it constantly moves in a multidirectional format, between and among different ways of thinking about and employing race, and the processes of racialization. However, the politics and performance of language is inextricably connected to the politics of race.

Therefore, thinking with raciolinguistic concepts transforms an identity category like race that, for some, seems to be so tied to a stable identity and allows it to be seen as more fluid. The meanings of words, how they are spoken and shared, and the context they are expressed within are constantly changing and in flux. The message with/in words, signs, and definitions are contextual, often bound by place and/or context, but at the same time always changing. Furthermore, people's use of language crosses boundaries, thereby remixing and enhancing their resources from new languages, context, and experiences to open up what we think are clear borders and limits. Raciolinguistics helps one to 
recognize that not only are race and language interconnected, but are also open to constant change, as the process of racialization is fluid and ever-changing.

\section{Economic}

This detail within my conceptualizations of race is an inclusion of how socioeconomic conditions influence how we recognize and think of race. KeeangaYamahtta Taylor (2013) theorizes the political economy of racism specifically stating that "race and racism is so integrated into capitalism and capitalist society that its physical manifestation does not need to be present in order for it to work." In other words, racism is so embedded within capitalism, that the two cannot be pulled apart. Therefore, when writing, speaking, and thinking about race and racism, it is important to understand that capital and material goods have always been intertwined with racism. Taylor reminds us that what we call American democracy was the byproduct of the quest for capital which was made possible through slave labor. We often think of this as an historical epoch, but in fact is intertwined with our present and is a definite of our future. However, the political economy of racism is complex and is constantly changing and shifting.

Additionally, Leong (2013) has advanced the concept of racial capitalism. Racial capitalism explains the problem and practice of people deriving socioeconomic gain from the racial oppression of others. Leong explained that this issue occurs when white individuals and institutions gain capital and status from non-white people ${ }^{5}$. An example of this is a focus within many institutions, especially in education, on superficial attempts

\footnotetext{
${ }^{5}$ Another example is my own dissertation. With a focus on race and racism, I am pursuing a Ph.D. with one of the goals being to advance my own career.
} 
at diversity. Consequently, constructs of diversity are pushed forward with discourses that emphasize the 'value' of people learning from individuals unlike themselves. Unfortunately, this is mostly aimed at increasing the abilities and competences of white people to gain from these experiences while non-white people are treated as specimens to be studied. Leong indicates there are ongoing harms for non-white people as a result of racial capitalism. Some of them are: a fractured racial identity, economic disadvantages, and demands for individuals to 'perform' their racial identity in inauthentic ways. Racial capitalism is pervasive within society and needs to be discussed more frequently.

Many other scholars and researchers have written about the intersection of race and class, often including other identity markers such as gender. Although I do not include them here, I acknowledge the important history of this work and that my brief discussion does not attempt to cover all that has been written and theorized in this area.

\section{Materiality}

In thinking of the materiality of race, I consider how race is embodied and exists deeper than the surface of our phenotypical traits. Alexander Weheliye (2014) builds on Black feminist thinkers to explore the relationship between racism and humanity. Weheliye argues that Black feminism and Black studies, though largely ignored within academia as valuable fields of study, offer unique perspectives due to their exclusion. The exclusion of both of these fields have forced the contributing scholars to live and exist both in and outside of modernity, providing a distinct perspective. Weheliye (2014) aims to explore our "uneven planetary conditions and imagine other worlds these might make possible" (p. 15) not just in theory, sociology, and politics, but also within the "flesh" and our bodily experiences. 
Weheliye critiques many posthuman scholars who have attempted to do this work but fail to notice how in doing so they recenter and reinscribe white supremacy. This occurs when through posthumanism, the idea of the human or humanism is essentialized and the human is understood to be a white, cisgender man. In rejecting this version of the human, we render all other humans invisible or non-human. Weheliye pushes one to (re)think humanity from a new perspective. This is a perspective from the "flesh" rather than what we commonly call the "body." In this divergent way of thinking and writing/speaking, we recognize differing ontologies, ways of being. The body is often expected to be known, and especially in much of academic discourse it conjures up the image of "man." By considering flesh, we consider our different ontologies, what our flesh has gone through and will continue to go through. Considering Weheliye's racial materiality, as existing within the body and the flesh, he demonstrates that race is more than just what we can see.

\section{Intersectionality}

Davis (2016), in her text, Freedom is a Constant Struggle, encouraged the reader to recognize how intersections of race, class, gender, sexuality, nation, and ability are intertwined and unable to be separated. This intersectional approach is key in working towards liberatory thinking as it draws lines of connection as well as parallelisms across diverse identities. Davis' (2016) writing is built upon her seminal text, Women, Race, and Class which masterfully provides a historical account and discussion of how racism, sexism, and class intersect. Davis clearly documents the role of working-class Black women as change-makers, activists, and foundational to contemporary understandings of intersectionality. Additionally, Audre Lorde (1984/2007) identified issues of class, race, 
age, gender, and health as central to the experience of being a woman. Lorde argued that often differences in gender receive all the focus, it is essential that these other differences are also recognized and addressed. These lines of connection acknowledge the impossibility of separation our social identities and encourages others to view them as associated and related. This new vision allows for one to understand that oppression based on identity, such as race, gender, class, language, and other identities can occur on multiple points and levels. Crenshaw (1989) who is credited with coining the term, advises that intersectionality is not just about intersecting and overlapping identities but a lens for understanding and examining power. Studying issues from an intersectional perspective allows one to see where power comes from, how it circulates, and where it collides.

Davis (2016) advised that to embrace the interconnectedness of our identities is a challenge, but is necessary in order to "understand the interrelationships of ideas and processes that seem to be separate and unrelated" (p. 4). Indeed, to be intersectional we must understand the intersection of capitalism with other identities and points of oppression. Davis writes about a key and pivotal paper titled Triple Jeopardy written by the Third World Women's Alliance in the 1960s. In this paper, the triple discussed are racism, sexism, and imperialism. A discussion on race and gender cannot take place without a discussion of class or capitalism. When we embrace an intersectional approach, we are better able to work towards more liberatory pedagogical and educational practices for all people and their intersecting and overlapping identities.

All of the components and resources which I have discussed provide different layers to how one thinks about and conceptualizes race. Phenotype often seems to be our 
default way of conceptualizing race, with one often conflating skin color as equivalent to race. Yet, in the discussion I have offered it is evident that race is much more complex than simply what one sees. Materiality, linguistic resources, gender identity, and socioeconomic status all fold into conscious and unconscious ways we think about and conceptualize race. Therefore, thinking more in intersectional ways about race is important. Race is more than what can be seen and identified and racialization is a living and moving process.

\section{Thinking About Race in this Dissertation Study: Antiblackness and Afro-pessimism}

Within this dissertation study, I am thinking with (Jackson \& Mazzei, 2012; 2017) the data produced in this research study and theory of the wake (Sharpe, 2016). The theory of the wake, which I describe in further detail later, is grounded in antiblackness and afro-pessimism theories and thinking. Below, I describe how I conceptualize Afropessimism and antiblackness.

\section{Afro-pessimism and Antiblackness}

Antiblackness is a way of thinking about and understanding the function of race and exists under the umbrella of Afro-pessimism. Dumas (2016) defines Afropessimism in this way:

Afro-pessimism theorizes that Black people exist in a structurally antagonistic relationship with humanity. That is, the very technologies and imaginations that allow a social recognition of the humanness of others systematically exclude this possibility for the Black. The Black cannot be human, is not simply an Other but is other than human. Thus, antiblackness does not signify a mere racial conflict 
that might be resolved through organized political struggle and appeals to the state and to the citizenry for redress. (p. 13)

Afro-pessimist scholars theorize that Black people and Black life exists within a synonymous relationship with and to slavery. According to Afro-pessimist thinkers and scholars, to be Black is to never be fully considered as human. Hartman (2007) names this as "the afterlife of slavery" where "Black lives are still imperiled and devalued by a racial calculus and a political arithmetic that were entrenched centuries ago" (p. 6). Wilderson (2010) described how Afro-pessimism is embodied in everyday life:

The election of a Black president aside, police brutality, mass incarceration, segregated and substandard schools and housing, astronomical rates of HIV infection, and the threat of being turned away en masse at the polls still constitute the lived experience of Black life. (p. 10)

The examples provided by Wilderson are just a small sampling of the ways "Black people live in a structurally antagonistic relationship with humanity" (Dumas, 2016, p. 13). Afro-pessimism demonstrates the complex and knotty ways that race operates within antiblackness. Antiblackness demonstrates that it is more than just discrimination, more than just a Black/white binary, and demonstrates the multifaceted and challenging reality of being a Black person. Antiblackness is an ideology—an ideology that bonds death and punishment with Blackness. Think about the way that Blackness is negatively and deficitly enacted each day. For example, in the Merriam-Webster dictionary, under "Black" the first example provided in a sentence is: "his face was black with rage" (italics in original; Merriam Webster dictionary, n.d.). This example demonstrates how being Black is synonymous with being angry, out-of-control, and terrifying/scary. 
As Dumas (2016) wrote, "The aim of theorizing antiblackness is not to offer solutions to racial inequality, but to come to a deeper understanding of the Black condition within a context of an utter contempt for, and acceptance of violence against the Black" (p. 13). Thinking with a theory that recognizes and conceives antiblackness, the wake, offers a framing of how antiblackness engulfs society. Antiblackness names the problem: the continual personal, cultural, social, legal, and structural attacks on Black people and Blackness.

In this dissertation study, I think with the theory of the wake (Sharpe, 2016), which is framed within antiblackness, in order to consider how we can think differently about the teaching and learning of race and racism in a first-grade classroom. Exploring the ways antiblackness might exist and be resisted in schools is an important endeavor. Dumas (2016) wrote about how educational policy is anti-Black in thought and action. In order to create a shift, Dumas (2016) informs that, "education must grapple with cultural disregard for and disgust with blackness... a theorization of antiblackness allows one to more precisely identify and respond to racism in education discourse and in the formation and implementation of education policy" (p. 11). Although not a study in education policy, pedagogical and curricular choices in classrooms are influenced and informed by policy choices and decisions. Dumas (2016) adds:

it is important for educators to acknowledge that antiblackness infects educators work in schools, and serves as a form of (everyday) violence against Black children and their families... Teachers, administrators, and district leaders should create opportunities to engage in honest and very specific conversations about 
Black bodies, blackness, and Black historical memories in and out of the school and local community. (p. 17)

This dissertation research responds to the call by Dumas not only to acknowledge how antiblackness works in schools, but also engages in critical thinking, writing, and theorizing about what we can learn from an analysis of the teaching and learning of race and racism through the lens of antiblackness. I do want to acknowledge that the way I have conceptualized race earlier and the contributions of Afro-pessimism and antiblackness differ. Having differences in conceptualization are productive because it is within these differences in thinking and theorizing we can produce new ways of understanding and recognizing how race and racism operates in early childhood classrooms.

\section{Why Not Another Racial Theory?}

At this point, I ask myself , why not think with critical race theory, whiteness studies, or a different racial theory? Why a theory of antiblackness? Below I briefly describe other racial theories that are often used in research that centralizes race and racism. I provide a discussion on what these theories are not able to offer to this research study. Then I describe the theory of the wake and what thinking with it contributes in particular for this research study.

\section{Critical Race Theory}

Critical Race Theory (CRT) originated from the field of Legal Studies. CRT developed from a need by legal scholars, lawyers, and others involved in policy to name oppressive experiences, policies, and conditions specific to People of Color (Bell, 1989, 1995; Crenshaw, Gotanda, Peller, \& Thomas, 1995; Delgado, 1984; Delgado \& Stefanic, 
2012; Matsuda, 1991). CRT underscores the necessity of experiential knowledge and storytelling from Communities of Color as an integral part of understanding and analyzing racial inequality. One of the fundamental principles of CRT is that racism in our society is indeed the norm and thus is rooted in the configuration of our nation and maintained through policies, institutions, and other structures. CRT assists scholars, educators, and other activists in understanding that racism exists within a complex interaction with other social and cultural factors. CRT also takes a critical look at many factors affecting people such as gender, social class, and sexuality and acknowledges the intersectionality that these multiple, often overlapping identities play in attempting to name multiple forms of oppression that people experience. Still, CRT generally focuses on the centrality of racism in the lives of all people, while acknowledging and critically examining the intersectionality and influence of classism, sexism, gender and other systems of oppression.

Applications of CRT to the field of education continue to expand and grow. In one of the first pieces ever published on CRT in education, Ladson-Billings and Tate (1995) critique the highly pervasive multicultural education approach and posit that race has been ignored as an explanation for educational inequality. According to Solórzano and Delgado Bernal (2001), CRT in education has five main tenets specific to education. Those five themes are: (1) the centrality of race and racism and intersectionality with other forms of subordination, (2) a challenge to dominant ideology, (3) a commitment to social justice, (4) the centrality of experiential knowledge, and (5) an interdisciplinary perspective. These five principles assist researchers, educators, and activists in having a specific framework with which to analyze and approach people's experiences. CRT tools 
assist educators in shedding light on theoretical perspectives on race and historical inequities that have plagued our society for generations.

An integral component of CRT is understanding the role of whiteness and white supremacy as an ideology that supports and reinforces the racist actions in our society that are thought of as common-sense ideas. Generally, white supremacy is the idea that being identified as white and that white ways of being (think of beauty and fashion, for example), is most ideal. White supremacy is not just about skin color and desirable traits, however. White supremacy is part of a system of racialized oppression which is historically-based, as well as institutionally and structurally perpetuated to maintain and defend wealth, power, privilege, and access. This standard of whiteness is positioned in U.S. society as normal and desired and sustains other ways of being and existing as abnormal and objectionable.

CRT scholars assert that racism is usual and familiar in our society. As Delgado and Stefanic (2012) contend "[racism is] the usual way society does business, the common, everyday experience of most people of color in this country" (p. 7). A frequent way that this racism permeates through society is through the purported objective of taking a fair and neutral perspective, known as a figurative colorblind positionality. In this stance, one actively takes the stance of not acknowledging racial differences with the contention of being unbiased. Bonilla-Silva (2010) refers to this position as "color-blind racism" (p. 25). When we reject any acknowledgement of racial differences, we also refuse to acknowledge differential treatment of people based on race. This position of colorblindness has become an ideology in our society, especially for much of white society. 
A constraint of CRT is the limitation of its tenets solely applicable within United States contexts. The explanations and theorizations for the processes of how individuals are raced only functions within U.S. settings. Also, while CRT provides a clear and critical explanation for how race and racism operate within the United States, it is less clear on actionable items. For example, reflecting on the five tenets of CRT in Education above, not one of those tenets a suggestion for a path forward in how to eradicate racism. By offering suggestions, I want to caution that I am not pointing to concrete solutions (i.e., step 1, step 2 type of suggestions). Instead, I am thinking about the posing of important questions, dilemmas, and implications to have us think more deeply and complexly about next steps. Last, specifically for this research study, typically the focus of CRT informed research is on meaning derived from narratives and stories. For this research study, I focus on processes, and how might things come to be as they are. While I believe we can never completely escape meaning making processes, the explicit goals of this research project differs from the goals of CRT. While CRT is a helpful set of tools for working to identify and name racism, it does conflict with the goals of this research.

\section{Racial Literacy}

Racial literacy is a framework for developing social proficiencies which assist people navigating the complex ways that race operates. Racial literacy rejects racial liberalism, the idea that racism is just acts of individual prejudiced or bigoted people, which ignores the deep structural roots of the problem of racism. This focus within racial literacy has often been referred to as working to destroy the disease of racism rather than just the symptoms. Sealey-Ruiz (2011) indicates that racially literate people "are able to discuss the implications of race and American racism in edifying and constructive ways" 
(p. 25). One of the goals of racial literacy is to have white people adopt an anti-racist stance and for People of Color to resist a victim stance (Sealey-Ruiz, 2011).

According to Guiner (2004), there are three components of racial literacy. First, racial literacy is contextual, bound to space and place. This rejects the universality of racial liberalism and instead focuses on being racially literate as specific and nuanced. Second, racial literacy connects power and race together, thereby recognizing the intricate bond between the two which cannot be separated. Racial literacy analyses then often look at structural and institutional forces and how they are responsible for the way that race is conceptualized, effecting an individual's agency. Ultimately, racial literacy acknowledges race's connection to other variables (for example, socioeconomic status). This is because racial literacy focuses on solving problems, and in order to directly address these problems we need to understand what they look like.

Stevenson (2014) focused on stress in schools caused by the choice to avoid and ignore racial conflicts. As a result, Stevenson explained that racial stress is major problem in K-12 schools. Stevenson provided broad contributions for both teacher professional development as well as school curriculum to assist with racial literacy skills for students, parents, and teachers. With a focus on Black history, King (2016) advocated for the incorporation of racial literacy principles in teacher education programs in an effort to provide more complexity and variation within Black history curriculum and implementation.

In a focus on racial literacy within family structures, Twine (2011) wrote about families in the United Kingdom composed of white mothers and Afro Caribbean fathers. In the use of photography and stories, Twine demonstrates how these white mothers 
deepened their racial consciousness over time, develop a racial literacy to navigate systemic racism while raising biracial children. I also acknowledge that racial literacy is a field of study that has been written about, explored, and researched extensively. There are many additional studies of racial literacy in different contexts and perspectives that I have not included here.

In many ways, the goals of racial literacy align with the research done in this study. I would add tenets of racial literacy inform the work that Ms. Rotter and I are engaged in within her classroom. Yet, like CRT, the focus of racial literacy is not just on social change but also focuses on understanding and meaning making. On the contrary, in this research study I focused on processes and how things come to be and how they unfold, rather than what they mean. For example, when a child asks a question, it is not that I attempted to interpret their meaning, but I looked at how that question came to be asked in that space and what asking that question produced. So, while many of the views and tenets of this theory are engaged, I do not claim to do the work of racial literacy.

\section{Critical Whiteness Studies}

Critical studies of whiteness focus upon the system of whiteness to simultaneously decenter whiteness from its position of supremacy (Frankenberg, 1993; Leonardo, 2009; 2013; Lipsitz, 2006; Roediger, 1991). The work of analyzing whiteness explores the social construction of what it means to be white, and how societies are structured with white experiences established as the norm and most valued ways of being. Whiteness studies teaches us to think critically about how social life is organized around white experiences. 
Whiteness establishes legitimacy through hegemony. In other words, it is an ideology established over time, through violent political dominance. Social and cultural institutions have created and maintained the state that white ways of being and culture are the most prized and considered as the 'natural' order. Social institutions funnel white culture so that it is pervasive: it's the key lens of history and art; it's the way in which we learn about science; it's the representations we grow up with in the media; it's white people filling most positions of authority. Additionally, Harris (1993) argued that white status provides individuals property rights which are unavailable to People of Color, constituting whiteness as valuable. As a result, the individuals 'possessing' whiteness are afforded rights of status, use, and claims of exclusion. Property rights foster whiteness to be the ultimate reward, and those who 'pass' are entitled to ample amounts of unearned benefits.

Whiteness is a global phenomenon, centered in colonialist spaces and places, but whiteness also goes unexamined in day-to-day life. Whiteness is both privilege and power; it means being at the top of the social hierarchal system but taking the hierarchy for granted. Whiteness is maintained through various practices in social, cultural, and educational life. These practices buffer white people from having to think critically about race, such as through the idea of color blindness (Bonilla-Silva, 2010). Over time, white people have come to understand that overt acts of racism are not permissible. As BonillaSilva (2010) argued, in general, white people do not want to be associated with being socalled racist. This leads to an avoidance of thinking about race, much less applications of how race impacts their own lives. This may lead to statements like: I don't see race, I just see people. Statements such as these demonstrate that white people are privileged to pick 
and choose whether or not to engage in discussions of race. To say that one does not recognize race is refusing to acknowledge how white people's opportunities in life have been enhanced through whiteness. Additionally, DiAngelo (2018) has written about white fragility where on the occasion when white people are confronted with conversations about race and the problem of whiteness, they make defensive moves that shut down any potential meaningful dialogue and social or structural change.

Although these critical theories for understanding race, racism, and whiteness are valuable and important work, I have chosen not to use theories of whiteness for analysis. I want to stay away from the potential to prioritize the dominant voices and perspectives of whiteness. Instead, thinking with the theory of the wake addresses this as a problem through a different approach, centering the way antiblackness effects all of our lives.

All three of these theories and frameworks are useful and innovative ways of analyzing and thinking about race and racism and how to dismantle our racialized and racist structures. Although none of these theories are explicitly used within this study, I believe fragments of this thinking, analyzing, and knowing may be found throughout this research.

\section{Theoretical Foundations}

Christina Sharpe (2016), in her book, In the Wake: On Blackness and Being, theorizes Black life in the aftermath of slavery. Sharpe's theorizations provide pathways towards recognizing and thinking of racism in our past, present, and future. The theorizing within the wake urge one to engage with what seems to be our past (e.g., slavery, segregation laws) as ongoing in our present day lives, thereby altering the future we are creating. Sharpe engages the analogy of a ship, a slave ship, to discuss the way 
that antiblackness and white supremacy normalize the death and destruction of Black people's lives. Sharpe writes about how racism is often historicized, attempting to place it in the past. Sharpe's acute analysis describes the complex ways in which racism and antiblackness operate in contemporary times. Sharpe utilizes segments of the oceanic journey of Black people in bondage during the transatlantic slave trade as analogies: the wake; the ship; the hold; and the weather. Below, I describe these analogies as theoretical concept strands which inform the analysis of this dissertation. I follow the path of Sharpe's four chapters in writing about these theoretical concepts as separate, however, I do recognize that these are concepts that are intertwined with each other. I work to temporarily disconnect them from each other, but they operate most effectively as an entangled unit. For example, when thinking with data from Ms. Rotter's classroom, I put them to work simultaneously to think with how these theoretical concepts are being lived out in the teaching and learning in her classroom. Additionally, based on the title of Sharpe's book (2016), I use the term the wake to refer to both a concept and the overarching theory. As Sharpe (2016) suggests,

I want to think 'the wake' as a problem of and for thought. I want to think 'care' as a problem for thought. I want to think care in the wake as a problem for thinking and of and for Black non/being in the world. Put another way, In the Wake: On Blackness and Being is a work that insists and performs that thinking needs care and that thinking and care need to stay in the wake. (p. 5) When thinking of a theory as "a problem of and for thought," one is prompted to not just approach theory as a theoretical way of analyzing data and thinking about research. It also changes the way we think, act, and exist in the world. It shifts how we see our 
presence and responsibility in world. I continually think of the phrase "that thinking needs care" written by Christina Sharpe and how thinking is an action, and how we think about and with communities as crucial and needed.

Below, I discuss and describe the four theoretical concepts: the wake, the ship, the hold, and the weather. I have organized each theoretical concept discussion in the following style: I first describe the concept, next provide an example that Sharpe uses to illustrate the concept, then provide a contemporary example to portray an ongoing way to see this concept in everyday life, and last include questions and connections for the field of early childhood education and what these four theoretical concepts might have to offer our thinking when exploring the teaching and learning of race and racism in early childhood classrooms.

\section{The Wake}

The wake is a mark a ship creates upon the ocean as it cuts through the current. The process of cutting through waves, slicing the water, and making marks that will be overlapped by new waves and currents, rendering the wake as (in)visible to many is similar to "racism, the engine that drives the ship of the state's national and imperial projects" (Sharpe, 2016, p. 3). In other words, racism is a part of our everyday lives, creating ripples in how we attempt to live, but continues to be lapped by new and different waves and movements, making it difficult to name and clearly see, but yet is surrounding us in our daily lives. In fact, the complex layers of history, injury, destruction, and more (like the layers to the ocean) are a part of the wake. As Sharpe (2016) recounts "in the wake, the past that is not past reappears, always to rupture the 
present” (p. 9). Sharpe argues that the past is not past, that the past continues to unfold and unravel within our present day lives.

Sharpe's example of the wake. Sharpe provides an example of how the past is not past in her teaching with college students. When teaching a course titled Memory for Forgetting, focused on traumatic histories, Sharpe noticed that slavery in the United States and the Holocaust, two main foci in the course, were reacted to differently by students. She shares,

I found that many, certainly well-meaning, students held on to whatever empathy they might have for reading about the Holocaust but not for North American slavery... Students would say things about the formerly enslaved like, 'well, they were given food and clothing; there was a kind of care there. And what would the enslaved have done otherwise?' The 'otherwise' here means: What lives would Black people have had outside of slavery? How would they have survived independent of those who enslaved hem? (Sharpe, 2016, p. 11)

Sharpe recalls after screening the documentary Shoah, which Sharpe describes as containing a scene where a Holocaust survivor, Simon Srebnik, who now lives Israel, returns to his town of origin in Poland. The people in the town, happy at first to see the survivor, then transition to tell Srebnik that the Jewish people of the town, killed in the Holocaust, are the ones responsible for the murder of their people. Sharpe shares that as the scene pans in on the face of the survivor, the students in the course are appalled by this and feel deep pain for him. Sharpe then asks the students to consider: what if this survivor had no other place to go except this place, this location, where people blame him for the murder of his friends and relatives? What if this survivor had to be neighbors with 
people who would have seen him dead or killed him? Sharpe (2016) follows up her questioning with the gloomy reality as it relates to North American slavery:

The conditions in the post-Civil War United States of the formerly enslaved and their descendants; still on the plantation, still surrounded by those who claimed ownership over them and fought, and fight still, to extend that state of capture and subjection in as many legal and extralegal ways as possible, into the present. The means and modes of Black subjection may have changed, but the face and structure of that subjection remain. (p. 12)

The reality that Black people have lived and still live with teachers, government officials, neighbors, salespeople, and others who believe their lives as unworthy of value and respect is sobering. Once we recognize that North American slavery is an event that is ongoing, not fixed in the past, it evokes questions about how we might teach and learn about it. Sharpe asks, "How does one mourn the interminable event?... how does one memorialize chattel slavery and its afterlives, which are unfolding still? How do we memorialize an event that is still ongoing?" (pp. 19-20). Engaging with/in these questions requires a commitment to sit and think with "processes; through them we think about the dead and our relations to them; they are rituals through which to enact grief and memory" (Sharpe, 2016, p. 21). Although this may seem like a difficult task and a dreary one at that, it is valuable task. The value is that it encourages us to sit with difficult questions, not to seek answers necessarily, but instead to think through the process which encourages us to have different relationships with the present. Relationships that seek to identify the way that racism and antiblackness are unfolding within our everyday lives. 
Contemporary example of the wake. Recently, I read a news article that discussed what Black women have continued to endure when travelling by airplane. Black women are constantly under heightened scrutiny and surveillance, but when they travel in airports, specifically, their hair has become an added point of discrimination. According to Medina and Frank (2019), an overwhelming amount of Black women receive pat-downs on their hair when going through security. While much attention has been paid to individual agents choice to conduct additional pat-downs, Medina and Frank (2019) note that it is actually the body scanners which indicate to TSA agents that they need to complete a more invasive pat-down. The scanners seem to read Black hairstyles as problem, and trigger an alarm. Holding security scanners responsible for inflicting anti-Black thinking and treatment is interesting. Who creates these machines and who develops their programming software? Reading over the continued treatment of Black hair as a problem, and as alarm worthy, brings forth the theoretical concept of the wake. The presentation of Black women's hair as the problem rather than antiblackness as the problem, normalizes antiblackness in everyday practices.

The wake and early childhood education. For early childhood education teaching and learning, the theoretical concept of the wake engages us in processes of how we might (dis)connect from antiblackness. For example, do we recognize that the in and out of school lives of young children are also steeped in antiblackness? How does this occur? What is the process that encourages and permits antiblackness to be sustained in our educational spaces? How does the recognition of the past as not past interrupt commonly held notions of young children as innocent? Instead, seeing children's 
knowledge and actions as connected to not only other others, but our difficult and ongoing histories?

\section{The Ship}

In the chapter on the ship, Sharpe (2016) brings the reader into encounters with Black lives in the ongoing aftermath of slavery. Sharpe writes about both the ship as a metaphor, as well as the actual object of the ship, and how it teaches and "makes ethical demands...demands to imagine otherwise" (p. 51). Writing about the ship seems like a task that is unable to be written. How do we write the violent horrors that People of Color experience each day as a result of antiblackness? Does writing it make it somehow more palatable and less horrific? Does neatly packaging the horrors of antiblackness make it more digestible? The ship explores and expands the "dysgraphia of the wake" (Sharpe, 2016, p. 33), demonstrating that sometimes writing is just not enough. Sharpe brings this theorizing to light through instances of: environmental disasters, historical narratives, stories of contemporary refugees, and art.

Sharpe's example of the ship. In an instance of an actual ship, Sharpe writes about the history of a slave ship, the zong. Sharpe writes that there were at least 442 abducted African men, women, and children on board - when the ship was built to only hold 220. These captive people, treated as property and cargo, were insured by the captors. During the voyage, as many as 130 of the African men, women, and children were murdered by being thrown overboard to "save the rest of the cargo" as well as ensuring receipt of the insurance payout (Sharpe, 2016, p. 35). The effect of this trauma, of being abducted, then residing within a ship where mass murder occurred, and then 
years of slavery and abuse, continues to reverberate within the ocean as well in contemporary life as Sharpe (2016) carefully shared,

A ship moving through water generates a particular pattern of waves; the bow wave is in front of a ship, and that wave then spreads out in the recognizable $\mathrm{V}$ pattern on either side of and then behind the ship. The size of the bow wave dictates how far out the wake starts. Waves that occur in the wake of the ship move at the same speed as the ship. From at least the sixteenth century onward, a major part of the ocean engineering of ships has been to minimize the wake. But the effect of trauma is the opposite. It is to make maximal the wake... And every time, every instant that the boat is moving through water it has the potential to generate a new wave. $(2016$, p. 40)

Antiblackness and the lives it destroys are unable to be contained. Instead, they ripple out, creating new waves, impacts, and effects. Sharpe writes about how existing solutions to the impacts and effects of the ship are difficult if not impossible to accomplish. Instead, doing the challenging work of recognizing, theorizing, and developing a critical consciousness of the somber realities of how antiblackness continues to violently harm the lives of People of Color can lead us to different understandings of how these processes work. As Sharpe (2016) composed,

Theorizing wake work requires a turn away from existing disciplinary solutions to blackness's ongoing abjection that extend the dysgraphia of the wake. It requires theorizing the multiple meanings of that abjection through inhabitation, that is, through living them in and as consciousness. (p. 33, emphasis in original) 
In another example of theorizing the ship, Sharpe describes a commissioned art installation from Charles Gaines titled Moving Chains. This future art exhibition is scheduled to take place adjacent to the Mississippi River, next to the St. Louis arch, and down the street from the courthouse where Dred and Harriet Scott fought for their freedom. The patrons of Gaines' art installation will walk on a platform where two sets of heavy mechanized chains, one silver and one red, move overhead in different directions. The silver moves at the speed of the river, while the red chain moves slower, similar to the speed of a slow barge.

Renderings included in Figures 1 and 2 below demonstrate the powerful imagery of this artwork. Sharpe points out that the Mississippi River was/is known as a gateway to Manifest Destiny, which was/is the belief that white settlers were promised land west of the Mississippi and justified in their conquest and colonization of what was thought of as boundless frontier. There is a juxtaposition of: the sound and movement of the chains, at the 'entrance' of promised land for white colonial settlers, adjacent to historically significant courthouse where Dred and Harriet Scott fought to be considered legally free, all within view and sound of the rushing of the Mississippi River. This is how Sharpe describes the ship, cutting through and yet bringing multiple forces together. The ship, as a theoretical concept, shows how our history is never really a history, but instead brings past, present, and future together to overwhelm us. 


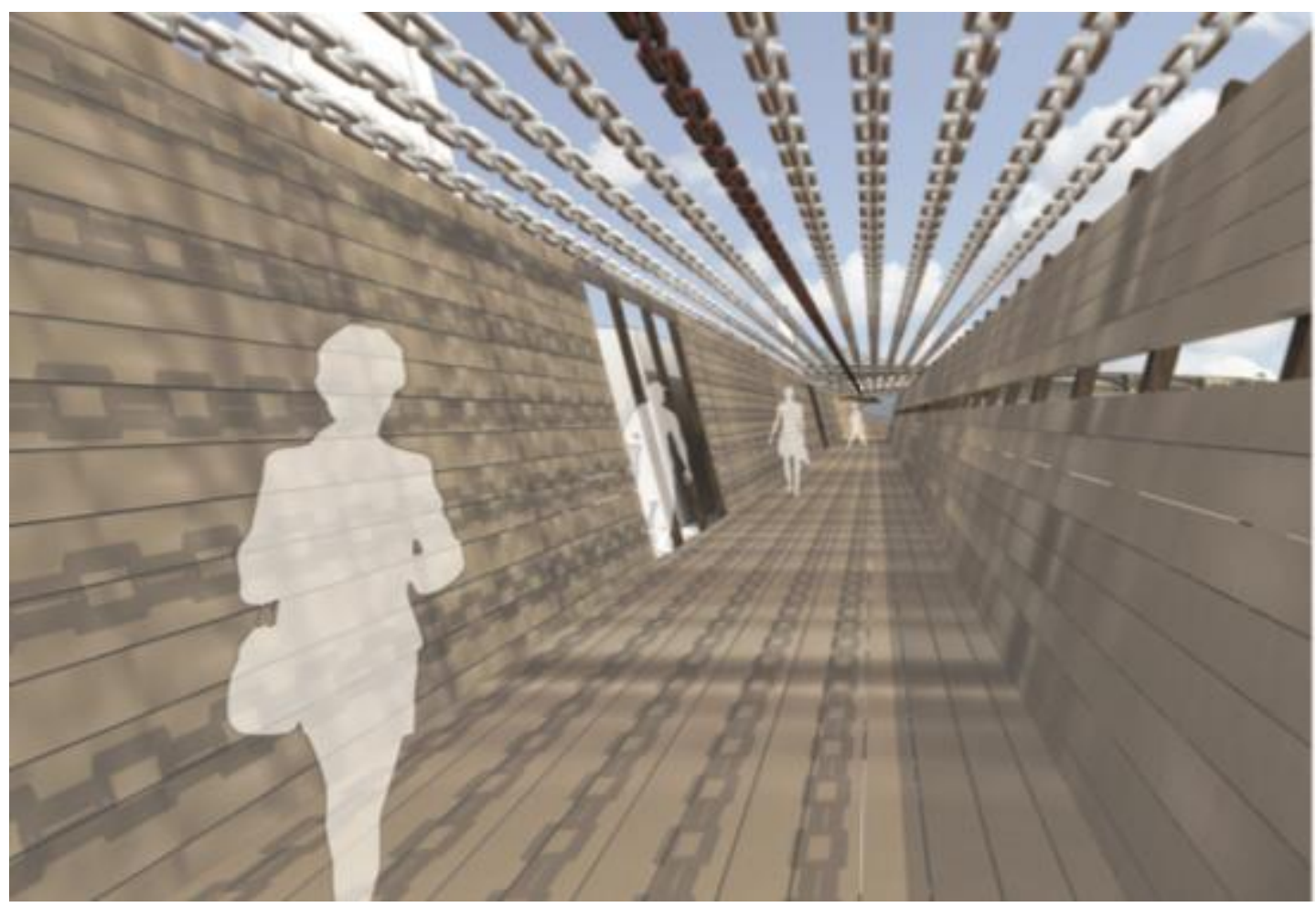

Figure 1. Walkway under Moving Chains with mechanized chains overhead. Image downloaded from http://toloarchitecture.com/pdfs/TOLO_Website_Art\%20Furniture.pdf

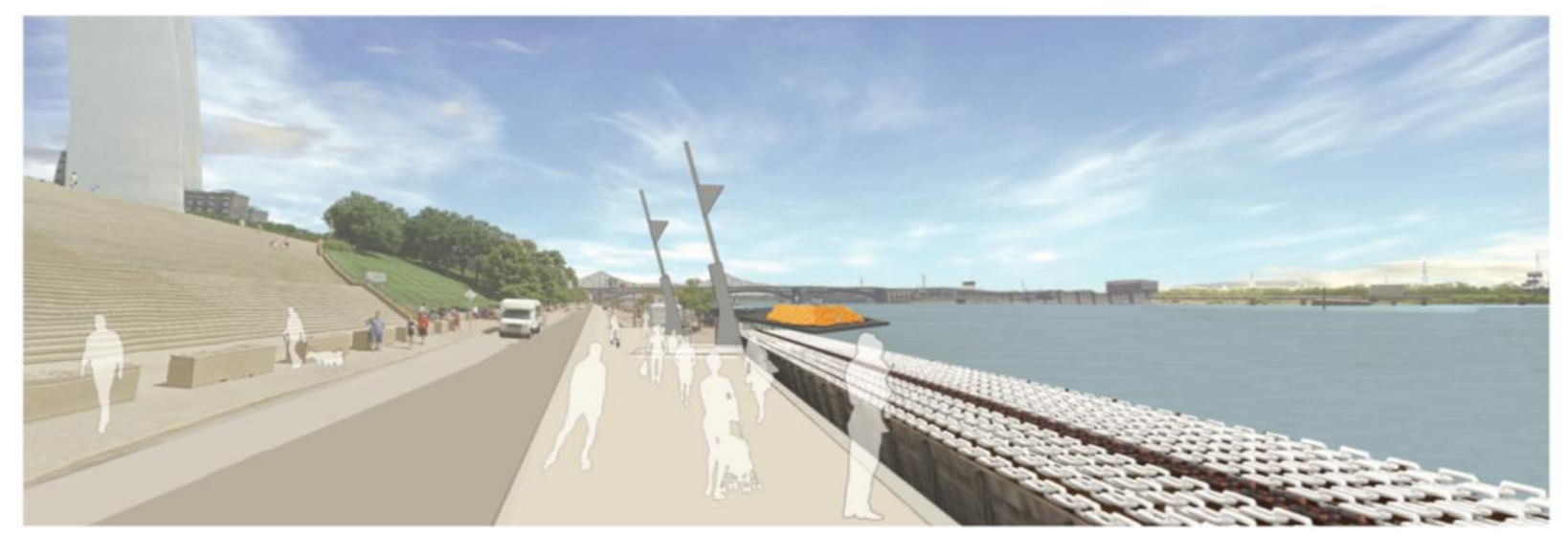

Figure 2. Installation adjacent to St. Louis arch with view of chains from top. Image downloaded from http://toloarchitecture.com/pdfs/TOLO_Website_Art\%20Furniture.pdf

Sharpe inquires, "How does one account for surviving the ship when the ship and the un/survival repeat?" (2016, p. 38). In this question, Sharpe addresses the often repeated narratives of individual grit and resilience assisting one with overcoming the obstacle of systemic racism and antiblackness. Sharpe, pointing us towards the purpose and intention 
of theorizing the ship, states "The question for theory is how to live in the wake of slavery, in slavery's afterlives, the afterlife of property, how, in short, to inhabit and rupture this episteme with their, with our, knowable lives" (Sharpe, 2016, p. 50).

Contemporary example of the ship. How does the ship exist in our contemporary realities? Recently a news story surfaced which shared the story of a Black first grade boy, Jonathan Browning, who came home from school with a note from school demanding his locs be cut before returning to school after winter break (Kai, 2019). The note sent home, is included in Figure 3. Jonathan is held in the school ship, being contained in a place where his ways of living and existing are being violated. In response, Jonathan's parent shared the notice on Twitter asking "how does his hair affect his ability to learn?" (Kai, 2019). This event is not an isolated incident, as similar reports of Black children, other Children of Color, and their families being forcibly told to cut their hair by school employees seems to occur regularly. This incident echoes Sharpe's (2016) reminders of how "the ship and the un/survival repeat" (p. 38). However, Jonathan Brown, the student whose hair is the focus this particular report, is the same age and grade level as the students in Ms. Rotter's class. Recognizing that Ms. Rotter's students are intricately connected to these incidents, including something like this particular incident occurring with one of them and their families is sobering. Perhaps even if it wasn't them directly, these students, like Jonathan Brown are their peers and contemporaries. How will they learn to navigate and recognize the ship and the destruction and damage to those within its path? 


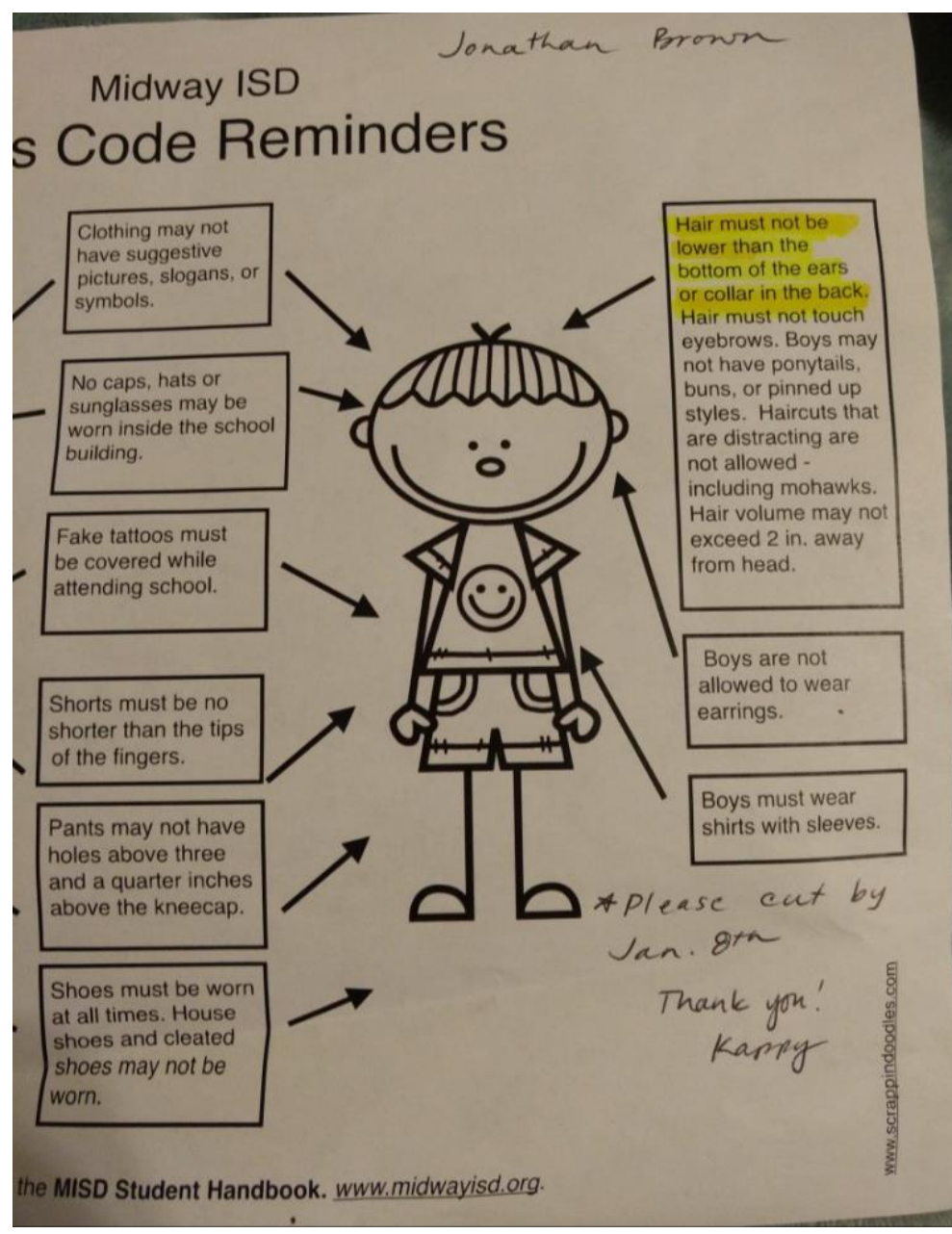

Figure 3. Note to Jonathan Brown's family to cut his locs. Image downloaded from https://theglowup.theroot.com/in-another-case-of-dreadlock-discrimination-texas-elem1831684144

The ship and early childhood education. In early childhood education, how do we live in the wake of slavery? In the ship one might wonder: How do we, as early childhood (EC) educators, exist in the repeating, churning disaster of the ship? Considering such provocations as Gaines' art installation, the violence against young people and their families like Jonathan Brown, within the complexities of the past not being past, how might early childhood education, as a field, address the teaching of race and racism? How might individual EC educators teach about the race and racism as disruptive, embodying the actions, being, and living with the ship? Further, perhaps 
research studies like this one can work against violent pedagogical practices. Practices such as the one which had a traumatic effect on Jonathan Brown and others around him, are meant to hold up a specific type of being, living, and looking as ideal. Recognizing that we are living in a past that is not a past might help EC educators and those who work with young children and their teachers think and act differently in these spaces.

\section{The Hold}

Traditionally, the hold is a term often used to identify the lower compartment of a ship containing valuables being transported. In using this term within the wake, Sharpe describes and names the physicality of the hold and what it might represent in people's lives through actions and places such as "carding, stop-and-frisk, family detention centers, holding centers, Lager, quarantine zones" (Sharpe, 2016, p. 83, emphasis in original). The hold is the location of being violated, viewed less than human (or not human at all). The hold is the action, doing, and outcomes of antiblackness.

Sharpe's example of the hold. Christina Sharpe describes a program called Cradle2Grave or C2G, which exists in the city of Philadelphia, PA. This organization is geared towards middle school aged students, largely Black, putting together a program that focuses on a "highly interactive, two hour experience that confronts participants with the realities of youth violence on a personal level...it brings teens into our hospital and trauma bays and uses real life (and death) scenarios" (Cradle2Grave program, n.d., para. 1-2). According to Sharpe and the organization website, within this two hour program, the students are exposed to images of violence, such as an actual 16-year-old Black youth, Lamont Adams, after he was shot. Afterwards, at least one young person is asked to be a volunteer where they put their body on a hospital gurney and an organization 
representative places stickers where the person, following the violent image earlier, would have been shot had they been the victim. Sharpe writes that the experience facilitated by the organization is a reminder that "to be Black is to be continually produced by the wait towards death...these young people's bodies are always already in the space of Lamont Adams's body" (pp. 88-89). In the hold, one can bear witness to the ways that Black bodies and Blackness are treated, ultimately less deserving of freedom, hope, and the promise of life. Sharpe writes about being Black as being synonymous with death and destruction and in this example of $\mathrm{C} 2 \mathrm{G}$, we see this lived out.

Sharpe declares that "education is the belly of the ship" (p. 92) and so, with the weight inherent in that statement, how might early childhood learning places recognize the hold? How might our teaching and learning with young people reckon with action, doing, and outcomes of antiblackness? Recognizing and being with the hold is no easy task. In fact, confronting this past, present, and future reality of the hold with/in ourselves is difficult and doing this work with the youngest learners is complicated. However, we are reminded,

We are positioned in the knowledge that we are living in the afterlives of slavery, sitting in the room with history, in a lived and undeclared state of emergency. The ground of compromise, the firmament, the access to freedom and democracy, littered with Black bodies. (Sharpe, 2016, p. 100)

Sharpe reminds us that we have a responsibility, and that the weight of living in the hold demands that we wrestle with "living in the afterlives of that brutality that is not in the past" (p. 99). 
Contemporary example of the hold. In the context of current day realities, it is difficult not to realize a comparison between the hold and the detention centers at the Southern Border of the United States. Recently, two young children, Jakelin Caal Maquin and Felipe Alonzo-Gomez, aged seven and eight respectively, died in the custody of the United States government (Sacchetti, 2018). These are children, living in the wake, in a world that demands their death and punishment, as a result of antiblackness. Sharpe (2016) writes,

The impossibility of Black childhood — as condemning one to a life of violence. We trace this history back to chattel slavery and the law of partus sequitur ventrem (again, "that which is brought forth follows the womb"), which dictated that the children of a slave woman inherited the mother's non/status. Black women and children continue to be cast as less-than-human victims and agents of “natural” disasters. (p. 79)

Although Jakelin and Felipe are not considered Black, antiblackness still influences their lives and how their being was and is considered worthy and important (or not). Jakelin and Felipe were seen as not only less than human, but underserving of being cared for and nurtured by family members and/or parents. Sharpe addresses childhood and mothering within the hold and asks, "Is it mothering if one knows that one's child might be killed at any time in the hold, in the wake by the state no matter who wields the gun?" (2016, p. 78). Sharpe's theorizing and questioning asks deep questions about childhood, freedom, and antiblackness. Who is childhood reserved for? Who gets to experience the carefree exploration we often associate with childhood? How do we continue to reside in the hold where antiblackness is intertwined in the lives of children? 
The hold and early childhood education. How might thinking through, and with, the hold open up new passageways and doorways of recognizing the way we are contained in antiblackness and anti-Black racism? In EC learning spaces, how does thinking with the theoretical concept of the hold move us towards considering with difficult and complicated ways that racism operates?

\section{The Weather}

In the last chapter of In the Wake: On Blackness and Being (2016) Christina Sharpe discusses the weather, the last theoretical concept which describes what she refers to as "wake work." Wake work, as Sharpe discusses, brings about possibilities for keeping hope adrift in weight of an existence heavy with antiblackness.

I've been thinking about what it takes, in the midst of the singularity, the virulent antiblackness everywhere and always remotivated, to keep breath in the Black body. What ruttier, internalized, is necessary now to do what I am calling wake work as aspiration, that is keeping breath in the Black body? (Sharpe, 2016, p. 109)

As centralized through her text, antiblackness is omnipresent, destructing lives and threatening harm. How does one survive, much less thrive, in this environment? The action and work of aspiration, keeping fresh, circulating air within the weather holds potential. Sharpe adds further, "Aspiration, here, doubles, trebles in the same way that with the additional of an exclamation point" (2016, p. 109). By continuing to breathe, bringing about fresh oxygenated air into our weather and climate, which is heavy with the toxicity of antiblackness, one might just work to make being Black and Blackness not only more survivable, but a place to flourish. In aspiration the exclamation point is added, 
altering atmospheric conditions. Sharpe writes about the weather as a place where that addition can take place.

However, this hopeful concept of the weather does not move towards an erasure of realities of living and residing in the wake, the ship, and the hold. The weather is just as much a part of those existence(s) and Sharpe reminds us that:

The weather is the totality of our environments; the weather is the total climate; and that climate is antiblack... while the air of freedom might linger around the ship around the ship, it does not reach into the hold, or attend to the bodies in the hold. (2016, p. 104)

Sharpe's example of the weather. Sharpe connects the weather to the use of excessive force by police upon Black people such as chokeholds or disproportionate gunfire as an example. The weather, the thick smog of antiblackness, is not only an ideology, but exists in physical and material conditions as an everyday reality. Sharpe writes about the murder of Michael Brown who was "in the posture of surrender" (p. 123) when he was shot at least six times by a police officer. Sharpe writes about the family of Michael Brown, who within their grieving, worked to provide aspiration into the weather during this tragedy of injustice.

Black annotation and Black redaction meet the Black anagrammatical and the failure of words and concepts to hold in and on Black flesh. Think, now, of the annotations and redactions of the second autopsies ordered by the families of the murdered and commissioned in the wake of so many murders. The second autopsy performed on Michael Brown was requested by his family and their legal team in order to show injury. In other words, the second autopsy was ordered to 
show the harm done to Michael Brown, who was shot at least six times, including two times in the head. (Sharpe, 2016, p. 123)

Michael Brown's family are unable to change what happened to him, unable to aspirate breath back into his body to keep him alive. Instead, Sharpe provides this example of how Michael Brown's family is changing the weather. In other words, the action of requesting and ordering a second autopsy to provide evidence of how Michael Brown was attempting to surrender to police when he was murdered can change our relationship to/with the outcomes of antiblackness. This is one example of actions taken by Michael Brown's family which remind us that, "In what I am calling the weather, antiblackness is as pervasive as climate" (Sharpe, 2016, p. 106). How might we foster different types of weather and atmospheric conditions where our awareness and interrogation of antiblackness can shift?

Contemporary example of the weather. In another example of how the theoretical concept of the weather might be considered within contemporary events, is from a 13-year-old student, Jada Williams. After reading The Narrative of the Life of Fredrick Douglass (Douglass, 1995), Jada, a Black teenager, wrote and submitted an essay for a contest. In the essay, she wrote about her experiences within the education system as similar to a modern-day version of slavery. When her local school discovered she had written an essay on this subject matter, her treatment by administrators and teachers took a cruel and vicious turn, where she was repeatedly told to leave classrooms, suspended, and received other inappropriate and unfounded disciplinary measures (Hibbard, 2012). Williams' essay is wake work; an attempt to breathe fresh breath into toxic systems of antiblackness. Jada Williams is naming her experience as young person 
being educated in our public-school systems, changing awareness and relationships to/with antiblackness. As Sharpe writes: "When the only certainty is the weather that produces a pervasive climate of antiblackness, what must we know in order to move through these environments in which the push is always towards Black death?" $(2016$, p. 106). The question of "what must we know" is so important. I would also add, how must we know.

The weather and early childhood education. In EC classroom spaces, and connected to this research study and Ms. Rotter's first grade classroom, how does the weather and the climate fostered within shift our relationships with/to antiblackness? How might we remain open and create spaces for aspiration and the addition of the exclamation point? How could EC educators consider ways to cultivate teaching and learning about race and racism that alters atmospheric conditions?

\section{Why Think With The Wake?}

The question of why this theory, what thinking with the wake might afford this research study is an appropriate question to ask. I discussed earlier, there are other racial theories which have a lot to offer research that has a foci on race and racism. There are so many valuable and important theories to think with, helping us to ask important questions about ways that we dis/connect with the world. However, the wake, as I thought with and describe with/in this research study, offers up particular ways of thinking about race and racism through a lens of antiblackness.

The wake, with a focus on antiblackness, moves one beyond black/white binary. The wake focuses on how antiblackness exists in different spaces, places, and through various forces. This variability brings together environment, materiality, and the flesh, 
recognizing more than just than discursive and written ways of thinking about racism. The theory of the wake recognizes that words and language are not enough and will fail to ever fully 'capture' the effects of the processes and outcomes of antiblackness.

Another offering of the wake is that it recognizes the fluidity of time, as the "the past is not past," and how we are continually affected by various events, histories, moments, often not within our lifetimes. The wake's recognition of these unceasing moments brings about a somber viewing and relationship to/with racism and antiblackness. At last, the wake is a theory that is malleable enough to work with a thinking with theory analytical approach (Jackson \& Mazzei, 2012, 2017) and should and must be thought with rather than applied and thought of.

\section{Ethical Considerations of Thinking with Antiblackness}

I want to bring attention to the tensions of thinking with the theory of the wake and my own identity as a white woman. As I discussed earlier, the theory of the wake sits with/in work done in Afro-pessimism and antiblackness. Both of these ways of thinking about Black people and Black lives are difficult, gloomy, and at times even bleak. I have thought often and continue to think about how a white woman thinking with these theories and ideas might contribute a deficit mindset of Black people. However, even as I think about that, I also think about the promises for a researcher who identifies as white to put antiblackness at the forefront of their work. Perhaps it has possibilities to provide new insights and thinking for education, and in this study, specifically early childhood education.

Still, Thompson (2003) advised that even critically engaged white scholars who have every intention of dismantling racism in thoughts and actions maintain structures of 
white supremacy and whiteness. It is because in doing this work, they seek to obtain laurels for their research and scholarship. This is a point of tension for me; how do I engage in critical work about the teaching and learning of race and racism while making sure I do not get lost in self-promotion? To this question, there are no easy answers. Staying engaged with scholarship and scholars that push me to be reflexive, self-critical, and thoughtful is important. Lee (1995) wrote about the possibilities of using race as a tool in the anti-racist struggle, adding "whether these tools harm or heal depends on what we do with them" (p. 447). The intention of the work is important. I keep all these thoughts and questions with me as critical companions in order to use these tools for healing.

\section{How Ms. Rotter's Students Conceptualized Race}

How I am conceptualizing, discussing, and thinking about race and racial identity may be different than how children, specifically the children in Ms. Rotter's first-grade classroom, talked about and conceptualized race. As I wrote about earlier, researchers have been invested in studying how children recognize race, or not, for quite a while. However, the words and descriptors for race used in these different research projects vary. For example, some research studies stick with color descriptors for race, often keeping it as a Black and white binary or dichotomy (Beneke \& Cheatham, 2017; Jordan \& Hernandez-Reif, 2009).

Along with other researchers who work with young children, I question typically used racial terms (i.e., Black and white) and what they might mean and do in their inquiries with children (Kuby, 2013). In my work with the students in Ms. Rotter's classroom, conflating race with skin color was often the way that racial terms were used 
and described. Students would talk about people being "white" or "brown" or "Black." Many of the students in Ms. Rotter's classroom shared that they believed that someone's race was the same as someone's skin color. I provide further analysis and discussion of one of these conversations in Chapter 5. Yet, in some class discussions, the students would question the racial terms being used as connected to skin color. Asking questions such as, "Well, who is white?" they questioned how could someone be white, when comparing everyday white classroom materials such as dry erase boards or sheets of paper. In this comparison, the children seemed puzzled as they could not recall anyone looking white in that way. Other times, during large or small group discussion the labels conflating skin color and race were not enough. For example, at one point, Stephanye, a student in Ms. Rotter's class, expressed concern that a student in the class had named her brown when she identified as Black. It seemed like in that moment, that Black was more than a color to Stephanye, the word Black and how she was conceptualizing it, held a particular sense about her identity.

Ms. Rotter and I struggled ourselves with which terms to use and attempted to follow the lead of the students in the class and/or terms used in the children's literature we were sharing at the time. Especially if the discussion emerged from or surrounded that literature. Ms. Rotter and I noticed and discussed that several of the white students in her class were the ones that struggled the most with their language and terms around race. Many of them used hedging language such as "well" or "I think" or "sometimes." Over time - reviewing transcripts, recordings, and field notes - I reconsidered these moments as students' ways of demonstrating their uncertainty and/or discomfort with talking about race. There was also a chance that they were unsure about using labels that conflated skin 
color and race. It's possible that as white people, this is the one of the only times they have been asked to talk and think critically about race and racism? As I discuss later in the dissertation, Amari and Alexa, two students in Ms. Rotter's class who identified as multiracial, shared with me that Ms. Rotter has been the only teacher they have had that talked with them about race and racism.

Therefore, throughout this dissertation study, race is conceptualized by different people in different ways and are not in complete alignment. The challenge of drawing clear alignment of the diverse ways race was conceptualized by different people throughout the dissertation research is a point of productive tension. This does align with tensions in the broader society about the different ways that people make sense of and conceptualize race.

\section{(In)Conclusion}

In this chapter I have described my conceptualization of race, bringing together diverse scholars and theories. The different bodies of scholarship that I have written about sometimes overlap and other times diverge. Although there is not clear alignment within different approaches to race, I find this friction productive. Tuck and Yang (2018) advise, "Rather than the goal of political unity with commonly shared objectives, an ethic of incommensurability acknowledges that we can collaborate for a time together even while anticipating that our pathways toward enacting liberation will diverge" (p. 2). I work to bring this scholarship "for a time" in order to think about antiblackness and the wake in early childhood classrooms.

I have outlined the four theoretical concepts of the wake (i.e., the wake, ship, hold, and weather), providing contemporary examples of how the overall theory of the 
wake is lived in present-day life. Within each theoretical concept, I also provide connections and questions for early childhood education, sometimes with questions oriented toward implications for the specific classroom and students within this research study. In the next chapter, I provide more context and details about the people and places within this research as well as the methodological choices and actions. 


\section{Chapter 4: Context, Methodology, and Relational Considerations}

In this chapter, I describe the context of the city, the school district, the school, and the classroom. I provide further details about Ms. Rotter, the teacher in this research study. Demographic details of the participating students (provided by families) are also included. Subsequently, I discuss the methodological approach within this research study, thinking with theory. The process of thinking with theory is described in detail to illuminate how it was engaged within this research study. Lastly, I provide a discussion on the ethical and relational considerations and deliberations.

\section{Research Setting and Participants}

\section{The City: Acacia}

The city where this research study takes place is a midsized Midwest university town, which I am referring to with the pseudonym, Acacia. The city of Acacia has several colleges and a university that bring in approximately 40,000 students total each academic year. Acacia has been steadily growing, with an estimated $11 \%$ growth in population since the 2010 census. The city has a primarily white population, with the latest census reports (2018) showing the demographics as: $75 \%$ white, $10 \%$ Black or African American, 6\% Asian, 5\% Mixed Race, 3\% Latinx, 0.3\% Native American, and $0.1 \%$ Native Hawaiian or Pacific Islander.

\section{The District: Acacia Public School District (APSD)}

The school district, Acacia Public School District (APSD; a pseudonym), which the elementary school in this study resides in, is the sole school district in Acacia. There are some private schools in Acacia as well. There are no charter schools, and there are a 
couple modified magnet elementary schools, but those serve as the only "choice" options within APSD and in the city of Acacia as a whole. There are approximately 20 elementary, six middle, and four high schools, as well a large early childhood center within APSD. More detailed demographic information for APSD can be found in Table 1 below.

Table 1

Demographics of Acacia Public School District During the 2018-2019 School Year Total Enrolled

Percentage

\begin{tabular}{llllllll}
\hline white & Black & $\begin{array}{l}\text { Hispanic } \\
\text { or Latino }\end{array}$ & Asian & Multiracial & $\begin{array}{l}\text { American } \\
\text { Indian or } \\
\text { Alaska } \\
\text { Native }\end{array}$ & $\begin{array}{l}\text { Islander } \\
\text { Ilac }\end{array}$ \\
\hline 18,654 & 59.1 & 20.4 & 6.7 & 5.3 & 8.0 & 0.3 & 0.2
\end{tabular}

Note. Retrieved from the APSD website in March 2019.

APSD maintains a focus on continuous improvement, recently laying out a five year plan which has three main goals: (a) all students graduate prepared for college and/or are 'life and career ready' which APSD is focusing on by increasing attendance, lowering and/or eliminating suspension rates, and improving students' performance on various assessments and other measures. Additionally they aim to achieve this goal through new curricular packages and programs, regular use of RTI (response to intervention) strategies, and adding additional assessment and measures of achievement; (b) a focus on teacher improvement which APSD is working on by implementing new standardized teacher evaluation tools and measures, regular trainings in equity, restorative practices, and AVID (advancement via individual determination) training, as 
well as meetings and forums where families with students enrolled in APSD and community stakeholders can provide feedback; and (c) A focus on the fiscal and logistical operations which APSD is working on through a focus on creating new buildings as needed and preserving existing structures, being 'fiscally responsible' by maintaining adequate funds in its reserves, and focus on 'safety and security' for all students. APSD and the city it resides in seem to have a generally positive relationship, which is evidenced in the way it is discussed by people in the community and how voting members of the city of Acacia have approved many local bond measures (at least ten) over the past 20 years. These bond measures detail the efforts to grow the number of school buildings, increase teacher salaries, and improve APSD as a whole.

However, more recently, APSD has experienced scrutiny from community groups and residents regarding unequal disciplinary data from the district. According to recent reports, Black and low-income students are more likely to receive disciplinary measures, such as suspension, than their peers. In response, as one of the components of the fiveyear plan, specifically the measure focused on teacher improvement, APSD is focused on creating a "culture of dignity." This plan is an attempt to respond to the disparate disciplinary data through: professional equity training for all educators across APSD, a focus on restorative justice practices, as well as eliminating out of school suspension as a disciplinary measure. Important to note is that the concern of disparate disciplinary data is not a unique to APSD, this is a troubling issue that is widespread across the United States. I focus on the area of racial inequality, specifically with Black students, that APSD continues to work on because it is what I wrote about within my request to do research within APSD. I emphasized that learning about and recognizing multiple 
perspectives aligns with a "culture of dignity" where we can learn from, with, and about different ways of existing, being, and knowing in the world.

\section{The Neighborhood and School}

The school, RB Elementary (a pseudonym) opened three years ago in August 2016. RB Elementary was named for renowned Black woman in the city. This Black woman worked for APSD for almost 60 years, founding the APSD's home school communication program. She was named an outstanding educator within APSD and was awarded a plaque affixed at the high school where she first worked about 10 years before RB Elementary opened.

RB Elementary is nestled within a newer part of Acacia, and within a neighborhood called Golden Creek (a pseudonym). The homes within Golden Creek are by far the largest in the city and the most expensive. While the median home price, according to the 2018 census, in all of Acacia is approximately $\$ 185,000$ the average home price is Golden Creek is higher, with the current lowest home prices around $\$ 250,000$. The boundaries that RB Elementary draws from are mostly upper class white students, as you can see in Table 2 below which displays the demographics of RB Elementary. However, RB Elementary also draws from a small pocket of Acacia that has apartments and townhomes and the residents typically have lower incomes. 
Table 2

Demographics of RB Elementary During the 2018-2019 School Year

Total

Percentage

Enrolled

\begin{tabular}{llllllll}
\hline white & Black & $\begin{array}{l}\text { Hispanic } \\
\text { or Latino }\end{array}$ & Asian & Multiracial & $\begin{array}{l}\text { American } \\
\text { Indian or } \\
\text { Alaska } \\
\text { Native }\end{array}$ & Islander \\
\hline 657 & 72.1 & 9.6 & 4.0 & 5.8 & 7.9 & 0.6 & 0.0
\end{tabular}

Note. Retrieved from the APSD website in March 2019.

When the school opened in 2016, the only Black people working at RB Elementary were paraprofessionals and custodial staff. Residents and community groups within Acacia expressed frustration that a school named for a Black educator did not have even one Black teacher. They expressed their concern at school board meetings and other gatherings with the superintendent of APSD. In January of 2017, the superintendent approached Ms. Rotter, the teacher within this study, who was currently teaching at a different elementary school in APSD, to ask if she would work at RB Elementary. Ms. Rotter said she was excited for the opportunity and agreed. Ms. Rotter told me recently, almost two years later, that she is still the only Black educator teaching at RB Elementary.

When I asked Ms. Rotter how she feels about persisting as the only Black teacher in RB Elementary she shared,

It's annoying... It always feels like I am the outcast. I feel like I am stared at and I feel like they [white educator colleagues and families] don't understand that how what they say can be offensive. Like what they say about certain kids or how I'm 
always told "you look the part" because my hair is a certain way and because of the way I may talk. But when I walk down the hall I feel like they question if I am the teacher. It always feels like I am the outcast.

Despite this frustration, Ms. Rotter shared with me how important she felt it is to be a Black teacher at RB Elementary. She noted that with a school with such a white population she feels that it is important for her to be there in order for the students and families to see and recognize Black people as educators.

\section{The Teacher}

Ms. Rotter is Black woman and a first-grade teacher. She began her career in education ten years ago in APSD. She was a homebound instructor and student-parent advocate for the first five years of her educational career. She then transitioned to a classroom teacher, where she taught for three years as a fourth grade teacher and has been a first grade teacher for the past two years. Ms. Rotter is currently pursuing a Doctorate in Educational Leadership and has shared that her eventual goal is to move into administration as an Assistant Principal or Principal of an elementary school.

I met Ms. Rotter in February 2017 while attending a "Making \#BlackLivesMatter in the Classroom" panel presentation at the University of Missouri where she was one of the expert panelists. While on the panel, Ms. Rotter shared steps she was taking in her classroom to draw on the importance of the \#BlackLivesMatter movement in her classroom, as well embed the contributions and work of Black persons within her teaching and instruction. Towards the end of the panel, Ms. Rotter shared some challenges she was experiencing at her current elementary school. She was experiencing trouble maintaining her commitment to making \#BlackLivesMatter. She discussed 
feeling resistance from families in her classroom regarding her teaching about topics of race and other social and cultural differences. She also expressed a lack of support from colleagues and administrators. I felt a connection when listening to Ms. Rotter talk on the panel, as it mirrored some of my own experiences as a classroom teacher. I was intrigued by what Ms. Rotter shared during the presentation as well as the question and answer session immediately following. At the conclusion, I approached Ms. Rotter to follow up regarding what she shared. I asked her if she would like to meet for lunch or dinner to talk further and she agreed. We met several times during the summer before the school year (2017-2018) and started to talk through how we might work together and what support she might be looking for in the classroom. We discussed how she was interested in bringing in diverse literature into the classroom and her desire to encourage students to write more deeply about race and cultural diversity. We also discussed our past experiences teaching about race, racism, and topics of racial diversity and the hurdles we both faced in the classroom.

When we met for dinner the first time, Ms. Rotter and I discussed her move to the first grade classroom. She shared her excitement with me at the opportunity to teach at RB Elementary. We discussed that her unique invitation to be at this school might provide her different affordances to incorporate teaching about equity and diversity than she had previously experienced. We also spent time discussing the resistance we had both faced, and continue to face, as educators who are committed to centering topics of race and racism in both past and present classrooms we were working in; connecting our professional/personal lives in positive and generative ways that I did not anticipate or expect. 
During the 2017-2018 school year, I spent at least one day each week in Ms. Rotter's classroom. During this time, Ms. Rotter and I got to know each other better and developed our relationship as colleagues, educators, and eventually friends. I had the opportunity to learn how topics of race and racism are taught and learned in Ms. Rotter's classroom. We asked each other questions, brainstormed curricular and pedagogical thoughts and plans, and developed an ongoing library of children's literature with narratives and stories with a particular focus on racial, ethnic, and gender diversity (see Appendix A for full reference list). During that year, Ms. Rotter and I read, talked, and engaged in intentional learning together. We read literature on multicultural teaching in the early childhood classroom together as well as several contemporary young adult books that also have race as the central theme or focus ${ }^{6}$. Reading and thinking together in this way has opened conversation between us about race and racism teaching in early childhood and elementary classrooms as well as ways that it exists in contemporary society. Additionally, Ms. Rotter and I met (and continue to do so) for meals or coffee and to talk through moments in her classroom and support each other as colleagues and educators.

After learning and developing a partnership with Ms. Rotter, I not only selected Ms. Rotter's classroom as the site for this study because of our work together as research collaborators and as now friends, but also because her approach to structuring and

6 We read The Hate U Give (2017) by Angie Thomas; All American Boys (2015) by Jason Reynolds; Dear Martin (2017) by Nic Stone, The Poet X (2018) by Elizabeth Acevedo as well as sections of Multicultural Teaching in the Early Childhood Classroom: Approaches, Strategies, and Tools Preschool-2nd grade (2013) by Mariana SoutoManning, In the Wake (2016) by Christina Sharpe, and Raising Race Questions (2015) by Ali Michael. 
conducting classroom instruction met criteria I created when selecting a setting for research. That criteria was as follows:

- Multicultural children's literature, where People of Color are central figures in order to provide openings for thinking, talking, and responding to themes of race and racism, are centered and valued in classroom;

- This literature is read to children each day and made available and visible to children throughout spaces in the classroom (see Figures 3 through 8 for sample photos of Ms. Rotter's classroom);

- The teaching of topics of racial and ethnic diversity is made a priority in the classroom; and

- The ideas, questions, and experiences of the students in the classroom are recognized as important and valued.

These were the pedagogical habits and practices that Ms. Rotter engaged in as I entered her classroom. As she and I worked, planned, and learned together, these habits and practices shifted and grew. It is difficult to pinpoint a starting place, as we collaborated and learned from each other over two years, and looking back upon it now, it seems that our work together was always already happening. However, a shift in these habits and practices occurred during classroom read alouds. Ms. Rotter shared that her read alouds extend for much longer stretches of time, as she recognizes the value in engaging multiple perspectives - providing time for students to question, share perspectives, and engage in deeper dialogue. It was not that she did not value these practices before, but through our work together, these practices became more comfortable and familiar. 
Photos of Ms. Rotter's Diverse Literature-Rich Classroom

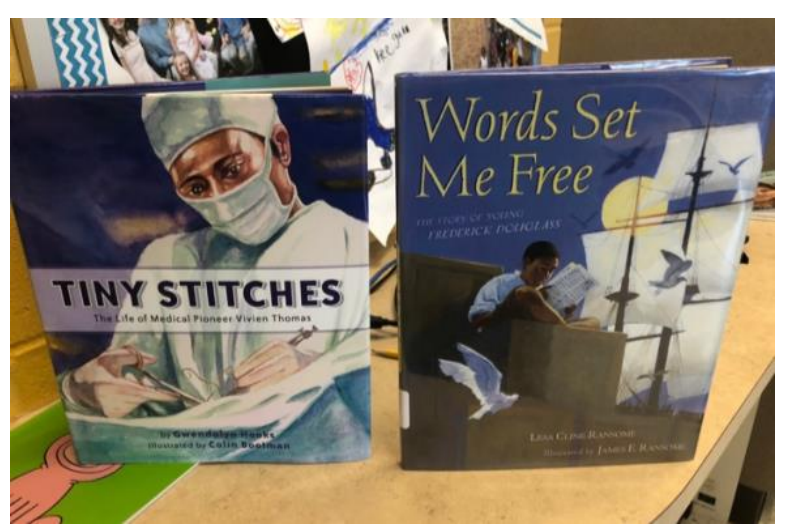

Figure 4. Literature in Ms. Rotter's class.

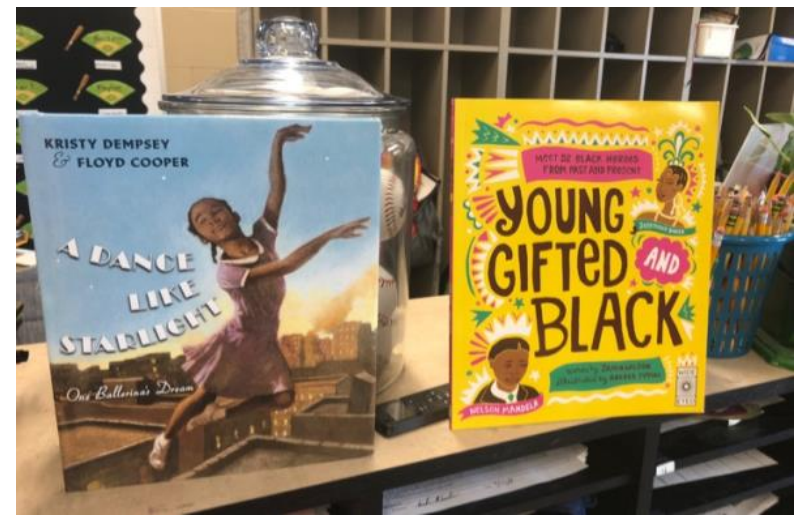

Figure 5. More literature in Ms. Rotter's class.

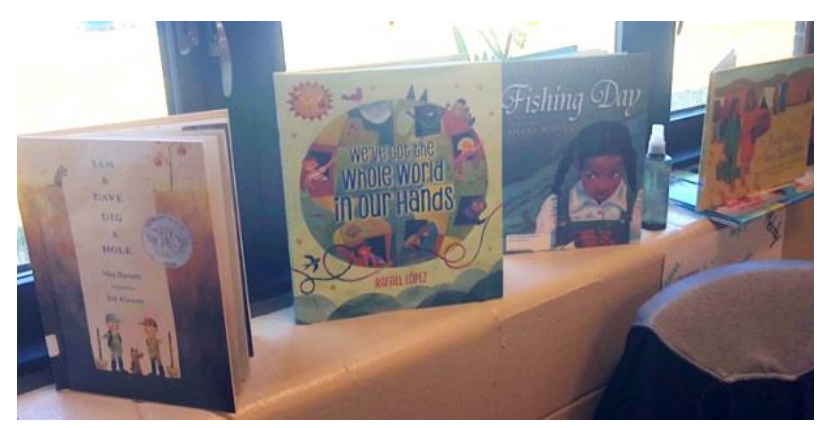

Figure 6. Literature display in Ms. Rotter's class. 


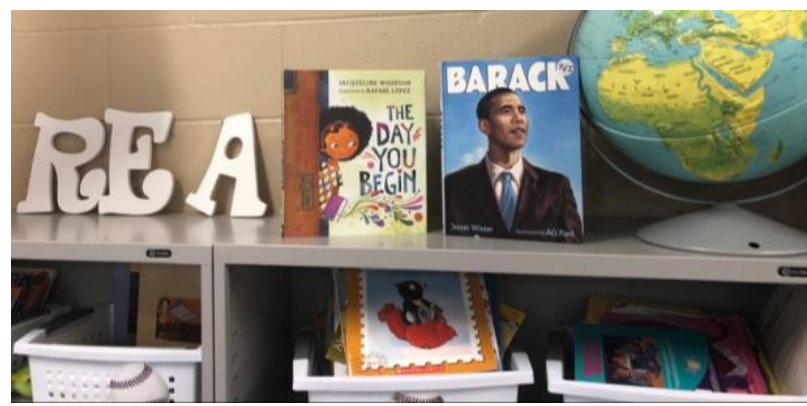

Figure 7. Literature area in Ms. Rotter's class.

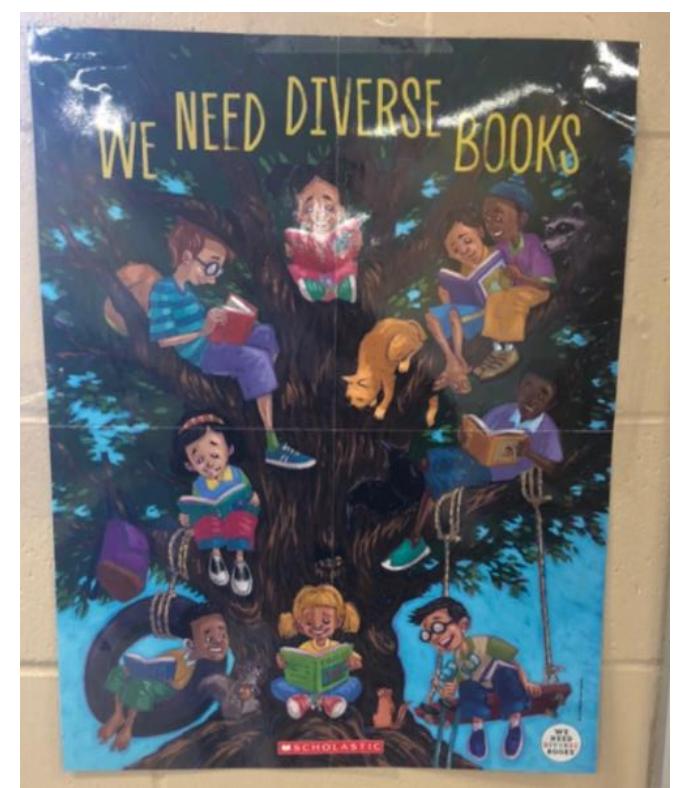

Figure 8. Diverse literature poster in Ms. Rotter's class.

\section{Recent Curricular Changes within APSD}

During the 2018-2019 school year, APSD has further implemented a phonics focused and highly scripted reading program for all elementary schools. This program was used previously in the district, but there seemed to be a bigger push towards implementation across all schools this academic year. With the implementation of this program, Ms. Rotter and I have noticed that there has been a shift in the control and organization of how time is used in her classroom. Part of this time shift is due to the required regular standardized assessments, regular professional development trainings, and a scripted curriculum that is required due to this reading and spelling focused 
program. This school year, we have noticed that many times when Ms. Rotter would plan a read aloud or other learning activity regarding this research, often an assessment would need to be completed or Ms. Rotter would need to attend a training for this new curricular program. Despite this new mandate I want to emphasize that Ms. Rotter values a balanced approached to teaching/learning reading and writing — which includes phonics instruction with exposure to and valuation of high quality literature. I provide this information to give further context, and to recognize the challenges many teachers, including Ms. Rotter, face each day. Generally, besides this new mandate and some other newer curriculum implementations (such as a district wide math program), Ms. Rotter is provided freedom at her school to teach in the way she wants and bringing in pedagogical materials and resources of her own choosing. Ms. Rotter's pedagogical autonomy has created an opportunity for us to collaborate on ways that she might think and teach about diverse ways of engaging students in topics of race and racism.

\section{Developing a Research(ing) Relationship}

Throughout our time knowing each other in addition to this research study, Ms. Rotter has welcomed me into her classroom on a regular basis to read with her students, engage the students in diverse reader response engagements, and participate in learning activities. I have been intentional in being open with her about questions, ideas, and wonderings I have. I also have strived to provide openings for her to share her questions, concerns, and ideas as well (see examples below). These deliberate choices are a part of my continuous ethical commitment to develop a relationship of trust with Ms. Rotter. It is imperative that she knows that she can share ideas as well as concerns with me at any time. She has the right to say no to anything I might propose; after all, this is her 
classroom. I entered into this relationship being intentional to ask Ms. Rotter about what support she was looking for in the classroom, and then using my resources, knowledges, and experiences to provide that support to foster a relationship in which we can work and learn together. She was not actively looking for a researcher to be in her classroom, instead, I was the one looking to work with a classroom teacher. So it is important to me to constantly check in with her regarding the work we are doing together and that it meets her needs as well as I my own. Some of the ways that I did this are as follows:

- After each visit to Ms. Rotter's classroom, when the students were at recess or lunch, we spent 10-20 minutes talking about how that day went, plans for the future, and asking questions;

- Every other month we scheduled a time to meet for a longer period (e.g., a dinner) to provide more time to talk, question, and engage in deeper conversation;

- We texted each other regularly sharing new things that happened, questions, funny stories and so on; and

- I made sure to check in with her regularly, asking if the work we were engaging in was helpful to her, supported her goals as an educator, and left openings (through questions, pauses, time) for her to pose alternatives.

Ms. Rotter and I often connect not just as educators working to weave in topics of race and racism in the classroom, but also as doctoral students working on such things as papers for courses, collaborative projects, and even the challenges of writing a dissertation proposal. I continuously work to check in with her to make sure the relationship we are developing is meeting her needs as a person, educator, and emerging 
scholar. These are just a few of the ways that I am working to maintain ongoing relationship of respect, trust, and open communication. I am open to new ways that we might connect in the future and share with her that I see this as a continuous and ongoing relationship.

\section{The Participating Students}

During this school year (2018-2019) Ms. Rotter had a total of 21 students in her first-grade classroom. Based on our prior relationship of researching, thinking, and working together from the prior year, Ms. Rotter and I had planned that she and I would formally ask the families of her classroom for consent to use the words, actions, and experiences of the students recorded through video, audio, still video, and field notes. The attached consent form (see Appendix B) was shared with the families by Ms. Rotter during fall parent/teacher conferences. Of the 21 students in her class, 18 of the families elected to provide consent for their child's words, thoughts, and work to be used in this research study. Although not all families elected to provide consent, all students were part of the ongoing teaching and learning in the classroom. The words, ideas, and work of students whose families did not provide consent were not included in this research study. In Table 3 below, the names (pseudonyms), as well as race, ethnicity, and primary language are included (families were provided an optional choice to identify these demographics if desired). 
Table 3

Demographics of Students in Ms. Rotter's Class During the 2018-2019 School Year

\begin{tabular}{|c|c|c|c|}
\hline Name (Pseudonym) & Race & Ethnicity & $\begin{array}{c}\text { Language Spoken } \\
\text { at Home }\end{array}$ \\
\hline Margaret & White & & \\
\hline Amari & Black & & English \\
\hline Jakob & White & Non-Ethnic & English \\
\hline Abelino & White & Latino & Portuguese \\
\hline Marshall & White & White & English \\
\hline Peter & Caucasian & & White \\
\hline \multirow[t]{2}{*}{ Alexa } & African American & & English \\
\hline & \& Caucasian & & \\
\hline \multirow[t]{2}{*}{ Mia } & Caucasian \& & Caucasian \& & English \\
\hline & Middle Eastern & Middle Eastern & \\
\hline Penny & Caucasian & Caucasian & English \\
\hline \multicolumn{4}{|l|}{ Kristoff } \\
\hline Wyatt & White American & White American & English \\
\hline Stephanye & Black & & \\
\hline \multicolumn{4}{|l|}{ Julian } \\
\hline \multicolumn{4}{|l|}{ Hudson } \\
\hline Colton & Caucasian & & English \\
\hline \multicolumn{4}{|l|}{ Julian } \\
\hline Charlotte (Charlie) & White & & \\
\hline Camila & & & \\
\hline
\end{tabular}

Note. Families were provided the option to identify their child's race, ethnicity, and/or primary language spoken at home. Some chose not to provide this information, while others chose to partially or fully disclose this information.

Ms. Rotter and I intentionally and thoughtfully discussed with the students the potential of recording audio, video, and taking still photographs of them or their work. We 
explained that we wanted to learn: from them, about their ideas, and about the best ways to be a teacher. Additionally, we made intentional choices together regarding recording at the start of the school year as well as throughout the year that we continued to change, refine, and shift over time. Some of those intentional choices are as follows:

- Introduced Oona as a teacher and shared the reason for her being in the classroom as curious in how students learn, what questions they have, and how she can help people become the best teachers possible;

- Asked permission from student before turning on any recording devices;

- Notified students that they could turn off or on recording devices as they wish;

- Asked permission before photographing any student work;

- Reminded students that their questions and concerns are important (for example: continuously letting students know they can ask questions, share ideas, talk through things) and can be shared;

- Advised students know that they can change their mind about any of these choices at any time; and

- Sometimes choosing not to record (video or audio or both) because it tended to seem invasive and imposing upon the students and the sharing of their ideas.

Here is excerpt of how we initially introduced the recording to the students:

Ms. Rotter: So, Ms. Oona has been coming here for a little while. Today she wants to talk to you about why she is here and has some questions to ask you all. You can also share with her your questions and ideas too.

Oona: Did I talk to you all about what I do when I am not here? (Several students say no) Oh, I didn't? So, when I am not here, one of the things I do is I teach 
people that want to be teachers. Teachers of people like you. Teachers of elementary students or preschool students. Part of the reason that I like to come here and talk to you all and listen to you is because it helps me learn how to be the best teacher possible. So, I'm wondering if it is okay with you all if when I come, I can use a device like this (I hold up the audio recorder) or a video camera? That way I can better remember what everyone talked about and listen and learn from you all. Would that be okay? (Pause to wait for responses) That would help me learn better and in a different way. You know, like when you all might watch a video, or listen to a book read to you? Kind of like that. (A couple of students share how they listen to audiobooks). So does that help you learn? (Students respond in the affirmative). Yeah, so that helps you learn. I can't always remember everything that was said and you all have so many interesting questions and ideas. Recording them will help me remember. So, is that okay with you all? (Pause to wait for responses) If it ever not okay with you all, just let me or Ms. Rotter know. You can always change your mind. That is okay. You can change your mind at any time. (Many students answer yes or okay or nod their heads). Each time we recorded, one or both of us asked students if it was okay to do so, letting them know they could stop or start the recorder or video camera as they wished. Many of them seemed to be intrigued by the recording devices. For example: touching them, asking the recordings to be played back to them, and asking about the buttons on the devices. In fact, there were a few whole-group or small conversations and dialogue that Ms. Rotter and I discovered were not on any recording devices because (we assume) a student turned them off. However, bringing devices into the classroom seemed to change 
the dialogue in some way, signifying to the children that what we were engaging in was somehow extra important or valuable. For example, a student named Margaret said to me as I came in the class, "Are you here to learn from us today?" to which I nodded in the affirmative and smiled. Margaret followed up with "Well, where is the thing you use to record us?"

Some might question the power dynamics of bringing recording devices in a classroom space with young children and, did students really feel as if they could turn off and on devices or refuse to be recorded? I acknowledge and appreciate this perspective and so, in an effort to consider student's rights in full participation in the research project, we always asked if recording was okay and reminded them that they could turn them off at any time. In addition, within Ms. Rotter's classroom, there is a freedom present with/in the students that I was surprised about. I found this freedom to be different from many classroom spaces I have been in and observed. For example, during a read aloud, students were allowed to get up, move around, and leave to sit at a table if desired. There were many times when Ms. Rotter would be reading and a student might get up, walk over to the classroom sink and wash their hands or a student might get up to take a break from the carpet and choose to sit at a table instead. As long as students are not actively attempting to disrupt others or the class as a whole, there was quite a bit of autonomy present for students to move about the classroom as they wished.

Asking for permission each time a new recording was made and involving the students in the ability to turn off and on the recordings was part of a commitment within this research study to engage the students in ongoing and continuous consent. Woodhead and Faulkner (2008) write of the process of research(ing) and obtaining consent with 
children as residing in a state of permanent flux. This is an agreement with other scholars (Albon \& Rosen, 2014; Cocks, 2006; Dockett \& Perry, 2007) who have written about the problematic nature of obtaining consent or assent from and/or with children because it can often be unclear if children recognize what they are consenting or assenting to. I also felt this tension in my work with the students in Ms. Rotter's classroom. Even with all of the steps taken by Ms. Rotter and I to make sure to obtain continuous consent. I acknowledge that this an area where an ethical and responsible path is unclear. This is part of the intentionality Ms. Rotter and were committed to, to make careful and deliberate choices to engage in ongoing conversations about consent and assent with the children (whose parents/guardians have provided consent).

One such effort is paying close attention to the way that the recording devices (video camera and audio recorder) change the classroom space. As I wrote earlier, I did notice that bringing these devices in and talking to the children about them and their purpose seem to let them know that the work they were doing (i.e., talking, reading, writing, thinking) was important enough to be recorded. The students would ask the recordings to be played back to them or talk about what they said. It did seem that the act of recording classroom conversations sent a message that their words and actions were of great importance and valuable. However, sometimes I felt as if the recording devices seemed to send a different message or act in the classroom in different ways. For example, when the video camera was used, beeps would sound when it turned off and on. Students would often turn and look at the camera when it would beep and as it was running, many of them would move closer to it and look at the screen and watch what it was recording. I worried that this recording device was disturbing the learning of the 
students and could possibly be making them feel uncomfortable in some way. After using the video recorder several times, I shared this concern with the students: that it was loud, it was bothersome, and was disturbing their learning. They all seem surprised and shocked about what I was sharing with them. Most of them mentioned that they didn't hear any beeps or noises and the video camera didn't bother them. I did let them know that I might not turn it on as a much in the future and reminded them that they could turn it off at any time. Interestingly, after this class discussion, some of the video recordings were cut short because students did in fact turn off the camera on a few different occasions.

I was introduced to the children (by myself and Ms. Rotter) as a prior classroom teacher, a teacher of people who want to be teachers, and as person who is interested in how students learn. I was able to build a unique relationship with the students in Ms. Rotter's class because my primary interest was a curiosity about them and their ideas. This is different than Ms. Rotter, who of course has district, school, parental, and other pressures and expectations continuously influencing her relationships with her students. Similarly, Albon and Rosen (2014) have written about building relationships in early childhood research and specifically note researchers working with young children have a unique relationship:

We want to highlight the seeming luxury of being able to respond to a child in this way [as researchers]. Often, observations of children by early childhood educators is conducted at a distance when the educator is simultaneously observing, undertaking some activity with the children, and maintaining a watchful eye over a group of children engaged elsewhere. As researchers, we had 
no such responsibility and this afforded greater opportunities for being 'in the moment' with children. (p. 56)

The ability to be "in the moment with children" influences the relationship I have cultivated with them. Researchers who embrace this in-between-ness (not teacher, yet not a distant observer), are able to build relationships with children that are based in similar interest and wonder. Some examples of how being "in the moment" in this research study unfolded were: informal conversations, observations, engaging in whole class and small group read alouds, and asking students questions about their work, ideas, and experiences. As a researcher, a commitment to be "in the moment" encouraged and supported my openness to the diverse ways that students engaged in learning about race and racism in their classroom. The opportunity to be "in the moment" with the students in Ms. Rotter's class influenced the relationships I built with the students in this study and the various conversations I engaged in with them.

\section{Data Coproduction ${ }^{7}$}

I have been working with Ms. Rotter, thinking and researching in her classroom throughout the 2018-2019 school year. For this study, I focus on data produced from December 2018 through March 2019. The data coproduced in this study includes: video recordings, audio recordings, researcher journal field notes, teacher journal notes, and photographs of student made artifacts. As a result of knowing Ms. Rotter for over two years, as well as observing and participating in her classroom since August 2017, my

\footnotetext{
7 I use the term data "production" or "coproduction" rather than "collection" as a way to signify how my being as a researcher and teacher in the classroom stimulated and produced new thinking and conversations. I borrow the term coproduced from Tallbear (2013) meaning that data is not thought of as able to be extracted or lifted from a location. Instead, data is coproduced by places, people, and things.
} 
knowledge, experiences, and memories all perform as data within this study to build analysis. Additionally, Ms. Rotter and I held many informal meetings to debrief and discuss what was happening in the classroom. Those also fold into the analysis and analytical questions throughout the dissertation.

\section{Methodology}

\section{Theory/ies/izing with/in the Dissertation Process}

Theory has the potential to transform and to heal (hooks, 1994). And, according to Spivak (2014), once we read and experience theory, it becomes a part of our mental furniture. In other words, theory alters how and what we see, our experiences, interpretations, and lives. Once we learn theory, we cannot just 'rid' ourselves of it, but instead it helps us to make sense of our knowing and being in the world.

Therefore, theory is present throughout the dissertation, and not just relegated to a specific chapter or section. As Kuntz (2015) writes, "theoretical questioning dwells in knowledges from below — materially situated and politically engaged—refusing, in this case, the separation of sound from bodies, voice from material circumstance" (p. 57). Theoretical writing, specifically writing on the processes of antiblackness and how it operates in contemporary life is both "materially situated and politically engaged" and is valuable for interrogating how the teaching and learning about race and racism unfolds with/in the classroom. As a result, the methodological process I have engaged in for analysis is thinking with theory (Jackson \& Mazzei, 2012, 2017). Thinking with theory, which I describe in further detail below, is a process methodology that brings data and theory together in the threshold in order to ask new questions and think differently.

\section{Thinking with Theory}


I engaged a thinking with theory approach (Jackson \& Mazzei, 2012; 2017) in this research study. In this analytical approach, Jackson and Mazzei write of "plugging in" where theory and data are plugged into each other, not to seek answers necessarily, instead to more carefully think about processes, actions, and doing(s). In other words, to ask, how do things work? Jackson and Mazzei write that the process of plugging in thinking with theory is threefold. The first is "disrupting the theory/practice binary by decentering each and instead showing how they constitute or make another" (Jackson \& Mazzei, 2012, p. 5, emphasis in original). When thinking with theory, it is not that you first 'collect' data and then read theory with the intention of analyzing. These things are happening all at the same time. Reading theory, producing data, thinking, asking theoretical questions of your data, and so on.

Next is the production of analytical questions that are formed during thinking with theoretical concepts. Theoretical concepts, which Lenz Taguchi and St. Pierre (2017) write as capable of "acts of thought are practices that reorient thinking, undo the theory/practice binary, and open inquiry to new possibilities" (p. 643). Theoretical concepts have the capacity to shift thought and promote new ways of thinking and seeing (Lenz Taguchi \& St. Pierre, 2017). When thinking with theory, the end goal is not to have answers to your research questions, but instead to name, describe, and think with specific theoretical concepts in order to produce new questions that encourage new thinking and wondering. Analytical questions are part of the process in thinking with theory. Analytical questions "flow from concepts" (Jackson \& Mazzei, 2017, p. 732) when thinking about data and theory together and ask, how does this concept work? This works differently than research questions because they occur in the middle of the researching 
process, not planned ahead of time as something to look for, discover, and find. Analytical questions keep the thinking, writing, and doing of researching moving - not linearly - but in a way that opens up different ways of knowing and thinking and encourages one to stay alert to the new. In this research study, analytical questions are written in-between and throughout the analysis in italics, to demonstrate the in-progress thinking and process oriented approach I engaged in. I employ these analytical questions to supply contributions and resist providing answers (as I discussed earlier).

Last, when working with data, quantity is not important because in thinking with theory, data are always already everywhere, multiple, and in-excess. St. Pierre (2017) discussed that often, researchers engaging with this approach will sometimes even focus on one piece of data, a moment, an action, or a conversation that might tug at ideas or continue to stick with them for years. It is the thinking, the new and different questions and ideas that continue to emerge that is the focus, rather than an amount or size of data. Additionally, in a thinking with theory analytical approach — theory, theoretical concepts, and theoretical writing can also be thought of as data. As Rubin (2018) stated, The thinking with theory analytic requires an understanding of both data and theory as texts, flattening the hierarchical relationship imposed by traditional qualitative constructions. Jackson and Mazzei $(2012,2013)$ use the term "plugging-in" to represent the process of reading theory and data, which they describe as being mutually constitutive and ultimately inseparable from each other and from methods of inquiry. In other words, the texts and theory analyzed in this article are, essentially, data. (p. 331) 
When we flatten the relationship between and among texts, theory, and transcripts we expand and deconstruct our notions of data. We are living, breathing, and creating data all of the time. Additionally, because thinking with theory is not a methodology solely focused on meaning and interpretation, one does not require a certain amount of data to confirm or validate an idea or concept. While not focused on interpreting, Jackson and Mazzei (2012) write that thinking with theory "is both within and against interpretivism" (p. vii, emphasis in original). So, it is a process opposed to interpretation and meaning making, but yet recognizes that completely letting go of these things is a challenge.

Researchers who are thinking with theory/ies may choose to spend a large amount of time with one particular data piece, bringing data and theory tog ether to "produce knowledge differently" (Jackson \& Mazzei, 2012, p. 7). Thinking is not just epistemological, it is ontological. Jackson and Mazzei (2017) share,

The work of thinking with theory is done as a process methodology, one that gives up the static properties of linear method and even cyclical, iterative stages and procedures of conventional qualitative data collection and analysis, in favor of dynamic becomings and generative differentiations. That is, a thinking with theory process methodology is entirely ontological. (p. 719)

Thinking with theory is not just a way of knowing, it is a way of living and being. There is not a right or wrong way to live/do/be. Instead, the focus is experiencing, becoming, and working through. That is why it cannot be measured as the right amount or just enough. It is intertwined with our existing in the world, knowing when something, someone, or an idea is "enough" is a continuous struggle. This is not a right/wrong, this/that logic, instead it is both/and. 
An integral part of thinking with theory, for me, is the with part. It refuses theory as a step or layer applied to bare or 'raw' data. Instead, thinking with theory treats theory as vibrant, alive, and "necessary to shake us out of the complacency of seeing/hearing/feeling/thinking as we always have, or might have, or will have" (Jackson \& Mazzei, 2017, p. 720). For example, in this research study this has looked like physically bringing theory and data together. Such as transcribing and then reading theory, listening to data recordings and then going back to re-read theory, reading theory and producing questions and notes, then bringing in data theory notes and questions. This is a move towards what Jackson and Mazzei write of asking what a particular theory or theorist might ask of the research or data. Some may critique this type of inquiry, wondering how research that pursues questions rather than answers might be helpful in research that explores a serious topic of young children's learning of race and racism. I believe that it is precisely our most crucial and serious topics that need more thinking and questioning. Racism is embedded within the U.S. as well as the world and hypotheses about solutions are not in short supply. Thinking with theory, then, pushes us "to open up previously unthought approaches to thinking about what is happening in our research sites and encounters" (Jackson \& Mazzei, 2017, p. 720, emphasis in original).

Although I name "thinking with theory" as a methodology in this research study, I want to emphasize that this analytical approach to research(ing) is not procedural, with a particular series of steps that occur within the process. Instead, I have experienced limitless possibilities and directions in thinking with theory approach to analysis. Some might wonder: How does it (the process of thinking with theory) work? Can it be replicated? Is it trustworthy and/or reliable? Because thinking with theory does not 
pursue meaning and interpretations, these are questions that are ineffective and unable to be answered. Instead, thinking with theory asks "what counts as knowledge, what counts as 'real' in educational settings, and who has the authority to determine this" (Jackson \& Mazzei, 2017, p. 720). Choosing to think with theory opens up new possibilities and approaches in analysis. As Jackson and Mazzei (2012) wrote,

We are doing and using the vocabulary and concepts as we push research and data and theory to its exhaustion in order to produce knowledge differently; in this way, we focus on the constitutive and generative aspects of texts. By refusing a closed system for fixed meaning... we engage the threshold as a site of transformation. (p. 7, emphasis in original)

With/in the threshold, which is an integral part of thinking with theory, data and theory are brought together for new questions, thinking, and insights. Thinking with theory is a process methodology with an ever-changing and open stance. As I described earlier, data, theory, questions, and thinking are brought together in the threshold to produce new ways of thinking about research problems which produces analytical questions that cause us to think and know differently. As Jackson and Mazzei (2017) guide,

Thinking with theory acknowledges that we alone are not the authors of the research assemblages we create; all other texts and agents (both human and more than human) insert themselves into the process - they emerge, bubble up, capture us, and take us into lines of flight. (p. 729)

Engaging in a thinking with theory process has been challenging as a researcher. I constantly asked myself questions such as: Are these the 'right' questions I am asking? Am I honing in on the essence of this theory or these theoretical concepts? Are these 
emerging questions actually new and different or am I just replicating what has been done before? Have I done enough—when do I stop asking questions, or do I ever stop asking questions? The challenging and taxing process of thinking with theory pushes me, as a person and a researcher, to deeply consider the questions I am asking and what they do. These are ethical questions and dilemmas that sustain me in the difficult work of being a researcher.

\section{Methodological Considerations When Thinking, Working, and Researching with}

\section{Ms. Rotter}

As much as possible, in this research study, I desired to research with Ms. Rotter, rather than on her and her pedagogical practices (Cole \& Knowles, 2000; Reason \& Bradbury, 2006; Orr, 1997). Michael (2015) has also written about her desire to work with teachers, making assumptions that "teachers are experts in their own classrooms" and "by following areas of interest in their own practice, they are likely to develop their practice in positive ways" (p. 8). I consistently viewed Ms. Rotter as an expert of her classroom, and considered myself as a support and resource as we explored and thought together.

We read some of Michael's (2015) book together and both agreed that our work together resonated with how Michael described her work with teachers who were engaging in explorations of race in their classrooms. Michael (2015) described the process in this way:

Inquiry, a process of constant engagement with a question, is the commitment to sit with a difficult query and keep asking it over time. It is a rigorous systematic 
process of research, experimentation, and community building around a challenging dilemma. (p. 2, emphasis in original)

Our project of inquiry led to lots of exciting proposals and plans as we researched together; some of these we were able to do, a few did not always work out, while others are unfinished and we plan to continue to work on them in the future. We outlined goals to read and plan together. In our meetings we would discuss what was happening in her classroom and plan for different learning engagements (e.g., read alouds, writing prompts, activities) to support what we believed would be useful, interesting, and engaging for the students in her class. We read some theory and reviewed some student artifacts and recordings together. In transparency, we often planned to do more but unexpected events of life got in the way (for example, her children became ill or one of us got sick). Even when we could not meet in person, we would continue to check-in and collaborate via text, e-mail, or other communication.

We have begun to outline plans for the future and continue to check-in with each other about what we have learned as well as what we are still thinking and wondering about; such as what modes and methods we might engage with to share our learning with others. I take steps as I discussed earlier to make sure our research, this inquiry we engage in, is still valuable to Ms. Rotter and assists her in reaching goals she may have or develop, personal or professional. As I discuss below, I provided Ms. Rotter with access to various drafts throughout different stages of the dissertation study including the full draft to obtain her feedback and consent.

Ethics and Positionality: In Other Words, "Why This? Why Me? Why Now?" (Patel, 2016) 
Patel (2016), writing about research as relational asks, "What would it mean, then, for educational research to be more explicit about how it is situated within, affecting, and affected by other material conditions and ideologies?" (p. 66). In other words, how might educational research be different if we took responsibility as researchers for our roles in shaping, creating, and producing it? In this research study, I constantly strived to consider this question, or dilemma, throughout all points of the research. However, even though I endeavored to take responsibility, I believe there was and is no clear way for me to claim or possess a clear answer to this question. This is because our understandings, relationships, and knowledge is shifting all the time and is never fully under our control, and therefore we must continue to stay on the move during our research(ing) process. The movement enables a focus on relationships and relationalities but also resists clear and succinct answers to questions. This, to me, is a move towards becoming ethical.

In connection with this question of ethics I included above, Patel (2016) urges one who takes on research to consider,

While we have a responsibility to understand, contribute to, and be fluent in existing research, we are also responsible for our ontological entry-points and impacts as researchers. Because all research is conducted by living beings, with specific histories, we are beholden to consider and answer, perhaps always incompletely, the three core questions of "Why me?", "Why this?", "Why now?" (p. 57)

As researchers, we often desire to know, explain, or investigate. However, do we consider what our doing with/in these desires does? Considering my own "ontological 
entry-points and impacts" in this research project, I discuss these questions in the section below.

\section{Why me? Why this?}

Toni Morrison, interviewed in 1993, was asked about her experiences with racism and stated,

Don't you understand, that the people who do this thing, who practice this racism, are bereft. There is something distorted about the psyche. It is a huge waste and a disruption and a distortion. It is like it is a profound neurosis that nobody examines for what it is. It feels crazy, it is crazy. It has just as much deleterious effect on white people, and possible equal, as it does on Black people... If the racist white person, I don't mean the person who is examining his consciousness and so on, doesn't understand that he or she is also a race, it is all so constructed, it is all so made, and it also has serviceability. But when you take it away, like take your race away — and then you're all strung out. All that's left is your little self, and what is that? Who are you without racism? Are you any good? Are you still strong? Are you still smart? Do you still like yourself? These are the questions. Part of it is, yes, the victim. How terrible this feels for Black people. I'm not a victim. I refuse to be one... If you can only be tall because somebody is on their knees, then you have a serious problem. And my feeling is white people have a very, very serious problem, and they should start thinking about what they are going to do about it. Take me out of it.

As a white woman, studying the teaching and learning of race and racism, Toni Morrison's words about what white people need to do are important. White people indeed 
have a very serious problem, and as a white person, I am working to see what I can do about it. Morrison encourages one to see racism as not only largely dysfunctional but also harmful to all people. Often we might consider racism as only negatively effecting people in marginalized communities, but Morrison points out, racism is "a profound neurosis" and it harms everyone. I have come to recognize that studying topics of race and racism, for me, cannot be just a concern to alleviate the oppression of People of Color. A focus like this contributes to a savior mentality for white person and it is important to recognize how racism harms the identities of white people. This is not an attempt to re-center white people and whiteness, but instead to recognize that work of dismantling racism needs to involve all people. Having an identity that is based and normed on being superior to others is harmful and toxic. If I aim to work towards justice (and I do), I recognize that all people need to be involved in working towards making our society a more just place. It is not that a white person works against the oppression of People of Color. I recognize that we are all intertwined in this circle of oppression and we must all work towards liberation (Freire, 1970). As an example, on the consent form for this research study, families were given the option to name and provide the race and ethnicity of their child. One of the families of a student marked their child's race as "white" and marked their ethnicity as "non-ethnic." I question how someone can be non-ethnic? Thinking back to Morrison, what happens if someone were to take this race, this marker away? Who are you? Who are you without race? Without racism?

For me, then, engaging with this topic, this work, is a life-long journey. As a classroom teacher, I felt that helping students build social and emotional competence was part of my role as a teacher. However, I was confronted by developmentalist writings 
which insisted on young children as 'egocentric' but I saw and experienced them differently. Part of empathy is being able to see, recognize, and value similarities across differences. However, if we are stuck in patterns of white supremacy and white superiority, how can we build those connections and empathy? The first way I began to do this is within myself. Reading, talking, thinking, acting, and more. I strove and still strive to be a person committed to equity in all forms. A part of this journey has been through my teaching with young children. In my classroom, engaging students in holistic conversations across difference was something we continuously worked on together. Through various experiences, I found myself interested and invested in this thing called 'research' and began a doctorate program.

When I began the Ph.D. journey, I found making the transition from practitioner to researcher challenging. First, being an academic spaces is quite different than classroom spaces - there is so much quiet! However, I remember thinking to myself, "so I am sitting here writing and reading about children? But where are the children?" It felt off, like something was out of place. I thought that being in a classroom, doing research and work with actual children might alleviate this feeling. So, during my second semester, I approached the administrator of early childhood programs within a local school district, letting them know the topic I was interested in. I let the administrator know that I would love to be in a classroom for the next semester, working with students and doing research. The administrator picked a preschool classroom, introduced me to the teachers and told me I could visit as much as I wanted. I was excited for the opportunity and arranged with the teachers to come twice a week that semester. However, during the semester of work in the classroom and research with the students I once again had the 
feeling of something being out of place. What did the teachers think about what I was doing? Did they agree, disagree? Where was their 'voice' or say in this research(ing) process? During this time I was taking a Qualitative Methods course where I had to the opportunity to think, read, and write more deeply about paradigms, methodologies, theory, ethics, and relationality.

I had a realization, that with/in the lines of inquiry that I am engaged with (the teaching and learning of race and racism in the early childhood classroom), I am researching in a classroom space and this classroom would not be my own. This was a new experience for me as I realized that even though I might not have labeled myself as a "researcher" when I was a classroom teacher, what I was doing was, in fact, research. The research I was going to be doing from now on, however, would be taking place in someone else's classroom. Therefore, how I entered ("ontological entry-points," as Patel names them) research spaces and worked to foster, nurture, and maintain research(ing) relationships was and is of great importance.

In this research study, there were several steps I took to be thoughtful about my ontological entry-points. Here are some of them:

- Regularly meeting with Ms. Rotter, both formally and informally to debrief about the research;

- Providing Ms. Rotter regular access to all research/dissertation writing and data recordings, making sure to check-in and get feedback if she would like to provide any;

- Regularly checking in with the students in Ms. Rotter's classroom, about recording classroom conversations, field notes, and obtaining feedback; 
- Sending monthly emails to the families of participating students about the ongoing research; and

- Engaging in writing as a method of inquiry (Richardson \& St. Pierre, 2005) to process and write through my own questions, ethical dilemmas, curiosities, and ideas.

\section{Why Now?}

When Patel wrote the question "why now?" and added "why here?" it was to consider place in research (Tuck \& McKenzie, 2015) and to reject universal truths about people, places, and material conditions. Although, as I wrote earlier, the teaching and learning of race and racism in early childhood classrooms is something I have been interested and engaged with for a long time, it is not something that can be universally understood or investigated. That is because context and place matters. For example, if this research is occurring within a school context, what the history in regards to racism where the school is located? Additionally, does the administration support this kind of work and how is it regarded overall within the school building? Since this research is taking place amongst people, what are the relationships being formed and how does that connect back to the material and contextual history of the space and the land?

In this research study, my consideration of the "why now" is important as I never want my desire to know, to understand, or to learn to cause harm to people and places where I study. I have taken multiple steps to consider a wide range of perspectives and consider consent, assent, and investment in this research(ing) process. Having the investment of Ms. Rotter and her engagement in this process is essential. Throughout my engagement in this research study I have constantly thought of the goals of the district, 
history and context of the school, families and students investment, and more.

Additionally, my role in co-producing this research is important as well. The time is always important for justice oriented research, but it is important to consider context as well.

\section{Ethical Deliberations}

When thinking about ethics, I think about theory. What is the theory you are thinking with and how does it inform one's research(ing) relationships? Thinking with the wake has provoked me to consider the ways that antiblackness exists, but also the way that it is obscured, hidden, and under erasure through conventional methods and practices of research. Sharpe (2016) writes that in the wake, "We must become undisciplined. The work we do requires new modes and methods of research and teaching” (p. 13). Becoming undisciplined seems like an almost impossible task. However, adhering to the way things have always been done is almost guaranteed to produce what we already have and already know. Instead, how can make the path ahead more difficult, less clear, and complex?

Childers (2012) in arguing against methodological simplicity states, "I argue that methods without theory are not only reductive and simplistic, but in some ways unethical" (p. 752). Research is complicated and messy. We make choices constantly, some quickly and some agonizingly slow. These are ethical choices which change and shift lives in myriad ways — some known, some surprising, while others might be ways that we do not quite recognize. Childers (2012) adds further,

I am interested in owning up to the (im)possibility of ethics and the uncomfortable admission that the safety net of IRB approval, informed consent, 
confidentiality, and some higher-order morality that sits in the shadows of whatever is meant by ethical practice are mostly seductive assurances and policing mechanisms that mask the unpredictability of research. Ethics includes quick, rash, split-second decisions that are difficult, potentially violent, possibly dangerous, and maybe even blatantly wrong. (p. 760)

Here, Childers reminds us that there is no easy or clear path towards ethics or being ethical. There are no set of steps, checklist, or form to sign off on that can clear us from making mistakes or possibly harming others. Instead, what if we worked to embrace the messiness of research and see this mess as valuable? Could bringing out the mess of research contribute to more ethical practices, relationships, and ways of knowing, doing, and being? Hancock and Fontanella-Nothom (under review) write about mess(es) as valuable in our research(ing) processes. They argue that the untidy and inconsistent nature of mess(es) is a part of their research becomings as scholars and should be included, not trimmed down to appear coherent and tidy. As a result, should we just give up on the idea of ethics? Is it no longer useful? Childers (2012) disagrees and writes, I am not completely ready to give up on ethics. Rather than being against ethics, I prefer to situate it as a quasi-concept, and view it more as an aporetic suspension, an uncompletable task, or an obligation that will never be satisfied. A refusal of classic ethics is a doubled move against methodological simplicity, which gestures toward a deconstructed ethics and a democracy to come. In its refusal it demonstrates the possibilities of situating theory as quasi ethical practice-it keeps us moving, forever on the hook, and responsible for attending to complexities of knowledge production—and this can be a political act. It was 
important that it mattered to them, was important to them, and something that they were interested in. To me, this is a consideration of ethics. (p. 760)

Viewing ethics as an "obligation that will never be satisfied" creates the movement, the becoming, the learning $\leftarrow \rightarrow$ unlearning process I have engaged with in this research study.

\section{(In)Conclusion}

In this chapter I have written about the research study context and relationships. I have included steps I took in order to consider and be inclusive of the perspectives, ideas, questions, and contributions of the people and environments in the study. However, I struggle with writing about the people and relationships I have formed and continue to cultivate within and through this dissertation. As I wrote in my research(ing) journal,

The more I write up the dissertation, it feels like a loss. The loss of thoughts that cannot be written, the loss of relationships that seem impossible to describe, and the loss of ways to demonstrate that I do not know or I am not sure. Many times I feel unsure and full of doubt about this thing, this dissertation. Does doubt have place in a dissertation?

It is impossible for me to ever be able to fully describe the people, places, and relationships within this dissertation. That is because people and places have more complexity than can be written and described. I endeavor to keep this in mind, but also challenge myself to continue even when I feel unsure. I also described the methodology and analytical process undertaken within this research study. I included ethical considerations and deliberations I have wrestled with and will continue to consider after the dissertation is approved. 
In the next chapter, I use italicized font to bring attention to the in-process analytical questions emerging from thinking with theory. As I wrote in the previous chapter, this is an intentional move where many of these questions are left hanging with the reader without answers. I understand that these maneuvers are uncomfortable, unconventional, and disrupts many of the expectations for academic writing. I drew inspiration from Thompson (2003) who interrogated race focused research done by white people and how it might lead to them feeling complacent because of the aims of their research. Thompson (2003) notes, "In the struggle to keep whiteness off-center in this essay, I violate several scholarly practices...I have specifically avoided offering implications for practice. I have also troubled scholarly preference for linearity and foundationalism” (p. 8). By choosing writing in this fragmented way, I work to bring about a sense of discomfort through the use of italics as well as providing questions without answers. Thinking about antiblackness in early childhood should be uncomfortable and the questions involved do not have clear or simple answers. 


\section{Chapter 5: Thinking With/in Moments From Ms. Rotter's Classroom}

As discussed previously, in my analysis, I bridge theory with transcripts, theory with imagery, and theory with journal and field note writing. I am intentional in thinking with theory as and/with data, made visible throughout my analytical writing in this chapter. To keep pace, I have organized through the use of headings, the analyses of the teaching and learning in Ms. Rotter's classroom in two ways. First, I provide the chronological week in which I was present in the classroom as it sits within the timeline of the data within the overall study. Second, I include a description and title of the central event occurring at that time. For example, an event might be a particular book/read aloud, a writing prompt, or context in which a discussion occurred. At the start of each event I provide a short description of what was happening and any materials used. As a reminder, in my process of thinking with theory, analytical questions are included with italics as contributions in bringing together theory and data to encourage new questions and new thinking.

\section{Week Two}

\section{Whole Group Discussion: So, what is race? What is racism?}

Ms. Rotter had read several books ${ }^{8}$ with her with her class that were overtly about race and racism. Several of these conversations took place before I had IRB approval

${ }^{8}$ Let's Talk About Race (2005) by Julius Lester; Racism and Intolerance (2017) by Louise Spilsbury; On the Day You Begin (2018) by Jacqueline Woodson; Little Leaders: Bold Women in Black History (2017) by Vashti Harrison; Separate is Never Equal (2014) by Duncan Tonatiuh; All the Colors We Are (2014) by Kate Kissinger; If You Were a Kid During the Civil Rights Movement (2017) by Gwendolyn Hooks; Four Feet Two Sandals (2007) by Karen Williams; and The Other Side (2001) by Jacqueline Woodson. For a full list of all books read, please see Appendix A. 
from the school district and signed consent forms from families, so I was present for many of them but did not record and write down notes about what the children said or shared. However, Ms. Rotter and I still talked and planned together, considering how to intentionally introduce these ideas to her students. We met before the conversation that I discuss below occurred, and mulled over what the children might be thinking about and understanding in regards to race and racism. We planned together for her to begin a conversation with the class regarding how they understood the terms.

Ms. Rotter: So, we've read several books that discuss race and racism. I am wondering if anyone can tell me what they think those words mean. What about race?

Charlie: I think it's your skin color.

Lots of students nod their heads in agreement.

Kristoff: Yes. It is the color of your skin.

Amari: Sometimes it is not. Sometimes skin color does not always match someone's race.

Ms. Rotter: Amari, can you give us an example of that?

Amari: Sure. Like, my mom is Black, but her skin color is not really black. It is sort of more like brown, or a darker shade of tan. But she is Black. Those are different.

Ms. Rotter: Okay, that makes sense. Does anyone else have an idea?

Alexa: I think it can be how other people see you. So it might be skin color or something else. It depends what they are looking at. 
Ms. Rotter: Hmm. Okay. Thank you. Would anyone else like to share? (She pauses for ten seconds but no one else responds)

Ms. Rotter: Okay. Now what about racism? We've talked about that a bit and even read some books that discuss it. Remember in the book Racism and Intolerance?

Charlie: So, I think it means there are different people, with different skin colors. But they can't all do the same things and go to the same places.

Amari: Yeah. Especially people who are not white. Racism makes it hard for them.

Marshall: (More quietly) Yeah. That's right.

Ms. Rotter: Thank you for sharing. Does anyone else have anything they want to add?

Kristoff: I think it means that people are really mean to other people.

Margaret: People should be nice to each other.

This is a brief discussion of how the students in Ms. Rotter's classroom were conceptualizing and understanding race and racism. It is challenging to discuss how students generally conceptualized race and racism because their understandings stretched in different directions and not all students shared their viewpoints. Similar to classrooms with adults, not all children feel comfortable sharing their perspective within larger groups of people. Even children who shared on this day had different conceptualizations of race from one another. For example, Charlie shared that she believes race to be equivalent with skin color and many of the students agreed. Throughout the time that I was in Ms. Rotter's classroom, that seemed the perspective of many of the students. 
However, Amari, sharing an example from her parent provides an example of how skin color and race do not always align. Alexa points out that race is how someone else views and conceptualizes you. Both Alexa and Amari point out that race is more than skin color, it can partially rely on someone else's conceptualization of you as well as your own claim of a racial identity. In engaging these different perceptions of race, Ms. Rotter allows a disruptive way of thinking and knowing to permeate her classroom. In this conversation, there is no 'correct' or 'right' way to know or understand race. Earlier, when I wrote about the theoretical concept of the ship, I asked "How might individual EC educators teach about race and racism as disruptive?" How does a refusal of one way of experiencing and knowing race open space for more complex understandings?

When asked about racism, Charlie returns to her conceptualization from the question about race to skin color and describes the color of a person's skin being a barrier to the ability to travel across different spaces. However, Charlie does not mention which skin color is prevented from going "to the same places." Does she believe that a white person might be prevented from going somewhere because of their skin? How might the power dynamics component of racism be missing from her conceptualization?

Differently, Amari does point out that people who are not white are more affected by racism as it "makes it hard for them." Marshall quietly agrees with Amari's statement. Additionally, Margaret and Kristoff seem to conceptualize racism as being grounded in nice versus mean, not mentioning anything about racial groupings, skin color, or other characteristics. The layers of complex history as in theoretical concept of the wake seem to be also present in this conversation. While many of the children understand racism as a harmful action, Amari and Marshall recognize the difference in experiencing racism for 
“people who are not white." We are all awash in the wake, with antiblackness seeping into the porous connections between and across our lives. Amari highlights how enduring racism is different for People of Color, perhaps indicating that white people have a responsibility to change.

This was not the only conversation that Ms. Rotter had with the students about their conceptualizations of race and racism. There were several times when the subject came up again, sometimes during a read aloud or other informal conversations. During our meetings, Ms. Rotter and I would discuss how different students were understanding race and racism, based upon their contributions. For example, Ms. Rotter shared with me that in guided reading groups, she felt that the leveled reader books she was provided with by the district were uninteresting and did not appropriately challenge the students in terms of content or complex writing. She would often substitute what she called "diverse literature" 9 that often included topics of race and racism. She shared with me in addition to providing more of a challenge for these students and their reading abilities, making this switch also gave her the opportunity to have one-on-one conversations with many of the students who did not share in larger groups about race and racism. Ms. Rotter consistently provided students openings to talk and discuss questions and ideas related to race and racism.

\section{Week Three}

\section{The Case for Loving: The Fight for Interracial Marriage}

9 Two titles that Ms. Rotter shared with me were Fishing Day by Andrea Davis Pinkney and The Story of Ruby Bridges by Robert Coles. 
Ms. Rotter settled in with her class for a daily read aloud. On this day, it was The Case for Loving by Selina Alko (2015). This picturebook shares the true story of Loving vs. Virginia, the case from 1967 that went to the Supreme Court to fight to make interracial marriage legal. Ms. Rotter asked a student to read the title and began to read the book when a student asked,

Peter: Is this real?

Ms. Rotter: It is a true story, it really happened. There are photos of the real people at the end.

Peter: Okay. I was wondering.

Kristoff: Are they still alive?

Ms. Rotter: I'm not sure. We'll have to look that up. Peter's question was interesting. Was his question about the people in the story as being "real" coming from a place of just 'wonder'? Or, instead, was the curiosity he expressed connected to a desire to relate to actual persons in history and actual events? I learned from my prior experiences with Kristoff that he often desired to forge connections focused on the proximity to his own life. I thought that perhaps Kristoff asking if this something current or an event that happened long ago was an attempt to once again make those connections. As a reminder, Sharpe (2016) writes 'I've been trying to articulate a method of encountering a past that is not past...I am interested in how we imagine ways of knowing that past, in excess of the fictions of the archive" (p. 13). How might we help children to see "a past that is not past"? How might we help them see that something which happened long ago, with people that are no longer alive, can shift and change the 
way that they live now? Perhaps by providing room for dialogue and questions, letting them linger and thinking more deeply about them.

Ms. Rotter continued reading. She arrived at pages 11 and 12 shown in Figure 9 below.

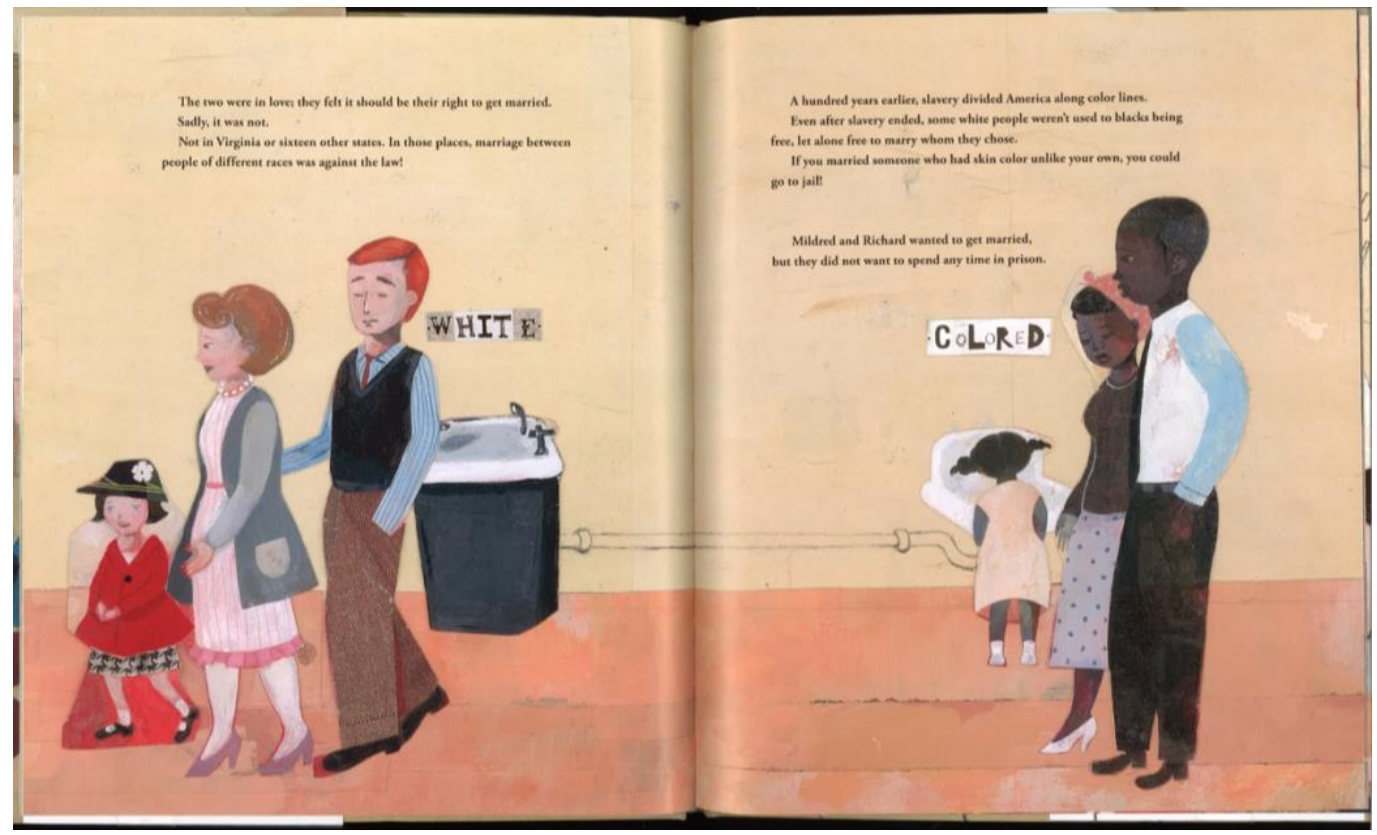

Figure 9. Illustrations demonstrating the differences in segregated water fountains. Image from Alko, S., \& Qualls, S. (2015). The case for Loving: The fight for interracial marriage (pp 11-12). New York, NY: Arthur Levine Books.

Ms. Rotter read from the page:

A hundred years earlier, slavery divided America along color lines. Even after slavery ended, some white people weren't used to blacks being free, let alone free to marry whom they choose. If you married someone who had skin color unlike your own, you could go to jail. Mildred and Richard wanted to get married, but they did not want to spend any time in prison.

The first person to respond was Alexa: 
Alexa: I noticed something. The white people's water fountain looks better than the water fountain for the Brown skinned people.

Amari: Yeah, see the bottom part? (She gets up, moves toward the book, and points at the page) That keeps the water colder. (She pauses) That seems unfair, the white people get the colder water and the Black people don't.

\section{Many students nod their heads and murmur.}

Ms. Rotter: Thanks for pointing that out. I didn't notice that before.

Amari and Alexa's response to the book at this point was heightened through viewing and discussing the illustration. Although the narrative within the picturebook clearly demonstrated inequality between white and Black people, it seemed to be that the visual imagery that helped produce a different response for many students in Ms. Rotter's classroom. How do visualizations of racial injustice foster different relationships with racism and antiblackness?

Looking closely at the illustration, Amari pointed out that the water fountain marked white held colder water. I am intrigued by this point. Amari caused me reckon with what it means to live. It is not enough just to survive, just to be provided water. Drinking cold water is something that makes life enjoyable and pleasurable. Amari's noticing, upon review and analysis of the recording and transcript, called forth the theoretical concept of the ship. The ship makes one who is looking into the past to consider the encounters with Black lives in the aftermath of slavery. Looking at the two water fountains, one could think that there is equal but separate access to water. However, Amari's noticing brought about a different way of responding and thinking about this history, the very symbolic visual of segregated water fountains within the civil 
right movement. Attentively watching through the lens of antiblackness poises one have new understandings. Sharpe (2016) suggests, "This looking makes ethical demands on the viewer; demands to imagine otherwise; to reckon with the fact that the archive, too, is invention" (p. 51). Amari's statements showed the ethical demands made through learning about this history and considering the implications.

Ms. Rotter continued reading and arrived at pages 15 and 16 where Mr. and Mrs. Loving are shown in their darkened bedroom where the only light comes from two white police officers who are shining flashlights at the couple. The police officers have their hands raised in a position of accusation, while Mildred Loving is shown resting in bed. Richard Loving is standing next to the bed, pointing at the police officers. Ms. Rotter read,

But soon, something terrible happened. In the middle of the night, they were awoken from their sleep. It was the police! An officer shouted at Richard, "what are you doing with that woman?" Richard proudly pointed at their marriage certificate hanging on the wall. "That's not good here!" the policeman boomed.

Margaret: That is so not fair. You can marry whoever you want.

Ms. Rotter: At that time, the law said you couldn't.

Margaret: When was this?

Ms. Rotter: 1955.

Margaret: Ohhhh.

Ms. Rotter continued reading the next pages which describe that the Lovings were then "taken away and locked up in jail." At the end of these pages, the Lovings are told that 
they must leave the state of Virginia if they want to remain married. Across these pages, the words UNLAWFUL and COHABITION are splashed across the page in all capital letters in bold print.

Alexa: What do those words mean?

Ms. Rotter: They were not allowed to be married. It was against the law.

Margaret: That's not fair either. You should totally get to live where you want.

Penny: You should get to do both. Marry who you want and live where you want to live.

Ms. Rotter: And they are not getting to do either one of those things?

Penny: No.

The whole class is silent. It seems that a new somberness has entered the space.

I felt uneasy about the somber mode that entered the space. I thought about sitting in space with young children who were learning about hard history. I am brought back to that question from a parent many years ago: "Does she need to be so sad?" This is being an early childhood educator in the wake. Where learning about race and racism occurs within repeating and churning disaster of the ship. The silence that Ms. Rotter allowed to hang over the space while we all looked at the illustrations embodied what it means to live in the ship. When one views the destruction all around you, cutting through ideas and feelings, but unable to change it. None of us can change this history. However, we can change our relationship to and with it. Perhaps students are shifting their relationships with the history of interracial marriage and that can change and breathe new life into the future. 


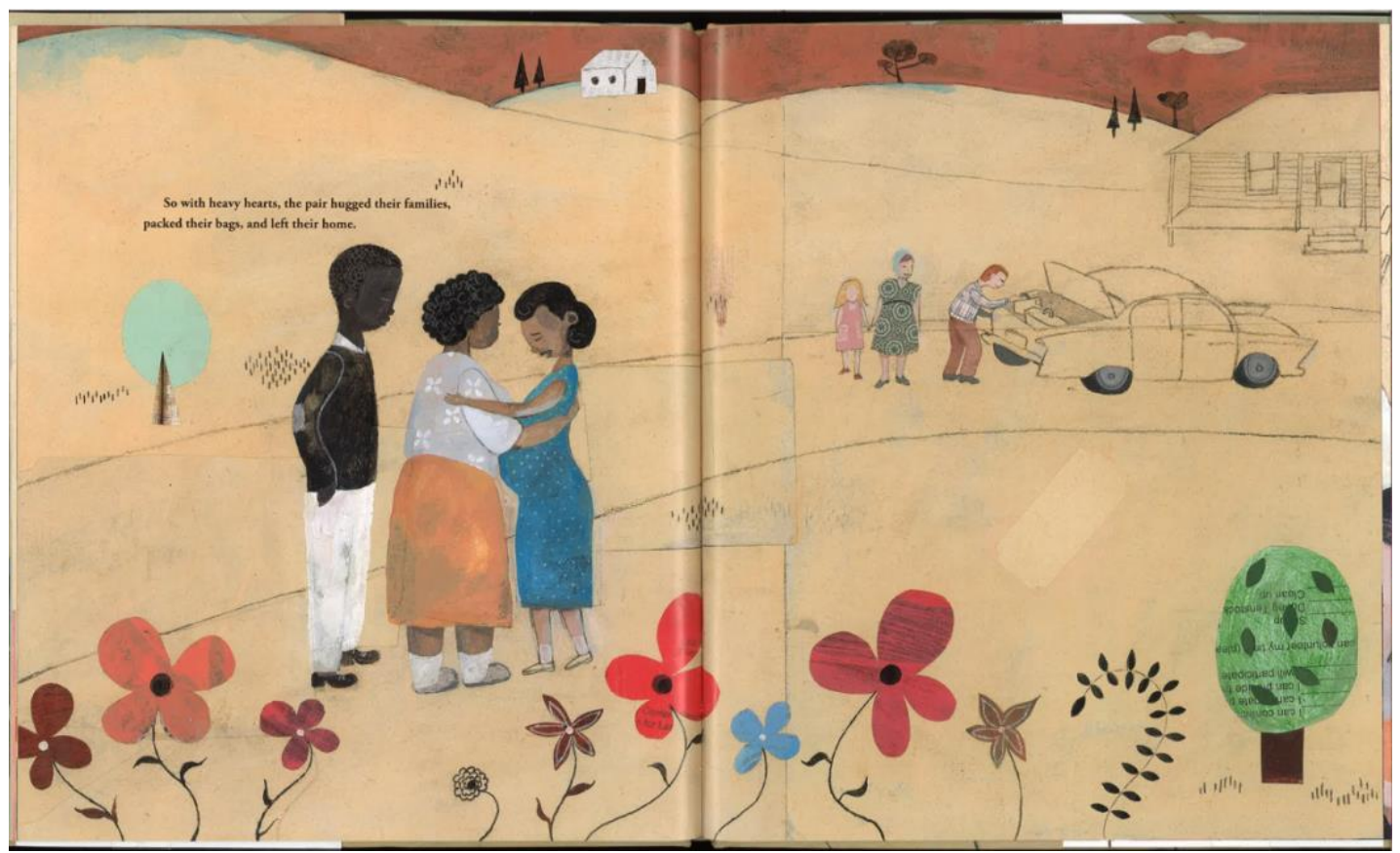

Figure 10. The Lovings leave Virginia. Image from Alko, S., \& Qualls, S. (2015). The case for Loving: The fight for interracial marriage (pp 19-20). New York, NY: Arthur Levine Books.

Ms. Rotter read the next page shown in Figure 10 above: "So with heavy hearts, the pair hugged their families, packed their bags, and left their home."

Ms. Rotter: How do you think they feel about having to leave their home?

Several student voices overlapped saying "sad" or "mad."

Margaret: Look, she's crying. (she points at the page)

Ms. Rotter: Mrs. Loving? She's sad, huh?

Margaret: I noticed that the two boys look like their mom and the girl looks like their dad.

Ms. Rotter: What makes them look like their mom? Or their dad?

Margaret: Because they have like their mom's skin or their dad's skin tone.

Camila: But look. She has a baby in her tummy. She's going to have a baby.

Stephanye: But it is unlegal to have a baby. 
Ms. Rotter: Why is not legal?

Stephanye: Because they [the police] said so.

Ms. Rotter: Hmm.

In Stephanye's statement of how it is "unlegal" for the Lovings to have a child, I am brought back to Sharpe (2016) who writes about the ship: "If the crime is blackness, is the sentence the circuit between ship and shore?" (p. 57). Because interracial marriage was illegal, a multiracial child must be illegal as well. How did Stephanye's statement place the concern upon the Lovings for breaking the law? How might one help Stephanye see the problem as being with those who made this illegal?

Ms. Rotter finishes reading the book and asks if there are any questions. Kristoff is the first one to talk and asks:

Kristoff: Are the author and illustrators the kids of the people in this book?

Ms. Rotter: No. They are just people similar to them that are people of different races who fell in love, got married, and had children too.

Amari: My parents are like that too. My mom is Black and my dad is white.

Alexa: Yes! Me too. Except my parents are the opposite. So, my mom is white and my dad is Black.

Amari: If this happened to my parents, there would be no me or my sister.

They both cross their hands over their chests.

In Amari and Alexa's response I consider the theoretical concept of the wake. How the reading of this book, and the learning of this history lets them know how their existence is so fragile, so delicate. So often we think of and teach the fight for interracial marriage as something that happened long ago yet it really is not that so far in the past. Sharpe 
(2016) writes, "Wakes are processes; through them we think about the dead and about our relations to them; they are rituals through which to enact grief and memory" (p. 21). Amari and Alexa are enacting grief and memory in connecting with their present-day lives with the past. How does thinking with the theory of the wake enable new and/or different recognitions of student responses to learning about racism and antiblackness?

\section{Ms. Rotter and The Lovings}

Several days later, Ms. Rotter talked to me about sharing this book with her own children at her home and shared the following writing with me:

My own children were in my classroom and saw the book about The Lovings on my back table. I decided to bring the book home and read it to them. They couldn't believe the injustices that happened in the past reflected in the book. They said this book is one of the first they've seen with pictures that look like our family. Seeing and hearing their responses made me think about how they don't see enough representation of their identities and their family. Teaching about race with Oona was making me think about more than just teaching in my classroom. It made me think about myself as a parent, we are our child's first teacher after all. (Ms. Rotter's journal notes)

Ms. Rotter's children are multiracial, having a white father and a Black mother, just like the Loving family. I was surprised, at first, to see the personal inclusion of her own children and how this book had made its way into her home and her personal life. When we talked about this in person, she shared more details how she shared this book with her children, including a conversation with them about their own racial identities and what they should 'call' themselves as multiracial children. My informal conversation with Ms. 
Rotter as well as written notes reminded me how personal teaching is. Our experiences, identities, beliefs, and ideologies all fold into what and how we teach and how we perceive ourselves and our responsibilities in the world. I thought about and shared with Ms. Rotter that it seemed her own identity as a Black woman and a mother of multiracial children was entangled with/in her teacher identity and practices, and she agreed. Sharpe (2016) states, "I recognize myself, but which I mean, I recognize the common conditions of Black being in the wake" (p. 45). How did thinking of the past as not past, compel different connections for Ms. Rotter?

\section{Week Four}

\section{Through My Eyes: 'The Wall' as a Solution?}

Ms. Rotter read the picturebook Through my Eyes by Ruby Bridges (1999) over several days. Through My Eyes is non-fiction picturebook which includes historical photos of the time before, during, and after Ruby Bridges' attendance of William Frantz Elementary School, as a description of school integration. During one of the read-aloud sessions, when the class was about halfway through the book, several of the students began to discuss segregation and the division of people ${ }^{10}$. The students began to talk about 'the wall' and how the people who were against segregation (as shared in the text) could just keep people separate with a wall. As the book described and provided photos of the anger from white people at Ruby Bridges' integration in Frantz Elementary School,

\footnotetext{
${ }^{10}$ As I have written elsewhere, to work towards ongoing consent with children, they were regularly told that they could turn on and off recorders if they would like. After this reading and conversation, we discovered that someone had most likely turned off the video camera during this read aloud. Therefore, I do not have a verbatim transcript. My sharing of this moment is from my field notes, Ms. Rotter's journal entries, and our conversation(s) after the event.
} 
several students presented 'the wall' as a solution to maintain order and keep people safe. However, many students disagreed with the proposition of 'the wall' with one student even yelling out "The wall is stupid!"

I was initially surprised by the student's inclusion of 'the wall' as a part of the discussion of this book. I soon remembered that Ms. Rotter had shared with me several weeks earlier that 'the wall' had been entering classroom conversation for a while. To provide context, this research study occurred during a government shutdown where the president refused to sign the operating budget for the federal government unless his demand for almost 6 billion dollars for a southern border wall was met. When Ms. Rotter first shared that they had been talking about the wall I asked her, "How do you think they know about that?" She first shrugged, reiterating that the students had been talking about it for a few weeks. A few moments later she added that they recently watched CNN 10 News (a broadcast made specifically for use in elementary schools) where demands and tensions over the need for 'the wall' to be built had been described and discussed. Below is an excerpt from Ms. Rotter's writing about this read aloud and discussion:

The discussion took several turns. We discussed how we could resolve the issue. One student thought that if we built a "wall," it would resolve this issue. That same student thought that if one race was on one side of the wall and one on the other side could do it [avoid the conflict of integration]. This issue would be tricky if different races married. A few students disagreed and stated if that were the case, where would they belong if they had one parent who is "black" and one that is "white." Which side do they choose if their families have two different 
races? They asked their peers "where would they (the student) go?” (Ms. Rotter's journal notes)

Often, the students in Ms. Rotter's class, when presented with issues or problems as presented in literature, wanted to find a way to solve the problem, even when reading about something that occurred in the past. This occasion mirrored that action, except that the students were using a racialized, xenophobic, and contemporary conception to 'solve' this particular situation. Ms. Rotter and I talked afterwards about our shock and surprise that this is where the group dialogue turned. We both were surprised that several students rather than being outraged or even concerned about the anger and cruelty over school integration from white people, these students wanted to find a way to keep schools segregated. This is not to say all students believed 'the wall' was a solution, or even a logical choice. Many of them disagreed, and as I discuss later, specifically Amari and Alexa shared with me their opposition to this line of thinking.

The phrase 'the wall' was used over and over in this conversation in the classroom. What does 'the wall' signify for the students? Sharpe writes, "As the meanings of words fall apart, we encounter again and again the difficulty of sticking the signification. This is Black being in the wake. This is the anagrammatical" (p. 77). The social, material, emotional, environmental, and and and ${ }^{11} \ldots$ impacts of 'the wall' contain so much more that could ever be held in a word or phrase and cannot be contained in simply writing about the 'the wall.' The construct, the notion of a wall, in the context of a

\footnotetext{
${ }^{11}$ I use the "and and and" to signify multiplicities. And and and is a Deleuzoguattarian philosophical concept which demands to "establish a logic of the AND... nullify endings and beginnings" (Deleuze \& Guattari, 1980/1987, p. 25). It is a move away from either/or and towards both/and.
} 
manufactured 'emergency' at the southern border is anti-Black. It is the embodiment of a fear of an unknown Other. In his writing about antiblackness Dumas (2016) writes about the aim in the United States to cleanse ourselves from dark-skinned people. He notes:

In this nation that has ostensibly advanced beyond Black and white, it is the Black that become anachronistic, an impediment to the realization of Americans' national-popular imagination of who "we" want to be. Even as the nation (and indeed, the world), embraces a certain kind of multiculturalism, people strain against the dark. (pp. 11-12)

How might some of the students in Ms. Rotter's class, through use of 'the wall' as a solution to conflict, embody antiblackness?

\section{Week Five}

\section{Through My Eyes: Exposure to Lynching}

The next week, as the class continued to read Through my Eyes, the topic of lynching came up ${ }^{12}$. Ms. Rotter read the following text in the book which specifically mentions it:

...The owners of the small grocery store at the end of the block suddenly told my family to stay away. Because we were part of school integration, the white owners no longer wanted our business. My grandparents telephoned from Mississippi to say they were afraid for us. They thought my father would be lynched-murdered by a lawless mob. (p. 36)

\footnotetext{
12 Again, we discovered after that a student had stopped the video recording during this read aloud.
} 
A student asked, "What is that? Lynched?" Ms. Rotter looked toward me to which I mouthed "me?" and she nodded. I shared with them that it was when a person is killed by a group of people sometimes called a mob, like in the book. The person has usually being accused of doing something and before they get to have a fair trial, they are lynched. I explained that lynching was something that usually referred to what happened to Black people at the hands of white people and that it often occurred when this Black person was hung. At the time of sharing this, I felt nervous. Was I providing an accurate description? Even if it was accurate, was there such a thing as too much truth? I looked at Ms. Rotter throughout my explanation to the students and she nodded along, providing confirmation to keep going. After this discussion on lynching Ms. Rotter shared in her journal:

A book about Ruby Bridges was being read to the class and the word lynching came up and a student asked, "What is lynching?" I wasn't sure how to answer so I asked Oona and she described it. The class seemed to get upset about the idea [of] people hanging another person. The looks on students faces were confused, upset, sad, and very disappointed. One girl shouted out, "I wish that white people could be slaves, or they are never going to get it!" (Ms. Rotter's journal notes) After discussing this specific pedagogical moment with Ms. Rotter and the commitment we both had to allow the children to explore their curiosities about lynching, we both felt like this was and is indeed a topic to teach with young children. How might students have experienced that teaching moment with new relationships, connections to, and understandings of the past? I consider Sharpe's writing about the wake and the weather as she carefully reminds, 
We are positioned in the knowledge that we are living in the afterlives of slavery, sitting in the room with history, in a lived and undeclared state of emergency. The ground of compromise, the firmament, the access to freedom and democracy, littered with Black bodies. (p. 100)

What if in that moment Ms. Rotter or I, or the both of us, had chosen to censor that part of the book? What if the student's question had been ignored? What would that erasure have produced? I acknowledge that "we are living in the afterlives of slavery" where lynching is not something just of the past but has current implications as well. Sharpe, writing about the ship and Gaines' art installation states, I read Gaines's temporary art monument as grounded in the knowledge of the wake, in a past that is not a past, a past that is with us still; a past that cannot and should not be pacified in its presentation. (p. 62)

How can we teach about difficult topics like fears and realities of lynching that are not "pacified it its presentation" but are still humanizing and ethical ways of teaching the past as not past? How will thinking and learning with a theory like the wake create different understandings of the past as not past as students, teachers, and researchers navigate and recognize being held in the ship and the destruction and damage to those within its path?

\section{Week Seven}

Separate is Never Equal: Sylvia Mendez and her Family's Fight for Segregation 
When I entered the classroom on this day, the students in Ms. Rotter's classroom were in the middle of math rotations ${ }^{13}$ in the classroom. After checking in with Ms. Rotter, I took a usual spot, finding a table in the classroom to sit at with my notebook. Many students chatted with me as they worked on various math assignments (for example: card games, sheets with math problems, counting games, iPads with math apps) with some students asking for my help with their different tasks. Once math rotations were over, Ms. Rotter asked the students to come to the carpet for a read aloud. One student, Margaret, who typically runs up and greets me as soon as I enter the classroom, and often with a hug or a question (“Are you here to learn from us today?" or "Are you going to read with us today?") took a book off the shelf. The book was Separate is Never Equal: Sylvia Mendez and Her Family's Fight for Desegregation by Duncan Tonatiuh and asked, looking towards Ms. Rotter, “Can Ms. Oona read this to us today?” Ms. Rotter made eye contact with me, and I felt as if she was asking me if it was okay, and I nodded. As I pulled up a chair to read, several students stated, "But we already read this one!" to which other students added "No, I want to read it again!” or "Let her read it!” I began reading the book, pausing to provide room for the students to make predictions, ask questions, and respond to those questions. When we arrived at page two I read the following text from the book:

...when a young white boy pointed at her and yelled "Go back to the Mexican school! You don't belong here!" For the rest of day, Sylvia did not speak or

\footnotetext{
13 The model of station rotations is commonly used in early childhood and elementary classrooms. Usually based in one academic subject, fixed small groups of students rotate through different activities and small group instruction based on a timed schedule designed by the classroom teacher.
} 
introduce herself in her classes. When she got home that afternoon, she told her mom, Felícitas, what had happened. "I don't want to go to that school anymore. The kids are mean."

Immediately after, Margaret responded:

Margaret: That is just the rudest thing I have heard all day.

Oona: Why do you think that happened?

Margaret: Because (pauses) he said “go back, you don't belong here. You go to the Mexican school." (Sighs, pauses) And because she is not the same color as their skin. They are white and she's (pauses) she's Black.

Other overlapping student voices: No, look, she's Brown!

Margaret: Yeah, she's Brown. And she's upset because he said that. She doesn't need to go to that school if she doesn't want to.

\section{Everyone is quiet for several moments.}

Alexa: You know, they are not even really white. It is just their skin is a little lighter and more like tan. It is just a lighter color of Brown.

Again, everyone is quiet for several moments.

Penny: You know, if I was a principal, and the Brown people wanted to come here I would just say yes. Everyone should have a school (pauses), you know, that they should want to go to.

Oona: I agree. I think everyone should have a school they want to go and that treats them well.

Penny: What about our school? Does our school do that?

Voices overlap for a few minutes, it's hard to distinguish what is being said. 
Stephanye: I want to say that Kristoff said that I am Brown, and it looks like I am Brown, but I am actually Black.

\section{Everyone is quiet for several moments.}

Oona: Do you ever notice that people are treated differently because of their skin color?

Stephanye: Oh yeah.

Oona: When do you notice that?

Stephanye: Um (pauses), my mom and her mom got treated differently because they were Black.

Oona: What happened?

Stephanye: They just (pauses). I'm not sure. I just know it. We know that in my family.

Reading over this data excerpt I am brought back to a quote about the wake from Sharpe (2016):

To be in the wake is to also recognize the way we are constituted through and by continued vulnerability to overwhelming force through not only known to ourselves and to each other by that force (emphasis in original, p. 16).

How are students making sense of the "overwhelming force" of race and racism "by continued vulnerability”? In this dialogue, some of the students in Ms. Rotter's class are working through the ways that their own racial identities and the racial identities of others are constituted through various forces. For example, Stephanye rejecting that her skin color dictates her racial group identification. 
Margaret, in her initial response of "that is just the rudest thing I have heard all day" seems to be reckoning with the reality of racist remarks being said to Sylvia Mendez, a student of similar age to herself. This is followed up by Penny, who is rejecting segregation as a practice but also questioning if similar practices might happen at their school. Perhaps Penny's question might comprise of a consideration of the forces that racialize herself and her peers at their school, providing a source of exclusion and inclusion.

Stephanye confirms that she knows that people are treated differently based upon the color of their skin. Stephanye, in that moment is not able to name the exact ways that racism occurs within her and her families' experiences, but she knows it be true, for example when she said "They just (pauses). I'm not sure. I just know it. We know that in my family." This sentiment shared by Stephanye in many ways echoes Sharpe theorizations on how antiblackness operates. For example, "In what I am calling the weather, antiblackness is pervasive as climate" (Sharpe, 2016, p. 106). Racism and antiblackness are so embedded in all that we do, that it is similar to breathing in the air each in each day within our climate, that is how common and typical it is. Stephanye's indication of "we" within her statement significant; her understanding of differential treatment based on Blackness is not just limited to herself, her family knows this reality as well. How does the wake cause us to form different relationships with the climate and the weather?

Stephanye 'just knowing' that her family experiences this, but unsure of how to name it, embodies the theoretical concept of the weather and the overarching theory of the wake. For me, as a white woman, I think about breathing in so much antiblackness 
each day that I can often choose to have it appear invisible. When I confirm Penny's statement that includes the language of "everyone," how might I be choosing to make antiblackness invisible? How can this be likened to the air we breathe, which has the appearance of being clear and invisible? Why would we take the time and energy to name all of the ways that breathing serves to further add to the destruction of Black lives? Additionally, how does Stephanye's addition of knowledge of how her family is treated differently because they are Black connect to the theoretical concept of the hold? The hold, which as I wrote about before, drawing on Sharpe (2016), are the actions, doing, and outcomes of antiblackness. While Penny, whose parents identified her as Caucasian, wonders if racism exists in their school, Stephanye, who parents identified her as Black, clearly states that she knows this to be true.

When Alexa states, "You know, they are not even really white. It is just their skin is a little lighter and more like tan. It is just a lighter color of Brown," no one seems to respond. Alexa has continually shared her multiracial identity as significant throughout class read-alouds, discussion and dialogue, and casual conversation. Along with Amari, they have complicated class discussions on skin color, race, racism, and segregation by adding how what we are reading about or solutions posed might conflict with their multiracial identities. Amari and Alexa, repeatedly disrupt notions of being "Black" or "white" and show how that choice is not possible for them.

As we continued reading, we arrived at page 18, and Kristoff inquired about the illustration on pages 18-19, shown in Figure 11 below. At his request, I read the sign depicted in the illustrations: "No dogs or Mexicans allowed: Public pool." Kristoff lifted his hands in the air and called out, beginning another dialogue exchange: 


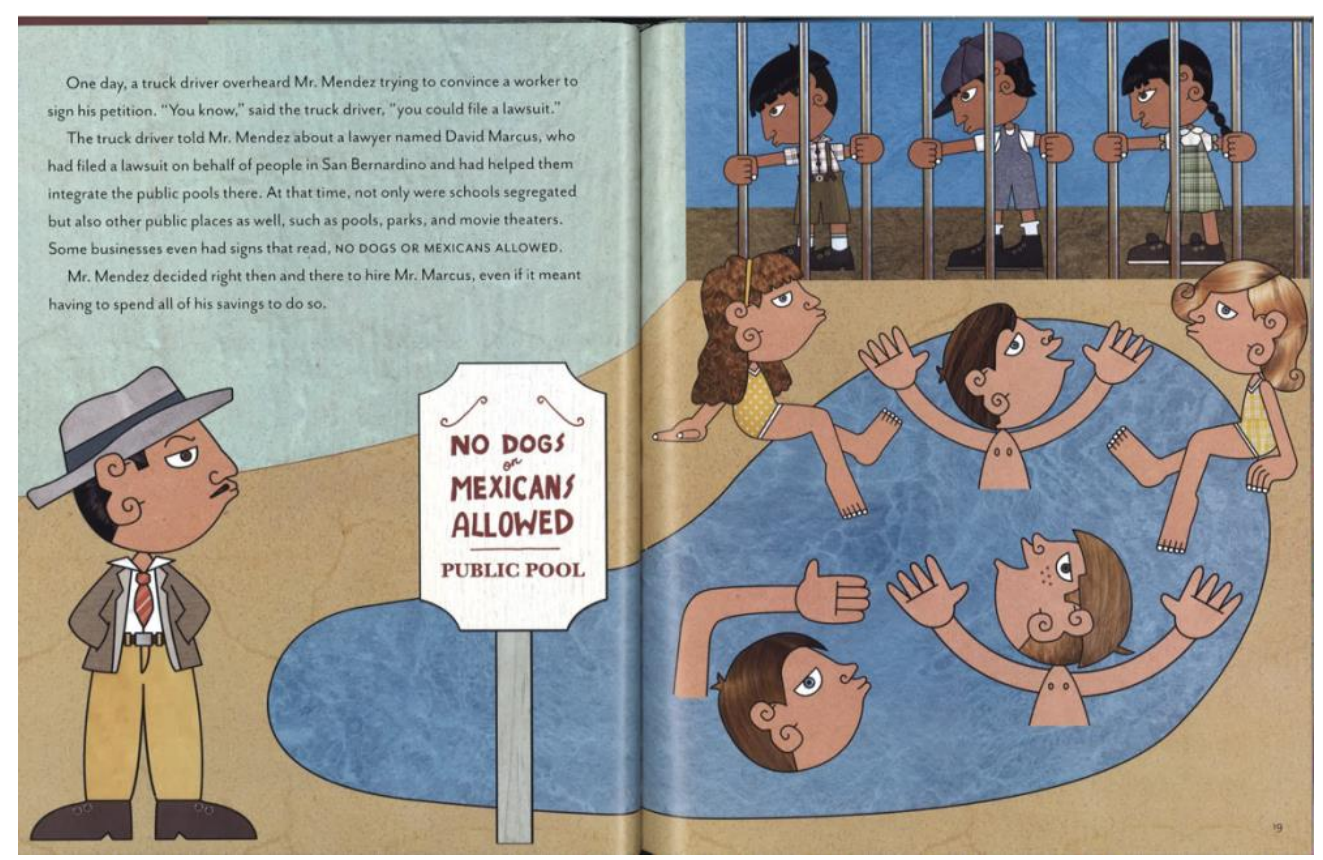

Figure 11. Illustration demonstrating the segregation in public pools. Image from Tonatiuh, D. (2014). Separate is never equal: Sylvia Mendez and her family's fight for desegregation (pp. 18-19). New York, NY: Abrams Books for Young Readers.

Kristoff: ....But they are so mean!

Oona: Who are "they"?

Kristoff: The white people. I think, think... the white people were saying they were Mexicans but they were not.

Oona: Does that make you mad? You look mad when you were saying that.

Kristoff: Yeah.

Oona: Hmm, the white people shouldn't decide what to call people. People should decide for themselves-

Kristoff: - Yeah! I think... I think the white people should go on the other side of the earth!

Oona: Oh, they should?

Margaret: No! That would be mean. That's mean. 
Oona: Well, I think they are not being very kind so I think Kristoff is... is wanting them to be kinder, to go away maybe?

Stephanye: But then you would be there! (She looks towards Kristoff)

Oona: Oh, so Stephanye is saying then you would be there, on the other side the Earth. Kristoff, would that mean someone like you would be there, on the other side of the earth?

Alexa: Yeah, 'cause he is white!

Oona: He is white?

Marshall: What about me? We would all be over there.

Some students start talking and pointing to others indicating who would be separated from each other.

Alexa: Yeah, and then some people wouldn't see Ms. Rotter, Stephanye, and well we would be separate-

Kristoff: -Well... well... It's just that the white people need to go over there until they learn their lesson and then they can come back. How they are is not okay. They are being unkind to the Brown people!

Oona: So, the white people need to go over there until they learn their lesson?

Kristoff: Yeah!

Oona: Who is going to teach them their lesson, though?

Kristoff: I don't know.

Marshall: But some people (he pauses) some white people are nice.

Alexa: Like my cousin. 
Marshall: Yeah, so some people shouldn't have to go over there if they are already nice.

Oona: Who decides who is nice and who is mean?

\section{Many students shrug their shoulders.}

Stephanye: If you want to be mean, be mean. You just (pause) you decide.

Margaret: You make your decision. How are you going to be with people? How are you going to treat people?

Oona: I think these are important discussions to have. I don't know. How do we get white people to be not so mean, nicer?

Stephanye: Teach them?

Oona: Oh yeah?

Stephanye: Hold up. I have an idea. Why don't we show kindness to white people and then they'll (pauses) they will do it to us (she gestures to herself)? Oona: Do you think that works?

I pause here to think with the theoretical concept of the wake and this exchange. When thinking with the wake, I focus in on the many students who were drawing connections between the event that we were reading about that took place in the past and their own current day lives. As we read the book, we discussed that this took place in the past (in 1947). Although the students talked about this event as happening long ago (even saying "whoa!" when I mentioned that it was over 70 years ago), they quickly made connections to their present-day lives. I wonder when thinking with the wake, which positions the past as not past, how does the students' positioning of past, present, and future as fluid and connected complicate the teaching and learning of race and racism? 
Within this excerpt of dialogue, students are talking about the past (i.e., Kristoff talking about the mean white people), the present (i.e., when Kristoff proposes for white people to go to the other side of the earth but then Stephanye reminds him that then he would be on the other side of the earth), to future (i.e., Alexa pointing out that they would never get to have Ms. Rotter as a teacher if Kristoff's plan came to fruition). All of the flowing and fluid conceptualizations from the students among and between past, present, and future allowed for a more complex discussion of the way that segregation affected, affects, and will affect all of our lives. How might a teacher follow and support the fluidity of how students express their questions, ideas, and experiences? How does this fluidity encourage more complex thinking and wondering? The complexity in this dialogue brings about recognition of how difficult it is to teach about race and racism.

The hold, the theoretical concept of the action, doing, and outcomes of antiblackness, draws in on Kristoff's statement about the impact of "the white people" and their treatment of "the Brown people." Taking note that this exchange occurred during the part of the picturebook which depicted through text and illustration that "Brown" or Mexicans or Mexican Americans were considered equal to dogs. In the illustration (see Figure 11) the Mexican Americans are shown on the other side of fence, which is reminiscent of a prison type fence with the large bars. As the lighter skinned white people bathe in the pool with the sign "No dogs or Mexicans allowed: Public pool" next to them, the actions, doing, and outcomes of antiblackness are visibly present. How does Kristoff notice and name the action of antiblackness by noting "how they are is not okay" and then engage his peers and teachers in difficult dialogue about this topic? How does Kristoff wrestle with the systemic issues of antiblackness by refusing to see this as a 
more micro level issue (for example, just a few mean white people) and instead he recognizes that there needs to be more systemic level change (i.e., white people being sent to the other side of the earth so they can learn and change their actions and behaviors)?

Thinking through the weather and how to aspirate breath in order to shift our relationships and recognition of antiblackness, I am brought back to Sharpe (2016) who writes,

It is not the specifics of any one event or set of events that are endlessly repeatable and repeated, but the totality of the environments in which we struggle; the machines in which we live; what I am calling the weather. (p. 111) In this exchange, the students struggle. They struggle to process this historical event, make connections to their own lives and lived realities, develop links and understandings with each other, and cultivate ways to resolve the difficult realities they are facing. What climate is being fostered in Ms. Rotter's classroom to produce new ways of thinking, relating, and (dis)connecting to ideas of race and racism? As a discussed previously, students experience a struggle in this dialogue; however, I have noticed that engaging in struggle in dialogue and thinking without a clear solution is typical of what you might see on any day in Ms. Rotter's classroom. The students often wrestle with dilemmas, questions, ideas and Ms. Rotter will often answer with "I'm not sure" or "I don't really know" or "Let's think about that." Welcoming questions without answers allows the students to grapple with hard and heavy dilemmas in ways that encourage deep deliberation. The quote from Sharpe above points to struggle as a movement towards creating a rift in the replication of antiblackness present throughout daily life. 
However, Stephanye's idea of: “Why don't we show kindness to white people and then they'll... they will do it to us?" as she gestures to herself for "us" causes me to stop and wonder. My question of “do you think that works?" is heavy with years of reading, writing, and researching about race and racism and believing that it takes more than just micro level actions to change a systemic problem like racism, which is engulfed in power and inequity. An excerpt from my field notes that day shows my additional thinking about this question:

When [Stephanye] shared that thought about just being "nice" as a way for Black people to combat racism my heart sank. Inside my head I was thinking "No! Don't go down this path.” I was worried that she was somehow internalizing racism and antiblackness, thinking that if she could just be nice enough, kind enough, good enough, etc... she could make it stop. Is there a way to encourage a more complex understandings of how this is more than her? More than this classroom? More than just what she can do as one person? Is that asking too much of a first grader? But yet... I don't want to fall into the trap of discounting the work of young children as less than. (Oona's field notes journal)

Sharpe asks about the wake, "How does one mourn the interminable event?" (2016, p. 19). In similar vein, how does one theorize and think through the teaching and learning of race and racism with first graders when racism seems to have no end in sight? Perhaps Stephanye's proposal is a way for her to move through an event that seems to have no end in sight, an ongoing and continuous struggle. Writing about the weather, Sharpe pens, "When the only certainty is the weather that produces a pervasive climate of antiblackness, what must we know in order to move through these environments in which 
the push is always toward Black death?" (p. 106). What does Stephanye feel like she must know, and do, "to move through these environments"?

Later on, towards the conclusion of the book, Alexa and another student, Amari spoke about their racial identities and how that complicates Kristoff's idea about sending white people to the other side of the earth.

Alexa: I want to add something important when you said like (she pauses), the white people treated other people... (overlapping talking, words are unclear).

Oona: Oh, okay.

Alexa: That means my brother and me and my mom would be on one side of the earth but my dad would be on the other side.

Oona: Oh, because your family has people of multiple races in it?

Alexa: Mmhmm.

Oona: How are you thinking about that?

Alexa: Sad, because then my family would be torn apart like that.

Kristoff: Well, I was just talking about people in the book. Not really people around the world. Just in the book.

Alexa: But okay (longer pause). Remember it is a true story? (Another pause) So, um, the cousins though. They wouldn't be able to be to see each other.

Whispering and talking in the group.

Alexa: So, like think about Black people—some Black people wouldn't be able to see other people, people in their family, that are like - more tan. That are lighter. Oona: So, we could even separate families?

Alexa nods in agreement. 
Oona: Huh. That's an important point, I think.

Everyone is silent for several moments.

Oona: I'm still wondering about what Kristoff talked about. How the white people that say and do these terrible things — like we read about today — how do we get them to change their actions?

Amari: So (pause). If white people went on the other side of the world, that means my dad would go on the other side of the world. And my grandparents too. Oona: Amari, you look sad. Are you feeling sad about that?

Amari: Yeah, I am.

Kristoff: Well, I wanted to solve this problem. The white people need to not act like that.

Marshall: But families shouldn't be split.

Oona: It's complicated. It's hard to know what to do.

Alexa: If you do this, if you separate people, that means certain people in this class would be on the other side (starts naming and gesturing at Black students in the class and includes Ms. Rotter).

Marshall: Well how do we know who is white or Black and who is not? Lots of students discuss skin color, comparing hands and arms, discussing colors like brown, tan, beige, black and so on. Overlapping conversations.

In this concluding dialogue, which took place as we finished the book, Alexa and Amari who had previously brought up their multiracial identities when we read, The Case for Loving: The Fight for Interracial Marriage, shared more about their families. Alexa pushes back on Kristoff's suggestion of the division of white and Black people as a way 
to solve the problem of "white people who say and do horrible things." Kristoff immediately responds stating, "I was just talking about people in the book. Not really people around the world." Nonetheless, Alexa reminds him that the story they are reading is non-fiction, a true story of people in and around the world. Alexa continues, reminding us of Sylvia Mendez's cousins in the book who were allowed to attend the white school, while Sylvia and her own immediate family was not. Alexa is bringing attention to the hypocrisies demonstrated through segregation policies and acts of racism. As Sharpe (2016) reminds us, “The problem is Blackness...such things [associating Blackness with a culture of poverty] are said and said with such regularity about Black and blackened people is some part of what it means to be/in the wake" (p. 34). Like Sharpe, Alexa is encouraging one to think about how antiblackness operates in complex ways.

As a reminder, Alexa said: "So, like think about Black people—some Black people wouldn't be able to see other people, people in their family, that are like more tan. That are lighter." Alexa is interrogating how her classmates, family, and her world is steeped in antiblackness. She recognizes that there is a preference for people who are considered lighter skinned ("tan") and brings that up. Alexa shares this dilemma and perhaps Kristoff and the members of the class might consider a more complex understanding of skin color and race. How does a more complex discussion of race identities and racism move early childhood students to recognize the processes of antiblackness in their own lives?

Learning from/with this data, along with Sharpe's theory of the wake caused a greater contemplation of the two people in this conversation that seemed to be the most focused on white people — me and Kristoff. How convenient that two people who identify 
as white, seem to be stuck in how to 'fix' white people, make them better, help them learn and grow. How might I have made different choices in order to refuse centering white people and whiteness? Alexa's insightful critiques of Kristoff's plan of separating people based upon being white (or not) wouldn't work because of the complexity of skin colors as well racialization within Communities of Color, and specifically within Black communities is an important critique. I am thinking through my response to this contribution by Alexa. At first, I ask a clarifying question and then follow up with a comment of it being an interesting point. Yet, after some moments of silence, I bring us back to getting white people to change. In this moment, why I might have felt propelled to re-center white people and whiteness in this conversation? Amari's contribution directly after my question provides direct response. People she knows and loves are white, why might we be talking about them saying and doing horrible things?

I asked Ms. Rotter what she thought about this (after it occurred) and she shared that she was so surprised and intrigued by the responses. When she read the book to them previously, the discussion had not gone "this deep." After this read aloud, the students in Ms. Rotter's class were asked to work on writing. Some students worked in notebooks while others pulled out paper stashed in the seatback pockets to work on. Margaret called me over and asked to show me what she was working on. A photo of it is included below as Figure 12.

I asked Margaret to read her writing to me which is included as Figure 12 below. In the title of Figure 12, I transcribed what she shared. I responded with: "Wow. That reminds me of the book and our discussion earlier. What were you thinking about when you wrote this?" Margaret answered, 


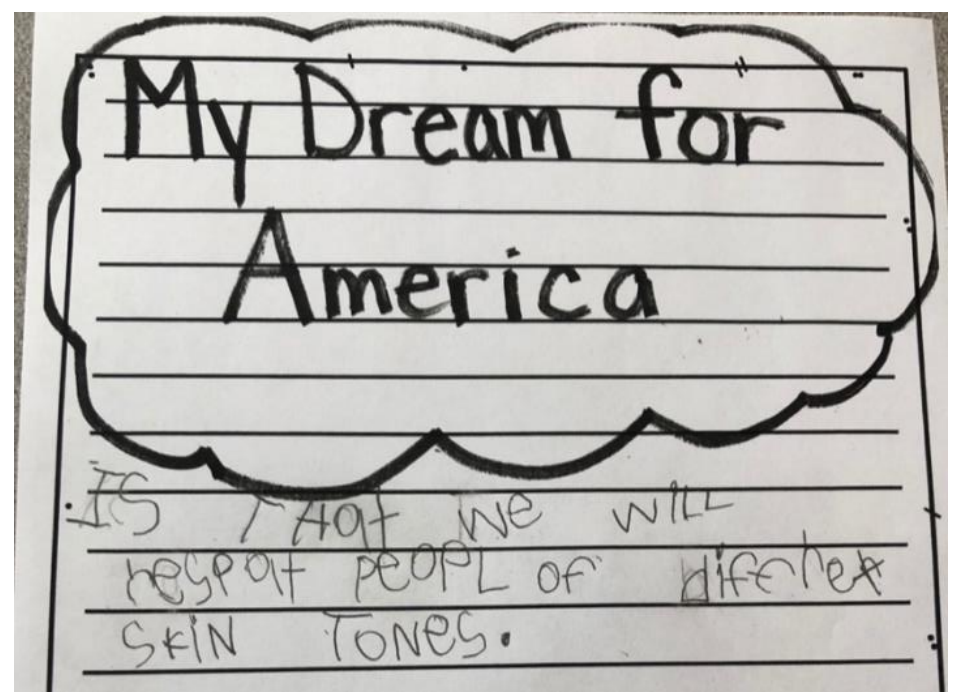

Figure 12. Margaret's writing. "[My dream for America...] is that we will respect people of different skin tones."

Well, it just that I want people to respect the different skin tones, see? We are all different tones and colors. (She pauses) I really want people to (she pauses again) people should (another pause and a sigh). I just want to people to be respected.

We are all different and it shouldn't matter! It shouldn't matter what your skin is. Margaret's response focused on skin tone and colors. It seems that for her, she is stuck between respecting people's "different tones and colors" and being figuratively colorblind (“it shouldn't matter what your skin is"). In analyzing Margaret's response, I have been wondering about how it connects to the title of the book, Separate is Never Equal. Margaret wanted skin color not to matter. Perhaps the title is misleading and sends a message different than what I am considering when thinking with the wake. In this title, the focus is on how separate schools are inherently unequal. The wake, with a focus on the processes and outcomes of antiblackness, might reject that integration could ever result in 'equality.' 
Could, in fact, separate be equal if an effort is made to have it so? In the picturebook, Tonatiuh describes the difference between the Mexican and white schools and how the materials, the buildings, and the overall environment was not equal. Yet, the fight is for inclusion of Mexican American children into the white school where they are told they do not belong. What if the narrative was told about how we could make separate equal? What if the focus of the narrative was that the Mexican school was not properly supported, funded, and valued as a place of learning? Of course, this is different from the argument made in Mendez v. Westminster (1947), but might be interesting to explore. This also reminds me of Penny's question and comment from earlier in the dialogue. Penny stated that "everyone should have a school they want to go and treats them well" and then followed up with a question if their school "does that?" (treats everyone well). How do Penny's contributions also show her to be in-between two places (where "everyone" should be treated well and questioning if her school actually treats everyone well)? Penny is considering if the past is not yet past, as Sharpe writes about in the wake. Writing about the weather Sharpe (2016) informs "aspiration is the word that I arrived at for keeping and putting breath in the Black body" (p. 130). Aspiration is a lens and approach for shifting our understandings and relationships when histories and actions cannot be changed. How do questions like Penny's shift recognitions of racism and antiblackness from the past as not yet past?

\section{Week Eight}

\section{An Interview ${ }^{14}$ with Amari and Alexa}

\footnotetext{
14 This was the word that Amari and Alexa used with me. When they approached me to ask about an "interview" I was unsure of what to expect. As I have written about, with
} 
Sometime after this read aloud, Amari and Alexa approached me and to tell me that they "needed" to do an "interview" with me. I asked them what an interview might look like and they said that an interview would be a place where they could tell me more of their thoughts and ideas. I told them that it sounded like a good idea but that I would need to check with Ms. Rotter. Before I could approach her, they both ran over to Ms. Rotter and explained their idea. Ms. Rotter looked me with a quizzical face which I took to indicate that she was wondering what I thought, to which I nodded, yes.

Amari and Alexa's proposal challenged, disrupted, and surprised my thoughts about ideas about research(ing) with children. Often, when researching with children we think about the power dynamics that adults have over children. However, Amari and Alexa flipped that script. As much as they could (within the restraints of schooling), they were asserting and enacting their agentic ways of knowing, being, and relating in the classroom by presenting their knowledge as valuable and of great importance. How are Amari and Alexa disrupting notions about our typical interactions with students, asserting their power and knowledge with/in the wake, in order to teach me?

Later Alexa, Amari, and I went out to the first-grade hallway directly outside of Ms. Rotter's classroom. I talked to them about video recording and audio recording if that would be okay as it would help me remember our conversation. They told me yes and then Amari added a caveat: "but only if we get to listen and look at it afterwards" to

my commitment to remain "in the moment" with the students, I strove to remain open and curious to the different ways that students were engaging and learning about topics of race and racism. I recognize that the term "interview" used in the context of a research study, connects to a specialized practice which has been written about extensively. In hindsight, asking Amari and Alexa about how they were conceptualizing an "interview" might have provided richer context and description. 
which I agreed. They helped me to setup the video and audio recorders and we got started. I reminded them that they could turn off the recorders at any time if they changed their minds. I asked them which device they thought we should use to record and they told me both of them. After some talk and questions about the recording devices and how they work and my experiences with them, I shared,

Oona: So, I'm excited to talk with you both. I've got some books here. Would you like to read a book together or would you like to talk together?

Amari: Let's read this one first. (She points to Marisol McDonald Doesn't Match by Monica Brown).

Alexa: Yeah. We will read it to you. I'll read one page and then she can read the next one. We'll take turns.

Once again, Amari and Alexa seemed to challenge the common-sense ways of doing school here by letting me know they were going to read the book to me. When they finished reading I asked if I could read them the author's epilogue as to why she wrote this book. They both agreed. I read:

I wrote this book because, like over 6 million Americans, I am multiracial. I'm the daughter of a South American mother and a North American father, and my childhood was spent in a close community of cousins, tios and tias. Like Marisol McDonald, my cousins and I are mixed—indigenous Peruvian and Spanish mixed with Scottish and Italian and Jewish, not to mention Nicaraguan, Mexican, Chilean and African. One thing most of us do share, are freckles... People sometimes ask us, "What are you?" and sometimes even say that we "don't match." But we know better. Our mothers told us that we are Americans, yes, but 
also citizens of the world. My life (and I'll bet yours too) is bound up with the history of many peoples, and like Marisol McDonald, I open my arms wide and embrace them all. (p. 32)

Amari and Alexa immediately began to respond, Amari: Well, well we are both American (she pauses) because one of our parents is Black and the other is white. We are kind of like the girl in the book too! Alexa: Well, her dad is white and my mom is white, and her mom is Black and my dad and Black. And so, I have a lot of languages too, Spanish, American, and more but I only know a few words.

Amari: I think I have about five languages. Irish is one. I have a lot. I just forgot. I forgot.

Oona: Well, I have some questions for you both. Ms. Rotter has read books and I have read books about people with different racial and ethnic identities. You have both shared about your racial identities in different class discussions. How do your identities help you learn about these topics in a special way?

Amari: Um, wellll11l-

Alexa: - I know my dad, when he was growing up, there were hard times. He had to survive when there was no food and a bunch of things. If this was back in the day-

Oona: Which day?

Amari: Like, when Black people were slaves.

Alexa: Yeah. So, like say I was walking in a park with my mom and dad and there was like this white person and they would just look at my family like 
'whaaaaat?' And he would walk right up to me and say, “I don't think you're supposed to have a dad of that color."

Oona: Oh.

Amari: Or, and, if it even wasn't allowed (pause) women weren't treated fairly so you would have to walk at least five steps, wait your dad, no your mom would have walk at least five steps behind your dad.

Alexa: Or me!

Oona: How true. Especially Black women weren't treated as fairly.

Amari: And, but, like say even if we were specially chosen to be at this school and it was a mixed school instead of a segregated school, since your mom is white and my mom is Black, and um if they came to pick us up, a boy would probably run to the principal's office and say "Um, principal, there are two moms and one is Black and one is white and they need to come take their children in the next five minutes or (pause) we are going to arrest one of them or both of them."

Oona: So, do you think anything like that happens anymore?

Amari: Ummm, well—

Alexa: - Well, Ms. Rotter told us that segregation and women, and that stuff still does happen.

Amari: Yeah, it still exists. (she nods as she talks)

Oona: Sure, yeah. Do you or anyone in your family experience that anymore?

Alexa: Well I know my nana and my meema, my nana is my dad's mom and my meema is my dad's mom. They um, got chosen (pauses) to go to um (pauses) to one of the smartest colleges. 
Oona: Oh, wow.

Alexa: In the world. They both got chosen. I know that for my meema, the principal was like we didn't actually make a decision about that but the board was like (she gestures, shaking her finger) and my meema was like, "yes you did" because the board made a decision. So that was like, it was like, just the hardest. It was all boys and there was no one like them. So, like, it was like recess and a boy came up to them and was like "hey, I don't think you're supposed to be here right now because it is boys only and whites only."

Amari: But, if slavery still exists, I wouldn't be able to have a mom or dad, right? Alexa: Yeah, like let us show what it would be like.

Alexa and Amari enact a scene from what they would imagine it would be like for them and their family if it was a different time.

As I reviewed the video of Amari and Alexa enacting their views of what their lives might be like if it was a different time period, I think with the theoretical concept the weather. Within this concept, Sharpe (2016) wrote about aspiration, which is tied to opportunity and class movement or "to keep breath in the Black body" (p. 109). How are Alexa and Amari mixing past, present, and future to create new understandings of antiblackness might work? They are both questioning how things might be different for them if this was a previous time period, and also negotiating how racism and sexism continue to exist in their present day lives. When I asked if they believe that racism and sexism "happens anymore," they both answered in the affirmative with Alexa letting me know that Ms. Rotter had taught her that it did and Amari answering that she knew it did. This is how EC educators can cultivate teaching and learning about race and racism that 
alters atmospheric conditions. In the exchange below, it becomes clear that Ms. Rotter's pedagogical content choices (such as her choice of children's literature) have assisted the students with more knowledge about how racism operates in contemporary contextsaltering atmospheric relationships.

Oona: So, I have a question for you both. In Kindergarten, or preschool, or a time before you came to this classroom — did you have any teachers that talked about race or racism with you?

Amari: No.

Alexa: Hmm. Nope.

Oona: So, Ms. Rotter is the first teacher to do that with you?

Amari \& Alexa: Yeah.

Oona: How do you feel about that? As a learner?

Amari: I like that.

Alexa: I like that too. There's just some books that I'm like, I like, like I do like reading books and race and stuff but some of them can get boring when you start going into them and stuff. And there are sometimes a bunch of questions going on and a bunch of shouting out and it's hard.

Amari: Yeah, like when Kristoff when he said the thing about building a wall to keep the Black people and white people separate. That was too much.

Oona: So, do you feel like your identity_having one white parent and one Black parent—helps your classmates learn something?

Amari: Yeah, like Kristoff can learn a lot of from us! (She gestures to herself and Alexa) 
Alexa: Yeah, and like a lot of the kids were probably like "whoa, they have parents of different races!" So, they can ask a bunch of different questions. Like Margaret, she might come up to us and ask, "how does it feel to be loved by a Black and a white person?" and we would be like "it's great." And she would be like, "well, just so you know I have, like, white people" and we would be like "okay" then she would be like "white people are better." Still that's not really kind of Amari's mom and my dad.

Oona: Sure (nodding in the affirmative). So, what do you think people that are teachers or people that want to be teachers should know about this- how to help kids have these conversations like you just talked about?

Alexa: So-

Ms. Rotter: - Ok, we are ready to begin the math test.

At this point, we start to pack up and head back in the classroom. Amari and Alexa ask me if we can continue the interview another day.

Unfortunately, our time was up for the day because of a math test the students were required to take. Yet, towards the end of the interview Amari and Alexa share that Ms. Rotter is the only teacher they have had so far that has talked about and/or taught them about race and racism. They also both share that they suspect or have observed their peers engage in racist, anti-Black thinking. This is the cruelness of living in the hold when "we are, though, living in the afterlives of that brutality that is not in the past" (Sharpe, 2016, p. 99). Furthermore, when Amari shares that it "was too much" when Kristoff discussed the wall to separate people, I am once again thinking with the hold. Sharpe urges, 
Across time and space the languages and apparatus of the hold and its violences multiply; so, too, the languages of beholding. In what ways might we enact a beholden-ness to each other, laterally?... This is what Spillers calls the intramural. How are we beholden to and beholders of each other in ways that change across time and place and space and yet remain? Beholden in the wake. (2016, pp. 100101)

How do these experiences of "too much" act as multiplying violences of the hold? How often are Black students as well as other non-white students experiencing this violence and are they provided space to work through and reject racism and antiblackness? How does Ms. Rotter approach to teaching and learning topics of race and racism create and encourage students to be beholden to each other? Holding each other accountable for their missteps, inaccuracies, and verbal wounds? How does being beholden to and of each other help students grapple with difficult and complicated ways that racism operates?

\section{Week Ten}

\section{Continuing the Interview with Amari and Alexa}

When I sat down again for the interview with Amari and Alexa, they wanted to watch their video and listen to the recording from the previous interview. We watched part of it together and they seemed to find it very funny to watch and listen to themselves as they giggled, laughed, and pointed out things they said or did. They asked me a lot of questions about the recording devices worked and how I saved the recordings and where. We talked about that for about ten minutes in between watching parts of the video from the previous interview. 
Oona: So, the one question I asked you but we didn't have time to answerremember you had the math test? —was, remember you shared with me that before you came to Ms. Rotter's classroom never talked to you about raceAlexa: - Nah

Oona: - or ethnicity

Alexa: - Nah

Oona: —or racism.

Alexa:-Nah, nah, nah.

Oona: So, I remember you told me that you liked that Ms. Rotter talked to you about these things in her classroom. So, what would you want to tell people who are teachers or people that want to be teachers?

Amari: I would say, you can be a teacher (she pauses) it doesn't matter what the color of your skin is because — say, if I was a Black person a long time ago, and pretend Alexa is my mom. She would say "yeah, sweetie, you can be whatever you want." But in some states that wouldn't be allowed. So, like, right now, in some states in the south, there are still some Black people who are treated unfairly.

Oona: Do you think that still happens, even in states like ours?

Amari: Nah (she pauses), well maybe a little bit.

Oona: A little bit?

Amari: Yeah.

Oona: Do you think that other teachers—-first grade teachers, Kindergarten teachers, preschool teachers—-should teach that history? 
Alexa: Yes! (Amari nods) I was reading this book called The Underground

Railroad, my brother gave it to me. And I read that Missouri was one of the slave states!

Oona: Oh, yeah.

Amari: Yeah. Remember that book we read, Not My Idea ${ }^{15}$ ? At the end she says that she does see color and I think teachers should be like that. So, I would say to teachers, "you can teach your class anything, you just need to make sure it's okay with your principal. And you have to make sure your team is okay with it- - you know, the other teachers in your grade."

Oona: What if the other teachers say "we shouldn't talk about race"?

Amari: You should do it anyway. You're-You should—be your own person. Oona: Okay.

Alexa: My turn. So, I feel like if your principal says, you can't do it, do it. Be your own person like Amari said. Do what you want to do.

Amari: Yeah!

Alexa: Like, it doesn't matter if your principal is like, white or Black, it just matters, like, your feeling, and how your feelings are. If your feelings are really strong and you really want to do it. Be your own person, do that! But don't get upset if he says no and you get in trouble.

Oona: So, you should still take a risk and do it anyway?

Alexa \& Amari: Yeah.

15 The class had read this book previously. Not My Idea: A Book About Whiteness by Anastasia Higginbotham. 
Alex and Amari provide many important contributions, so it is difficult to know where to begin. Amari, in her advice to future and current teachers acknowledges the past and that Black families encourage their children to pursue their dreams and desires but the social and legal structure of antiblackness in many cases prevented them from fulfilling those dream and following those pursuits. Amari does connect current day practices, but provides a caveat, saying that only Black people in the south continue to be "treated unfairly." Although not inherently clear in the transcript, in the moment, I recognized her designation as "the south" as a different place from where we were in that moment. I considered where this research study took place. In order to preserve the anonymity of the people in this research study, I have chosen not to reveal the location. However, generally, there are ongoing debates about whether this state is "the south" or not. I have had questions about that too and have been told by several people that the major interstate highway running through the state from west-to-east is what determines your belonging in north or south. Above this highway is "north" and below this highway is "south." Of course, these are my thoughts and experiences and may differ from Amari's in myriad ways. I do question though how this notion of "the south" as a place where Black people "are treated unfairly" occur and had wished I had asked more about that specifically.

When I asked Amari if she believes that Black people are treated unfairly within the state we are in, she first dismisses that possibility and then shifts her response to "maybe a little bit." What changed her initial response, I wonder? Alexa informs us that she read a book where she learned that the state we are currently in was a "slave state" or one of the states where slavery was legalized. This information shifts the conversation and acknowledges that we are in a different place than previously (just a few seconds 
ago) imagined. Sharpe (2016), writing about the ship asks, "What does it look like, entail, and mean to attend to, care for, comfort, and defend, those already dead, those dying, and those living lives?" (p. 38). How does this conversation attend to difficulties of living in the ship? In the theoretical section of this dissertation, when writing about the concept of the ship, I asked: "How will they [young children] learn to navigate and recognize the ship and the destruction and damage to those within its path?" How does Alexa's reminder that we are residing within a "slave state" recognize the ship and the destruction and damage inherent in that history? How does the knowledge of living in a "slave state" change the understandings and navigations of present day realities?

The interview wraps up with Amari and Alexa sharing their thoughts and ideas about how teachers should approach the teaching and learning of race and racism, with additional thoughts about what to do if you face resistance. Amari, remembering from a previous read aloud, wants teachers to admit they do "see color" but they need to seek permission from the principal and other teachers before teaching about race and racism. I followed up with a genuine question and wondering about what to do, when you might be told as an educator of young children not to talk about race and I was surprised that Amari said "do it anyway." Both Amari and Alexa agreed with the sentiment of "be your own person." Returning to the theoretical concept of the ship, Amari and Alexa seem to be urging educators who work with young children to teach about race and racism in ways that "imagine otherwise" (Sharpe, 2016, p. 51). Otherwise is "be[ing] your own person," one who makes speculative choices in the interest of a fuller humanity for all. Again, I come back to a question from theoretical writing earlier where I wrote about school employees demanding first grader Jonathan Brown cut his locs. I asked, "How do 
we, as EC educators, exist in the repeating, churning disaster of the ship?" Amari and Alexa remind EC educators to be their own person when choosing to teach about topics of race and racism. Alexa added, "If your feelings are really strong and you really want to do it. Be your own person, do that! But don't get upset if he [a principal] says no and you get in trouble." How might EC educators learn to take risks and consider the wake in their teaching with young children?

\section{Week Eleven}

\section{The Children's March}

When Ms. Rotter and I were meeting, I asked if she was familiar with the book The Children's March by Monica Clark-Robinson. She wasn't and I suggested it as a read aloud, thinking it might provide a hopeful opening to connect what actions children have taken, and seeing what they can/are able to do as children. Ms. Rotter asked if I would be willing to read it and I agreed. The Children's March is historical fiction picturebook that shares the true story of the Birmingham Children's March in 1963, but with fictional characters narrating the events.

After the read aloud, Ms. Rotter and I invited the students to respond to the book with blank and lined paper, and the cups of markers, pencils, and pens at their tables. Several students did and shared their work with me. Below, in Figures 13 through 16 I include drawing and writing by a few of the students along with what they shared with me when I asked "can you tell me about what you are creating?" 


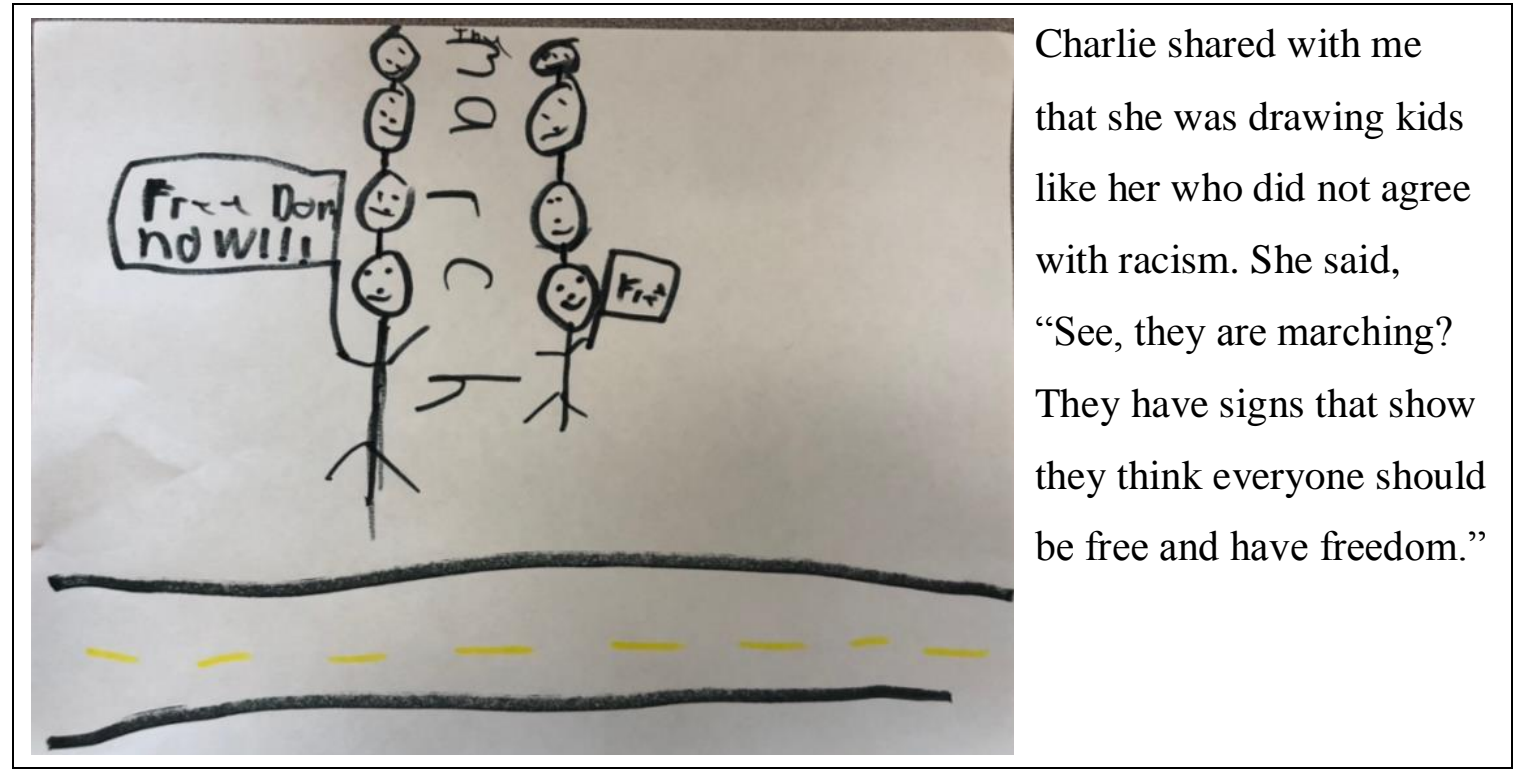

Figure 13. Charlie's drawing: "Freedom now!!! March. Free."

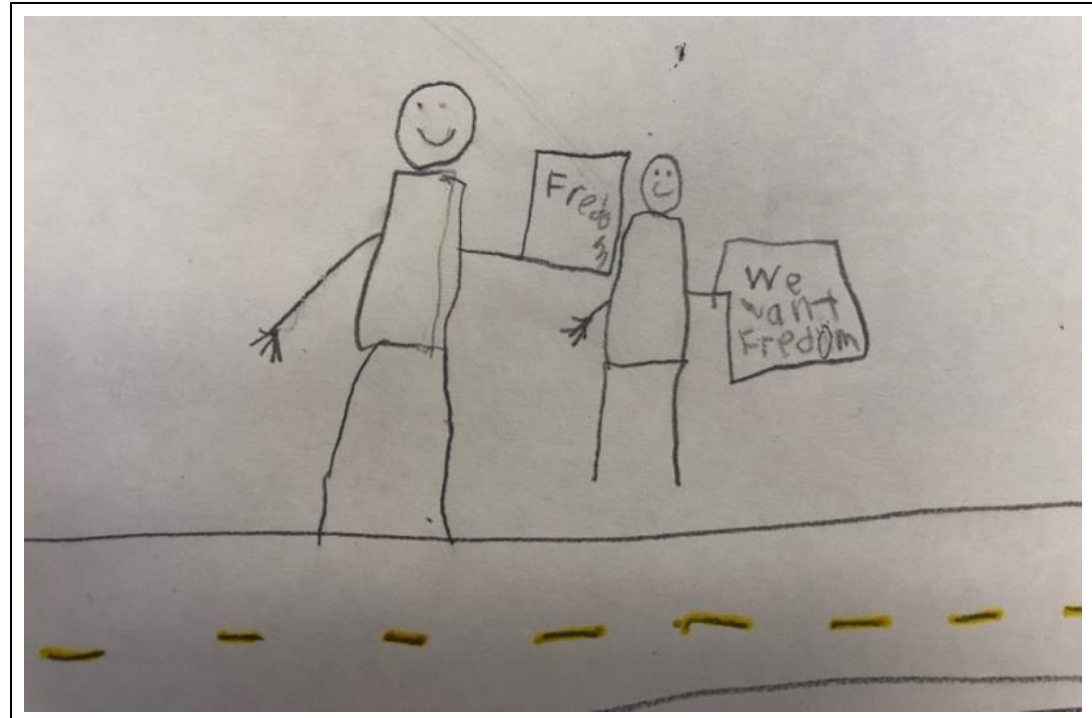

Marshall described his drawing to me. "These are the children like in the book. They are marching because they want freedom and they want equal rights.

They are really brave. They don't even care if they're arrested.

They want freedom.”

Figure 14. Marshall's drawing: "Freedom. We want freedom." 


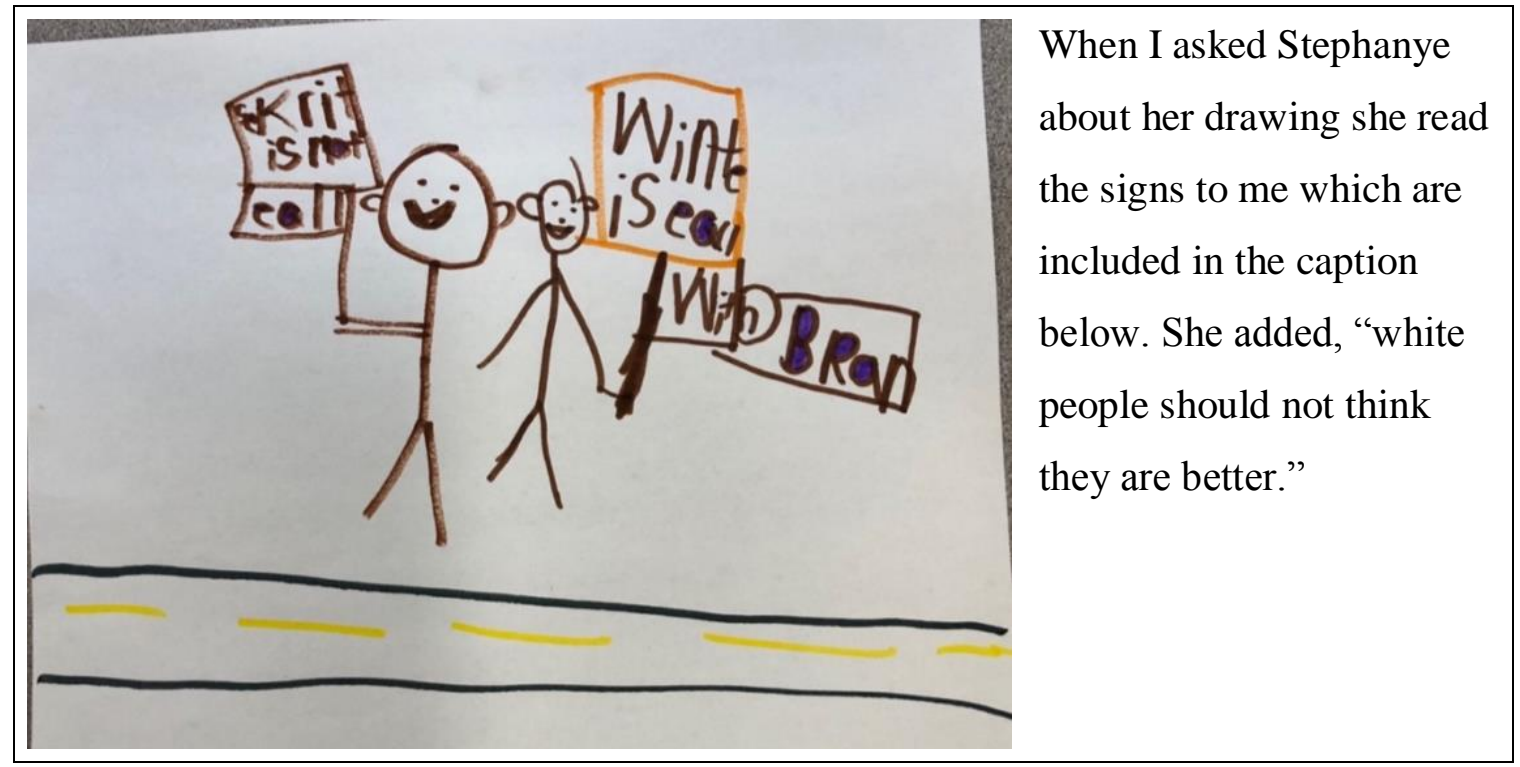

Figure 15. Stephanye's drawing: "Separate is not equal. White is equal with Brown."

In Charlie, Marshall, and Stephanye's drawings they included people marching, analogous to what they learned about and saw in the book. Charlie made a point of telling me that she was drawing kids like her. Marshall also pointed out that he was drawing children. Both Charlie and Marshall's drawings included the word "freedom." Marshall added “...they are really brave. They don't even care if they get arrested.” In fact, the children getting arrested was a part of this book that many of the students talked and asked questions about. In the afterword of Let The Children March, there is a photograph of the actual children marching with a quote from one of the children which reads "I knew I was going to jail” (p. 34). In the wake, Sharpe (2016) writes about the need to understand and recognize "Black modes of resistance" (p. 14). This book demonstrated one of these Black modes of resistance, with children who were similarly aged to the students in Ms. Rotter's classroom.

Stephanye's drawing included signs which read "separate is not equal" and "white is equal with brown." When I asked Stephanye about her drawing she told me that "white 
people should not think they are better." In this moment, it seemed that Stephanye was fighting against white supremacy through her artwork. Stephanye's artwork conjures the theoretical concept of the weather, as she aspirates new breath into an event that happened long ago. Stephanye is rejecting antiblackness in her visual and written responses.

I noticed that Kristoff's drawing in many ways mirrored the imagery on pages 19 and 20 of the book The Children's March, pictured in Figure 17, below. However, in his drawing he provided an opportunity see the facial expressions on the people, which is not present on this page of the book illustration. In the picturebook, the reader is imagined above, looking down upon the scene. Kristoff provides a different vantage point, with the reader looking at the scene from equal level and he has paid attention to including emotion on the faces of the individuals as he describes.

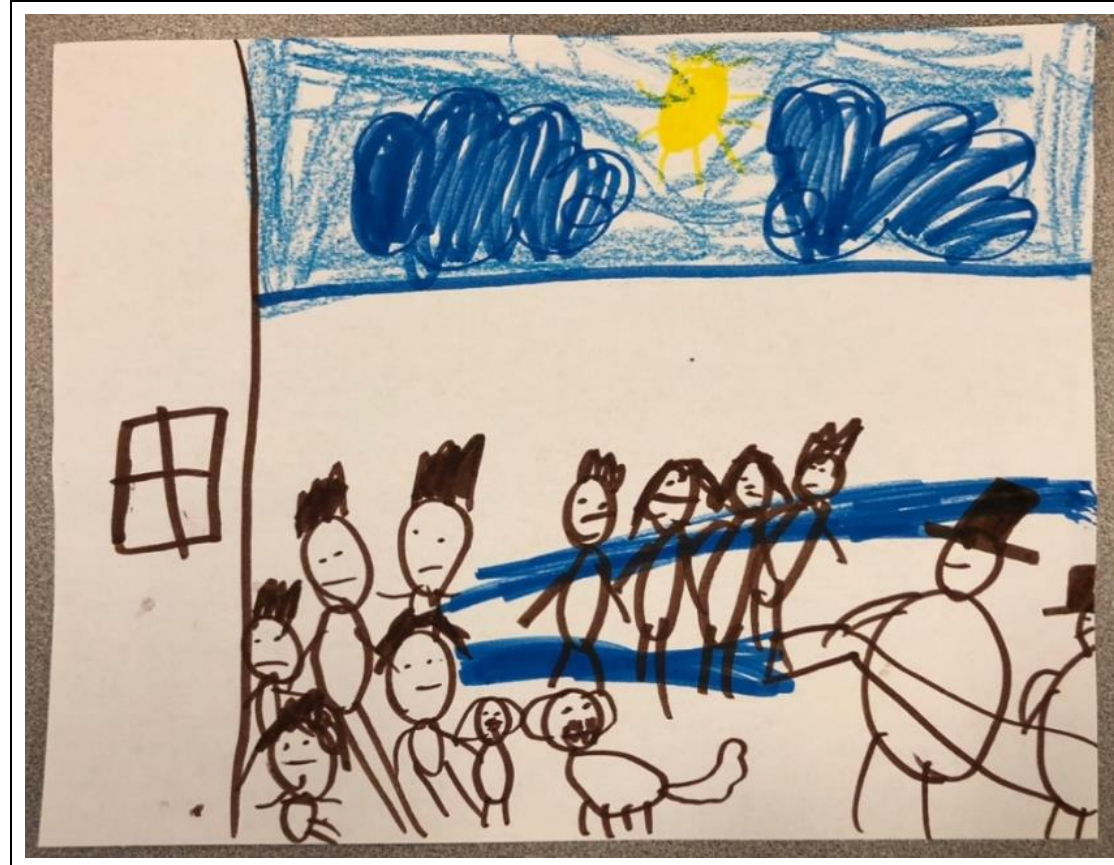

Kristoff explained, "Remember when we learned about how the police sprayed the kids with water? I made that. There was also dogs being mean to them. See, the kids are sad and the police look happy because they are being mean."

Figure 16. Kristoff's drawing. 


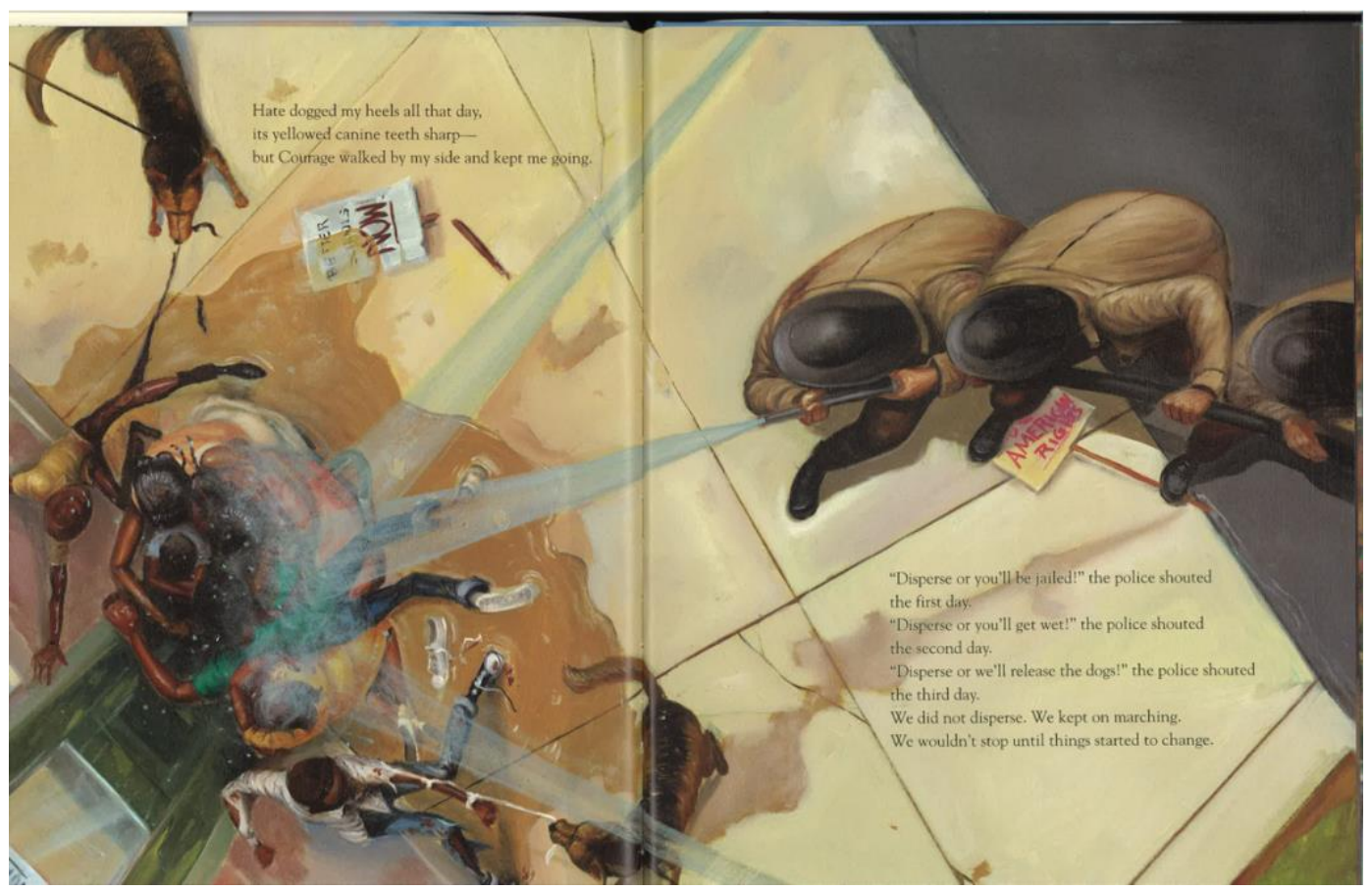

Figure 17. Illustration depicting child marchers being water hosed by the police. Image from Clark-Robinson, M., \& Morrison, F. (2018). Let the children march (pp. 19-20). Boston, MA: Houghton Mifflin Harcourt.

In their drawings, students continued thinking through what they had just read.

The story of children, around the same age as themselves protesting and even getting arrested seemed "... to be a mode of inhabiting and rupturing this episteme with our known lived and un/imaginable lives" (p. 18). This rupture is what Christina Sharpe refers to as "wake work" by disrupting "known lived and un/imaginable lives" of Black people living and dying through antiblackness. How might thinking with and through wake work with children help us think about the teaching and learning of topics of race and racism differently?

\section{Week Twelve}

A Conversation with Penny: "Where are the books about Black people and white people?" 
When I entered the classroom on this day, Ms. Rotter's class were beginning their reading and writing rotations. Different groups rotated through stations with the following selections: read on your own or with a partner, guided reading group with Ms. Rotter, and writing on your own or with a partner. During the first rotation, Penny was holding an iPad and sighing loudly. I noticed she was looking up and around the room so I walked over to her.

Oona: Do you need some help?

Penny: Well, it's just that (she sighs, silence for five seconds).

Oona: Is something wrong with it? (I gesture towards the iPad)

Penny: Well, it is just that I am looking for a book about white people and Black people. See? (She points at the search box in the electronic book library which shows she has typed "white people black people" but she received the message "no books found")

Oona: Hmmm. What kind of book are you looking for?

Penny: A book about white people and Black people.

Oona: I'm wondering_-(I pause for several seconds) — about a different way we could get to the books you are interested in. (I pause again). Since you are interested in books about people with different races, what if you searched for "race"?

Penny: Oh, that's a good idea. I'll put that in.

She deletes her original search terms and types in "race" and clicks search. The app brings up a screen that reads "no books found." 
Penny: See? (She sighs). I can’t get any books. Where are the books about Black people and white people?

Oona: This is tricky, isn't it? Maybe we could look at the books available and find the kind of books you are looking for on our own?

Penny: Okay.

Penny and I browse the book titles together until she found a book that told the story of slavery and a young girl's journey from enslavement to freedom.

Penny's search for books with the terms "Black people white people" was interesting. Her choice of original search terms seemed to make sense to her. However, when she shared them with me, I felt a recognition that these terms would not be in a keyword search, but did not share that thought with her. Instead, during later thinking and analysis I also wondered why these terms did not even bring up one book. I thought for sure entering in "race" as a keyword search would bring up at least a few books, but was even more surprised when the search came up as no books found. Penny's frustration resonated with me. Were young children not expected to be interested in learning about race? Why was there a book that she eventually found that was about the topic of slavery and centered on a person who was enslaved but did not include race as a keyword term?

I began to wonder if this happens to other students when they might be interested in learning more about people of different races and racism. With Ms. Rotter's consent, later on in the day I used the iPad to search on my own. I typed in keywords with in the search bar that I thought students might use including "racism," "difference," and "skin color" but continued to see the message: no books found. I have no way of knowing if this was an error in the app or search function, or another issue altogether but the incident 
caused me to question how we might support students inquiries when they are interested in learning about topics of race and racism. As I think back on it now, I would have liked to talk to Penny further, to discover more about what she was searching for and her interests. What did searching for "Black people white people" mean to her? What was it she wanted to know more about? Looking back at the way I responded, I see a lot of pauses in my response to her. I notice these pauses as hesitation and feelings of uncertainty. How could I have responded differently?

I wrote about Sharpe's (2016) example of the ship in Chapter 3, how the histories of the Holocaust and slavery in the United States are treated differently. Sharpe add further, "The disaster of the Holocaust is available as human tragedy in a way that slavery, revolution, and their afterlives are not" (p. 34). In this search by both Penny and I, we are looking for the afterlives of slavery (Hartman, 2007) in books available to young children. Throughout different searches, we come up empty. What might experiences like this teach young children? How might that skew their learning about topics of race and racism? While Ms. Rotter and I have worked together to intentionally provide her students with access to children's literature, I recognize that does not always happen.

\section{Strange Fruit: Billie Holiday and the Power of a Protest Song}

After the mention and question about lynching in the book about Ruby Bridges several weeks earlier, Ms. Rotter and I had discussed revisiting this topic with the students but were unsure of how. During our meetings we came across the picturebook Strange Fruit: Billie Holiday and the Power of a Protest Song and thought it might be a way to bring it up and see if the students were interested in talking about it further. I 
ordered the book and we planned for a time when we could read it. The book describes Billie Holiday, her career as a jazz singer, and the racism she faced when performing at jazz clubs or being banned from jazz clubs because of her race. The book then describes how Billie Holiday discovered the song Strange Fruit and her performance of it at Café Society. Ms. Rotter asked me if I would be willing to read it with the students and I agreed.

Oona: (Reads the title of the book). Does anyone have any idea of what a "protest song" is?

Charlie: I think it is song that talks about people who aren't treated fairly. You know, like those other books we have read about people who protested and marched when they didn't agree with things?

Oona: Oh, so you've made a connection. Between what this book might be about and other books you've read. Does anyone else have any ideas?

Penny: Maybe it is about Black people who weren't treated fairly. They are protesting the white people that are always making the unfair laws and rules?

Oona: Hmm. That's an interesting idea.

While Charlie brings up ideas of fairness when asked about what the word protest might mean, Penny brings about a thought of holding white people responsible, a different take. Over the past few months, I have noticed Penny taking a deeper interest in topics of race and racism. When Ms. Rotter and I talked later about what Penny shared, we were both surprised how her talk seem to demonstrate new thinking and a different direction in her thinking about racism. If Penny's understanding is that "white people are always making the unfair laws and rules" how might her understanding lead her to interrogate her own 
whiteness? How might Penny's question demonstrate a different thought and relationship with racism and protest? Writing about the weather and the aim of writing her book, Sharpe notes "I wanted to stay in the wake to sound an ordinary note of care. I name it an ordinary note because it takes as weather the contemporary conditions of Black life and death" (2016, p. 132). Does Penny's contribution show ordinary notes of care? For me, Penny's language and thinking over time have shifted. Several weeks earlier Penny questioned if her school treated everyone fairly and now she is beginning to recognize the legacy of white supremacy ("white people that are always making the unfair laws and rules"). A recognition of the oppression of Black persons embodies "ordinary note[s] of care" as it reckons with the contemporary conditions of life for Black people. How can educators shift their teaching and learning to curate "ordinary notes of care"?

We started reading the book and about halfway through I read from the page where Billie Holiday is introduced to the song "Strange Fruit" and the last line of the page reads: "It was a song about lynching."

Peter: I remember we read about [lynching] in the Ruby Bridges book.

Oona: Yes, I remember that.

Peter: So, I have a question. This was a long time ago, right?

Oona: Yes.

Peter: So, it must have been like the 80s, right?

Oona: It was the 1930s, so it was long before the 1980s.

Peter: Oh.

Penny: Actually, the 80s were not that long ago. 
Oona: It depends—-For some people it may seem like a long time ago. Peter, was there something you were trying to figure out?

Peter: Well, I just thought, if that happened, it must be a long time ago.

Peter, immediately responding, seemed to focus on the time period and perhaps wanting to know the proximity to his own life. Although I initially chuckled internally about the 80s being "a long time ago," I thought the question and discussion of it being a long time ago was interesting. Was it that Peter could only imagine this happening in a time long ago or was he attempting to understand when it occurred? In the theoretical concept of the wake Sharpe (2016) informs that "wakes allow those among the living to mourn the passing of the dead through ritual" (p. 21). How might young children questioning time and its proximity to their own lives encourage a mourning of people that have died as a result of antiblackness?

We continued reading but stopped at pages 23 and 24 shown in Figure 18 below. I read, “At a party in Harlem, Billie sang 'Strange Fruit.' Her voice, with Abel's words. Everyone in the apartment became quiet, and the smiles left their faces." I took a few moments of pause and then asked, "Why do you think the smiles left their faces?"

Kristoff: Well, well, everyone became quiet because people don't really like to think about people dying.

Alexa: Well, look at the people's faces. See the Black people and the white people have different faces. It is because they have different experiences because they are of different races.

Amari: I think the smiles left their faces because her other songs were different from this song. They weren't used to this song. 
Oona: Oh. Interesting. How do you think they felt?

Peter: They were surprised. This song made them sad.

Amari: Yeah, it is a really sad history.

Kristoff: I'm sad that it happened.

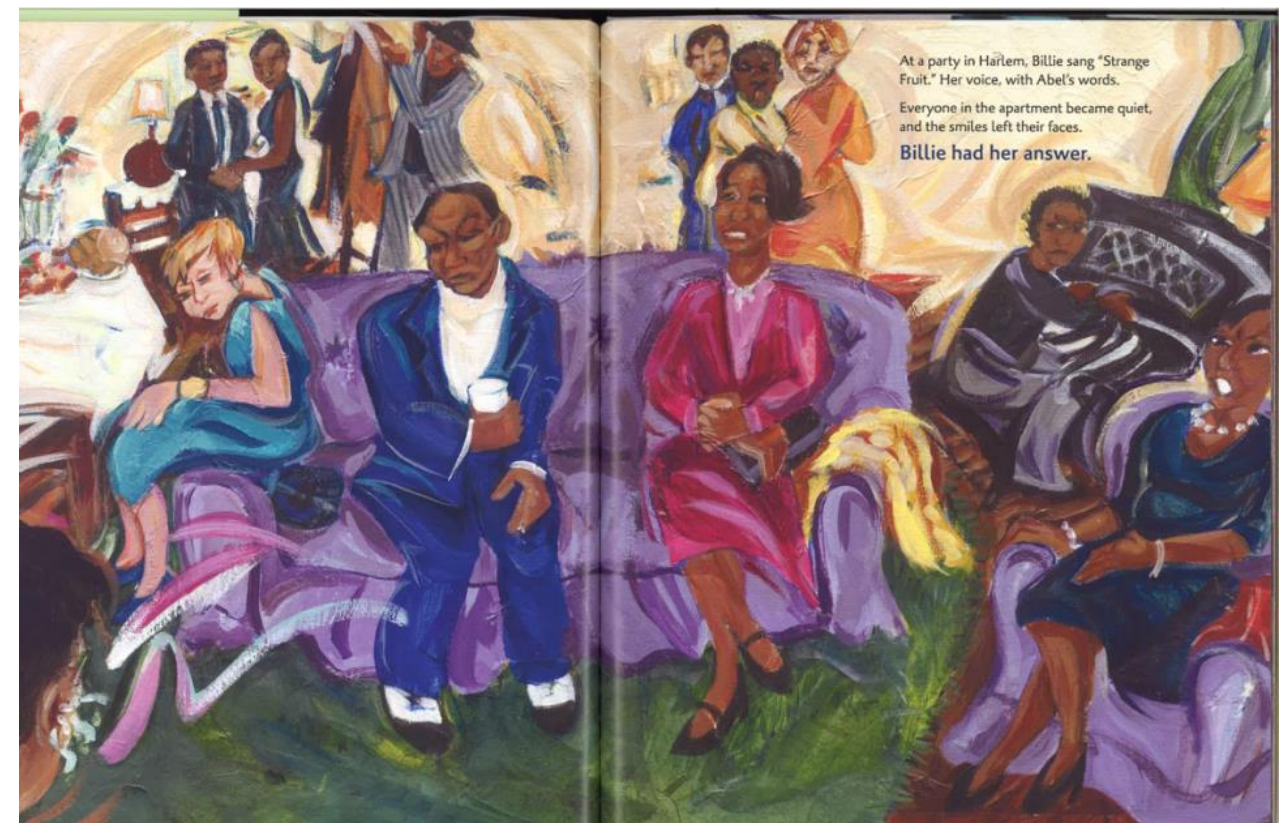

Figure 18. Audience members listening to "Strange Fruit" being performed. Image from Golio, G., \& Riley-Webb, C. (2017). Strange fruit: Billie Holiday and the power of a protest song (pp. 23-24). Minneapolis, MN: Millbrook Press.

The students engaged with the seriousness of learning about lynching in this conversation. Again, the wake, which positions the past as not past, and interrupts our present day existences is helping me to (re)think my conceptions of what young children can know and understand. Alexa recognized that your experiences in life are different due to your racial identity. While many of the children in the class recognized the sadness and difficulty of lynching history. They chose to allow themselves to feel sorrow in the moment for something that happened in the past, developing their present day connections. How does the recognition of the past as not a past interrupt commonly held notions of young children and their ability to think about hard history? 


\section{Week Thirteen}

\section{Opinion Writing: Should We Read Books about People of Different Races?}

Ms. Rotter and I discussed on multiple occasions how, much of the time, the ways that the students were being engaged in learning about race and racism were through conversations. We brainstormed ideas together for her students to express their thoughts, ideas, and questions in different formats and modes. One approach was for students to draw and illustrate. One example of this approach was in the earlier discussion of their responses after reading The Children's March. As we discussed other ideas, Ms. Rotter shared that the students in her class enjoyed writing. She discussed that the students seemed to show an intentional focus during writing that she did not always see during other times of the day.

Her class had been working on persuasive or opinion writing — stating an opinion and then writing supporting statements - and so I suggested, could she create opinion writing based on the teaching and learning about race and racism they had been engaged with? Ms. Rotter showed excitement about that idea and we worked together to come up with a question to begin. Based on the read alouds they had been sharing together, we came up with a question: Is it important to read books about people of different races? Why or why not?

To introduce the writing prompt, Ms. Rotter had everyone sit on the carpet and discussed an opinion writing prompt from earlier in the week that she had engaged them with. It was about their favorite movie, and they had described reasons to convince someone else to see this movie. Ms. Rotter then talked about the books they had been reading lately and that did they remember they were about people of different races? 
Most students nodded yes. Ms. Rotter said that today, she would like them to write their opinion about this. She asked them to take a stance on whether or not it was important for kids to be reading books about people of different races. Once they stated their opinion, they should write reasons to persuade the person reading their work to agree with their opinion. Ms. Rotter asked if anyone would like to share their opinion and a reason to persuade someone to support their opinion. Several students raised their hands to answer. Peter: Yes, I think it is important. Because, um, when you read them, you can learn about Black history.

Ms. Rotter: That's an important reason.

Charlie: I think it is important so we know how to treat each other fairly. And to make sure that Black people and white people are treated equal.

Ms. Rotter: Another important reason.

Alexa: We should read books about people of different races because people need to know about racism. They need to know there was a history where Black people are not treated fairly.

Ms. Rotter: That's important too.

Alexa: Because maybe if people don't learn it [racism], they might do those same things again.

Stephanye: I agree with it [reading about racism]. Because it is not fair how the white people acted. We should learn about that.

Ms. Rotter: Yes, also important. Anyone else?

Several seconds pass by with no response and so Ms. Rotter lets everyone know to go to their tables and begin writing. 
Students went to their tables and began writing. Ms. Rotter asked if it would it be helpful to have the question and some sentence starters on the board and many students answered or nodded yes. I have included her writing on the board in Figure 19. She and I walked around the classroom helping students who were looking for spelling assistance or other support to talk through questions and ideas. Below, I provide some of the student's writing. I asked individual students if they would read me their writing and then what they read to me is what I have transcribed next to the image of their writing in quotes. After the images of student writing in Figures 20 through 23 and transcription of their writing, I include discussion and analysis.

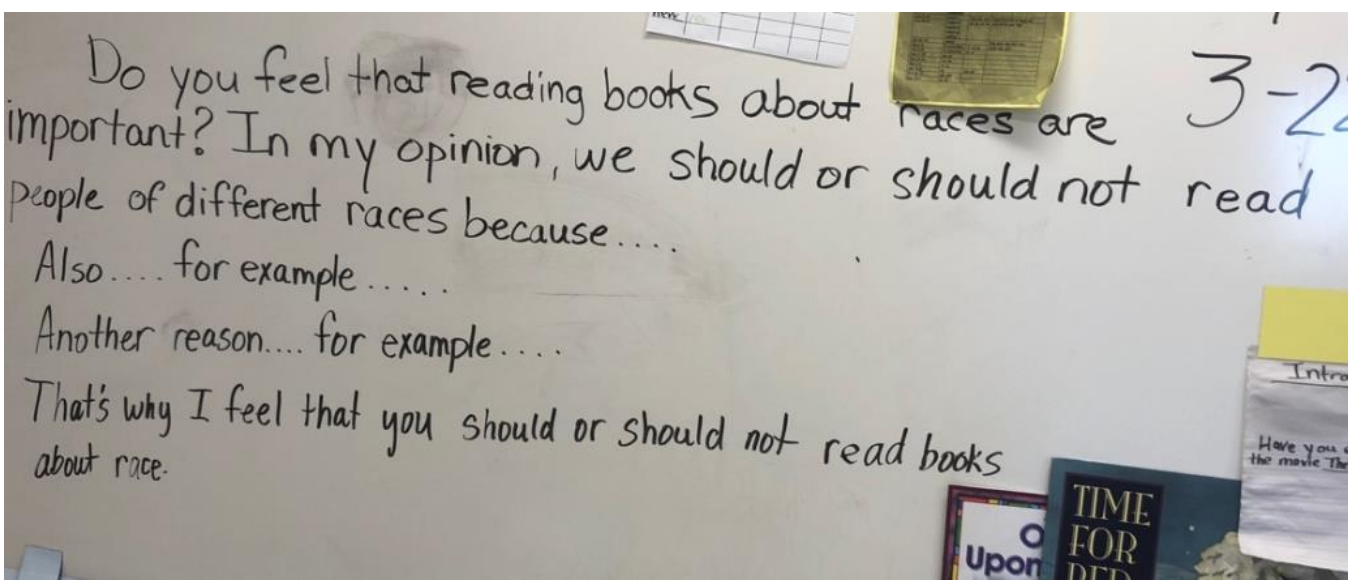

Figure 19. Ms. Rotter's question prompt for writing your opinion about reading books about different races. 


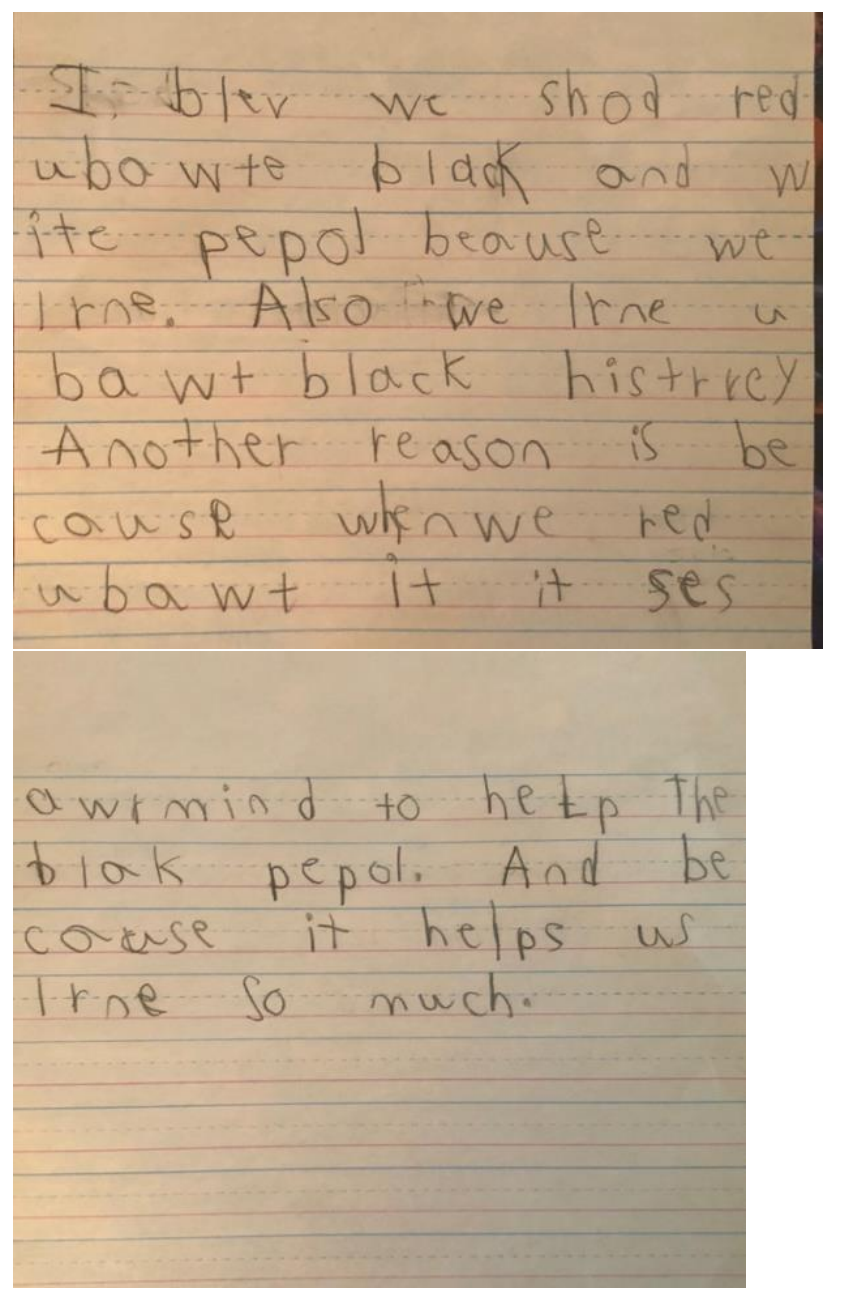

Figure 20. Penny's writing.

"I believe we should read about black and white people because we learn. Also we learn about Black History. Another reason is because when we read about it sets our mind to help the Black people. And because it helps us learn so much." 
"Do you feel that reading book about races are important? In my opinion, we should read

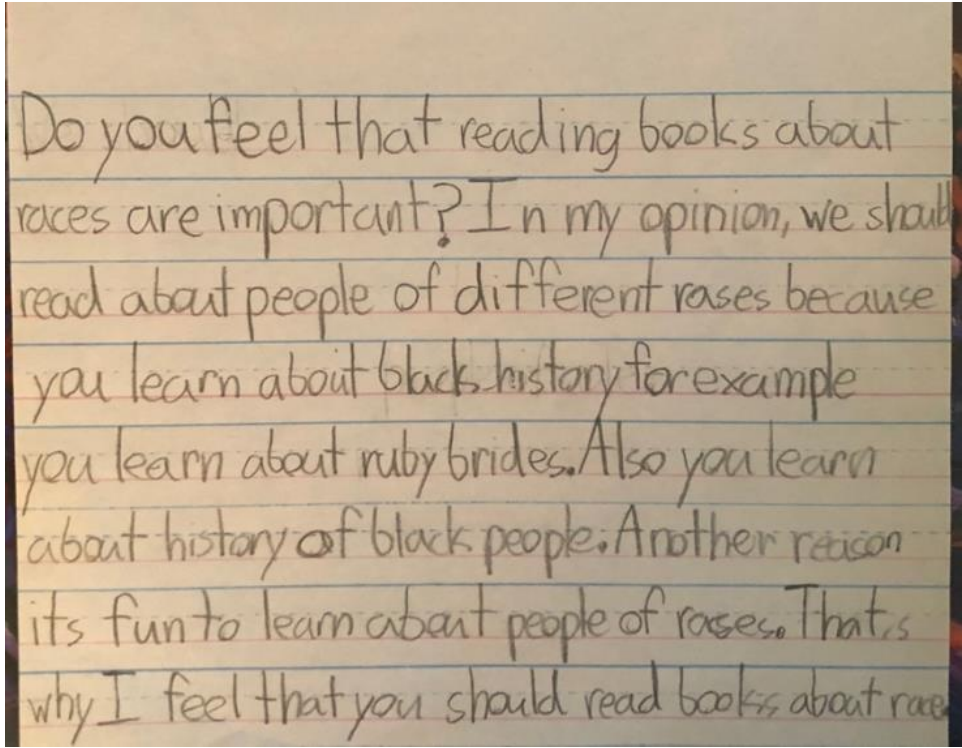
about people of different races because you learn about black history for example you learn about Ruby Bridges. Also you learn about history of black people. Another reason it's fun to learn about people of [different] races. That's why I feel that you should read book about race."

Figure 21. Peter's writing.

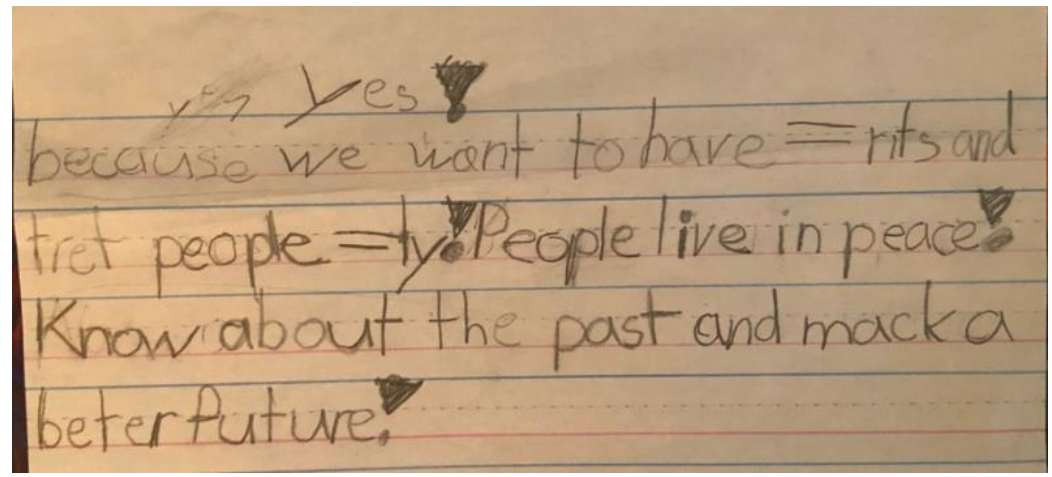

"Yes! Because we want to have equal rights and treat people equally! People [should] live in peace! Know about the past and make a better future!"

Figure 22. Charlie's writing. 


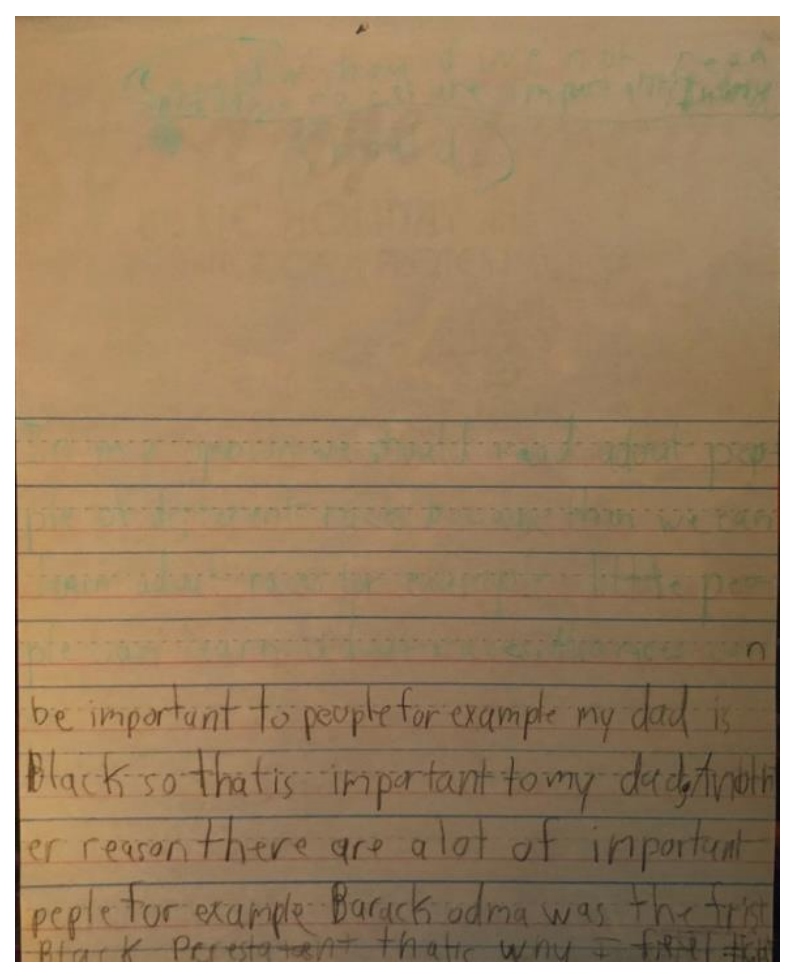

"In my opinion we should read about people of different races because then we can learn about races. For example little people can learn about race. Also race can be important to people for example my dad is Black so that is important to my dad. Another reason there are a lot of important people for example Barack Obama was the first Black President that's why I feel that you should read books

about race."

Figure 23. Alexa's writing.

Even after writing time was up, many students expressed wanting to continue writing their opinions and reasons. It was time for lunch and recess, so Ms. Rotter shared that they could save their writing papers at their tables spots and continue writing later. While the students were at recess, Ms. Rotter and I met for a short while to debrief. We both expressed excitement about how engaged the students were in writing and especially about this topic. We talked about how we noticed that some of the students who do not share as much during a read aloud or in group discussion seemed to be very engaged in this writing prompt. We also both discussed our surprise that most of the students did not ask for as much help getting started or expressed a need to conference about expanding their reasons when they typically do during writing. Ms. Rotter compared this writing 
time to the time earlier in the week where she had asked them to write about a movie where they seemed to have more difficulty.

Within many of the students' writing they wrote about learning about or knowing Black history as an important reason to read and learn about people of different races. Ms. Rotter and I talked about this and she said she felt "proud" that the students talked about Black history as important knowledges to learn about. Ms. Rotter said she planned to ask the students to engage in similar writing in the future and we planned for a day where we could meet to come up with new questions for her to share with her students.

In Penny's writing one can see her similar strand of interest and focus on learning about Black and white people. This has been her interest and focus for a while, and the example of the conversation she and I had when she was searching for an eBook demonstrates that. Her writing about how reading books about different races helps Black people is interesting. I wonder who she envisioned as the reader of the books and how that would help Black people.

Peter provided a clear example of what he believed to be important reason for reading about people of different races; learning about Ruby Bridges. I wondered about his use of the word "fun" when describing a reason why he believed it was important to read books about people of different races. I am unable to know what the word fun meant for him and what helped him make that word choice, but at first I was surprised. So much of the discussions and reading we had been doing about race and racism seemed difficult and somber, how could that be fun? Maybe, for him, he felt joy, pleasure, or fun learning about this and expanding what he knew. 
Charlie focused on equal rights in her writing and I smiled as I looked over her equal signs and familiar exclamation points. As she read her writing to me, she seemed to have an liveliness in her body language and voice. Charlie's focus on knowing the past and making a better future reminds me of the wake. How does Charlie's understanding of knowing the past as informing and influencing the future influence her perspectives regarding learning about race and racism?

Last, Alexa's writing contains many thoughts which she has shared and discussed in the interview with her and Amari, her large group conversations, as well as other contributions she has made throughout class. Alexa lets her audience know that "little people can learn about race.” Alexa seems to be advocating for herself and her peers to be fully included in conversations about race. Different than some of her classroom peers, who contributed thoughts about the learning and reading about topics of race and racism being helpful to everyone or people outside of themselves, Alexa shares that learning about race is important for Black people specifically.

After reading through the students' writing, I am struck that everyone in the class that day believed that reading about different races was/is important. These students have been in engaging with hard history: slavery, lynching, the fight for interracial marriage, people who protest being treated violently and sometimes imprisoned, death, segregated and unequal schooling, and more. I want to be careful not to romanticize and be idealistic about their ideas and their writing, however. Christina Sharpe (2016) writing about the weather asks,

...the repetition of the visual, discursive, state, and other quotidian and extraordinary cruel and unusual violences enacted on Black people does not lead 
to a cessation of violence, nor does it, across or within communities, lead primarily to sympathy or something like empathy...what kinds of ethical viewing and reading practices must we employ, now, in the face of these onslaughts? (emphasis in original, pp. 116-117)

I imagine when Sharpe wrote this she was thinking about adults, but I believe it can apply to children. So, I wonder, what kinds of ethical viewing and reading practices can we employ and enact with young children to lead to change? Is that possible?

That question is a difficult one and like many of the others posed throughout this chapter, I have no answer. I return to Sharpe who writes, "So we are here in the weather, here in the singularity. Here there is disaster and possibility" (2016, p. 134). We are definitely in both, and and and maybe more... more than words can hold, say, or contain. Our attempts will fail, creating and sustaining disaster, but perhaps they also hold possibility, for a world we have not yet lived and imagined to take hold.

\section{(In)Conclusion}

Within this chapter I discussed many moments that unfolded within Ms. Rotter's classroom. Over four months Ms. Rotter, her students, and I engaged with topics of race and racism, coproducing questions, ideas, and new understandings. I brought theoretical writing together with data in effort to collapse the hierarchy between the two and bring about analytical questions that cause new thinking, relating, and wondering. I have posed many, many analytical questions for those invested in the teaching and learning of race and racism in the early childhood classroom to think more deeply about.

The analytical questions are produced as contributions which I share through theoretical analysis of the different moments that took place in Ms. Rotter's first-grade 
classroom. The students in her classroom engaged with hard history, difficult topics, and shared their thinking, ideas, and questions. Their engagement in learning of race and racism demonstrates how capable young people are in this work. The questions produced from thinking with theoretical concepts from the wake and the moments in the classroom are difficult and demanding; yet, so is the work of teaching and learning about topics of race and racism. These are important questions to think through and in this chapter, at times I provide discussion, but I do not provide clear answers. I recognize that this practice deviates from conventional ways of thinking about what the contributions of research can and do provide. I do engage with some of these questions in the next chapter, but often by providing more questions. I intentionally do this, as a writer, to invite you in to think and wonder with me. The questions I have provided embody the process oriented methodology in which I have engaged during this research study. As I wrote earlier, I have flattened the relationship between data and theory, bringing them together "to shake us out of the complacency of seeing/hearing/feeling/thinking as we always have, or might have, or will have" (Jackson \& Mazzei, 2017, p. 720). In this next chapter I think through the discoveries with/in this research study and what they have to offer in terms of methodological, theoretical, and pedagogical contributions. 


\section{Chapter 6: Contributions}

Within this dissertation, I provided an in-depth discussion of different pedagogical moments that took place within Ms. Rotter's classroom over four months. In the discussion and analysis in the previous chapter, I included many analytical questions to bring the four theoretical concepts of the wake, ship, hold, and weather together with the moments that unfolded in Ms. Rotter's classroom. The analysis of these moments provide a multitude of theoretical, methodological, and pedagogical contributions for deeper thinking about the teaching and learning regarding topics of race and racism in early childhood classrooms.

In this chapter, I describe and discuss the contributions of this research study while bringing in several analytical questions introduced in the previous chapter. With an aim of clarity, I organize this chapter by methodological, theoretical, and pedagogical contributions. However, I believe that the lines these sections draw between methodologies, theories, and pedagogies are blurry. Although I organize the writing in these sections, I believe these contributions can work across these (arbitrary) divisions. Within the discussion below, while I elaborate on data and theory, at times, I also connect back to the literature, research, and theory discussed earlier in the dissertation. I include additional questions, thoughts, and ideas as persistent wonderings I continue to have regarding this research. I conclude by providing a discussion on future directions. As a reminder, the guiding question for this study was: How do early childhood students and their teacher navigate the wake while teaching and learning about race and racism?

\section{Theoretical Contributions}


The wake, as I have written earlier, is a complex theory which theorizes Black life in the aftermath of slavery. The wake as an overarching theory and the four analogies of the ship, hold, weather, and wake (which I describe as theoretical concepts) open up pathways towards recognizing and thinking of racism as interconnected with/in our past, present, and future. The theorizing within the wake urged my engagement with what seems to be our past as ongoing in our present day lives, informing the future we are

continuously creating. The wake provoked new configurations of thinking regarding how subjects of race and racism are taught and learned in early childhood classrooms. In addition, thinking with the wake, I considered what antiblackness looks like during discussions of race in this classroom, rethinking our orientations when teaching young children about topics of race and racism.

\section{Challenging Our Relationships To and With the Past}

Many of the moments within Ms. Rotter's classroom involved conversations and questions where I recognized the past, present, and future becoming fluid. The theory of the wake which distinguishes "the past as not past" helped me to see the importance of unsolidified time when thinking and learning about the effects of racism. Thinking with the wake opened up rigid conceptions of time and encouraged recognition of the way that histories and events which I assumed as past to be ongoing. In many of the picturebooks that we read and talked about, the wake helped me to see this process more fully. For example, when reading Separate is Never Equal and Penny asked "What about our school? Does our school do that?” when talking about school segregation. Penny's question wondered if it was possible that segregation practices took place at the school 
she and her peers attend. Penny seemed to be recognizing that the past was indeed not past.

In addition, one of Penny's responses provided another example. When reading Strange Fruit: Billie Holiday and the Power of a Protest Song, I asked the students what a protest song was and Penny added, "They [the Black people] are protesting the white people that are always making the unfair laws and rules." I have italicized the always in Penny's response because it seems to represent the ongoing nature of antiblackness as written about by Sharpe. Penny is naming whiteness and white people as perpetrators of antiblackness (unfair laws and rules). Perhaps Penny's statement assists Penny and her peers towards exploring the complexity of how antiblackness functions.

Additionally, in their interview, Amari and Alexa talked about and acted out the fluidity of time. When I asked them about their learning of race and racism and their own identities. Amari and Alexa began by presenting stories of ancestors they did not know. Alexa referred to "back in the day" and Amari added "Like, when Black people were slaves." They (re)mix these histories with actual histories that their families passed down to them. They both connected these histories together to imagine how their own lives would be changed. They formed a bond between themselves and the past.

In Chapter 5 I presented the following analytical question: How are Alexa and Amari mixing past, present, and future to create new understandings of antiblackness might work? As Amari and Alexa performed and talked to me about how their lives were entangled with the past, I thought with the wake. I remembered Sharpe's (2016) analogy of the wake and how race and racism makes cuts, rippling all of our lives "in the wake, the past that is not past reappears, always to rupture the present" (p. 9). I asked Amari and 
Alexa if "anything like that happens anymore?" desiring to know their connections to present-day and future. They both agreed that it does, and Alexa connected that Ms. Rotter has taught them "that stuff still does happen." Amari and Alexa described the "stuff" as segregation, sexism, and potential anti-Black sentiment by their peers (e.g., "white people are better"). They saw antiblackness as an active process continuing to occur in their lives. Ms. Rotter also discussed antiblackness and racism as an active and current process as well. During one of our meetings I asked Ms. Rotter: "Do you intentionally try to teach students about the ways racism exists today? Why and how?" She responded,

It is kind of like what we read [the wake] and talked about, antiblackness. Racism is still happening and ongoing, not over. I want to teach the truth about the past and future. I just want them to know the truth so they can form their own opinion. I think all students need to know about it. So yes, I intentionally teach about racism.

Ms. Rotter understands racism as "still happening and ongoing, not over" and connects her recognition to the parts of the wake which we read together, and the theory of antiblackness. Within her deliberate pedagogical choices, Ms. Rotter not only wants students to know about racism, she believes that they need to know about it. Thinking and learning with the theory of the wake creates a different consciousness of the past as not past — as students, teachers, and researchers navigate the sea of antiblackness. This insight brings together the theoretical and the pedagogical; causing one to see how theory can be pedagogical. Ms. Rotter's response, her intentional choices as a teacher, as well as 
many of the pedagogical classroom moments demonstrates how she continues to see racism still happening and how to teach about it.

How might thinking about the wake help us recognize the fluidity of time when teaching and learning about race and racism with children? Rather than a focus on understanding and recognizing time periods, we can provide opportunities for children to collapse the space between events and wrestle with how their lives continue to be affected by racism. The theory of the wake helped me see these relationships among time, and the teaching of race and racism differently.

\section{(Re)thinking Orientations When Learning About Race and Racism}

When Sharpe wrote about the different theoretical concepts in the wake, she often presented visual imagery as a way of (re)presenting and embodying her theoretical contributions. One example, as I discuss in Chapter 3, is the proposed art installations surrounding the St. Louis Arch by Charles Gaines. In Ms. Rotter's classroom, I often observed visuals and imagery facilitating different relationships with what the students were learning about. When reading the book, Separate is Never Equal, Kristoff asked about the page which showed white people swimming in a pool with a sign that read "No dogs or Mexicans allowed." Kristoff had a strong reaction which led to a larger discussion of his intention for "white people should go to the other side of the earth." Kristoff's response to the image engaged many students in a lively discussion and debate of his frustration with "white people" and led to complex discussion of race, racial identities, and assumptions.

When students were invited to respond through visuals after reading The Children's March, Ms. Rotter and I noticed that some students who didn't talk as much 
in class felt more comfortable expressing their ideas through drawing. One example is Marshall who shared his depiction of students marching "because they want freedom" and "they don't even care if they're arrested." There were several picturebook illustrations that were described as sad that seemed to enable students to further engage with topics of race and racism, such as when Margaret noticed that Mildred Loving was crying. Another example is from the Strange Fruit picturebook when Billie Holiday sang "Strange Fruit" for the first time to an audience. The narrative of the book described that "the smiles left their [the audience] faces." Alexa acutely notes that the white and Black people in the crowd have different expressions. She concludes that white and Black people "have different experiences" of racism. Illustrations and visualizations of racial injustice can assist students with having transformational and aspirational relationships with racism and antiblackness.

Differently, 'the wall' was not an intentional image within a picturebook or from an illustration. Instead, it was part of conversations, brought from students' everyday lives and CNN 10 News. Still, a visual representation of antiblackness, the students in the class debated 'the wall.' Bringing in the concept and visual of 'the wall' provoked different classroom conversations. 'The wall,' and anti-Black sentiment contained within, is the theoretical concept of the hold. With 'the wall': "We are, though, living in the afterlives of that brutality that is not in the past" (Sharpe, 2016, p. 99). The hold, the brutality of 'the wall' that is indeed not in the past. As Garlen (2018) shared, childhood innocence is a way of preserving whiteness. Rather than view children as too innocent to discuss such matters and shut down students dialogue, Ms. Rotter provided space for the 
students to engage in respectful discourse regarding the connection to race and racism and 'the wall.'

While Sharpe draws important points about the importance of visualizations and art in recognizing and understanding the wake; this research adds understandings of what this might look like for young children. Some examples include: seeing and learning about the Birmingham Children's March of 1963, 'the wall,' and seeing the segregated water fountains in The Case for Loving: The Fight for Interracial Marriage. How we provide and facilitate different orientations are important to consider in the teaching and learning of race and racism topics with young children.

In this research study, book selection was important. Although conversations about race and racism did not only occur through literature, it was a central approach to open up spaces for new learning, insights, and conversation starters. Ms. Rotter already valued diverse, multicultural literature (Bishop, 1990; Botehlo \& Rudman, 2009). However, through our work together, we developed a robust library of literature to share with students. We spent time looking at and talking about children's literature together. I brought books into our meetings and then into her classroom (after talking about and agreeing on them together). I often shared newer and recently published children's literature into the classroom, as we were eager to learn how the students might respond. We collaborated by building this ongoing collection together, selecting picturebooks that centered stories of race, racism, and/or People of Color. Ms. Rotter and I did not have pre-set criteria, instead these picturebook selections came upon more organically from our experiences and learning. For example, Ms. Rotter would stay in contact with her school media specialist to learn of new and upcoming titles that fit this criteria. While I, 
on the other hand, often looked towards award winning lists, or online literacy

newsletters and bulletins to learn of new titles. Learning from Boutte et al. $(2011,2017)$, I aimed to be careful to provide varied perspectives about race and racism through literature; making sure that the lens of oppression was not the only way we approached this topic. In Appendix A I have included a reference list of the literature we shared with the students. Thinking of future research, developing a more clear criteria of how we selected the picturebooks shared might be useful.

\section{Methodological Contributions}

Earlier in the dissertation, I wrote about considerations and deliberations I made throughout the research study when working with Ms. Rotter and her students. I continuously strove to be aware of the processes that I was engaging in to make sure I was respecting the ideas and needs of the students and teacher (Ms. Rotter) involved in this research study. Below, I discuss two methodological contributions. The first recognizes that the choices we make with children matter. The second contribution discusses how our work-with and description of teachers in our research matters.

\section{The Choices We Make With Children Matter}

I inquired in Chapter 5: What kinds of ethical viewing and reading practices can we employ and enact with young children to lead to change? As I briefly mentioned earlier in this dissertation, Ms. Rotter has cultivated a classroom community where students have some autonomy. Not only does this mean that students have choice in (for example): reading materials; choosing where to sit, stand, or move as they work; and also in their participation. Students that are having a hard day are given the benefit and respect of time to feel ready to participate. In addition, in this research process, I followed those 
leads. For example: asking the children if I could record conversations or photograph their work; letting them know they could turn the recorders off if they wish; and an openness to listening to their ideas about the directions for the learning about topics of race and racism.

With these considerations guiding the structure of the classroom, specifically regarding the teaching and learning of race and racism, Ms. Rotter has continuously shared with me that she believes that children can talk about the real issues of racism. Her belief in what children can do and respect for their capabilities is important. As she shared with me:

I try to find ways for students to learn [about race and racism] so it means something to them. Reading books and watching CNN 10 [news show made for elementary students] allows for something to come up that revolves around racism. When questions come up, I welcome it. I just do the best I can. I don't know it all. But I can try.

Ms. Rotter and I both, then, worked as hard as we could to consider the students' agency and participation in this research study. Not only did we approach students with our ideas and questions about race and racism, they approached us as well. We both remained open to where their thoughts and ideas might lead. How might young children's agentic ways of learning and thinking about race and racism be closely thought of as we craft and refine our research studies? In one of the last moments shared from Ms. Rotter's classroom in the previous chapter, Alexa shared in her writing that "little people can learn about race." Alexa was advocating for herself and her peers to be included in learning about race. Over time, Ms. Rotter and I learned and grew our practices to fully involve 
the children in our thinking process(es). These reflexive choices are methodologies which educators and researchers can embrace to recognize young children as already having important knowledge and ideas to contribute to the teaching and learning of race and racism.

I engaged in this research study curious about how children consented (or not) to be part of studies. I located few research studies that overtly focused on the teaching and learning of race and racism with young children and also discussed the consent and assent process. In studies such as Beneke and Cheatham (2017) and Rogers and Mosley (2006), for example, I found no such discussion. Did students have choice in whether or not they wanted to be recorded? Did these students know where and how the data that they produced was shared with the world? The students in Ms. Rotter's class were very interested in the recordings and would often ask to listen and watch them. Ms. Rotter and I worked to share this research(ing) process with the students in her class. For example, I had a discussion with Alexa about her words used as a title for the dissertation, asking her thoughts about that. Additionally Ms. Rotter shared a draft of this full dissertation with the class, reading parts with them, sharing the images of books that had been read, and reading back transcripts. Peter, specifically was fascinated by the length of the dissertation once compiled.

As I discuss earlier, being a researcher in the classroom provided a different sort of relationship where I was solely responsible to be curious about children (Albon \& Rosen, 2014). I embraced this opportunity and reviewed recordings with students, asked questions of them, and took the opportunity to get a fuller understanding of them as agentic people. Amari and Alexa, in their interviews with me, disrupted my (incorrect) 
assumptions. I was attentive to and worried about how my role in the classroom might create feelings of invading or taking over the space for some students. I thought about ways I could bring in provocations to stimulate new thinking and learning. Instead, they both approached me on multiple occasions to ask me questions, share their ideas, and tell me things I should know. Amari and Alexa asserted their power and knowledge of the wake, the way that antiblackness may continue to be ongoing in everyday lives, in order to teach me, Ms. Rotter, and the students in the classroom.

\section{How We Work-With and Conceptualize Teachers Matters}

Teaching young children about topics of race and racism is hard work. As many scholars have noted, this work is personal and requires intentionality, reflexivity, and deep engagement (Boutte et al., 2011; Husband, 2018; Kuby, 2013). I had the privilege of learning from and with Ms. Rotter for almost two years. Building a relationship of trust, collaboration, and learning takes time. I intentionally planned time for us to get to know each other, observe her teaching, and discover ways to support her professional growth.

I think often about how I have described Ms. Rotter, how I share her pedagogical practices and choices with others, and ways I might conceptualize her work with young children. So much educational research takes place in classrooms. As researchers we have the opportunity to see and learn so much, but we are always missing something. Do we own up to our fractured and partial views? We need to be careful in our critiques not to dismiss, diminish, or disparage the important work of teachers. What are some of the ethical commitments we might maintain to think of teachers from asset-based perspectives? Sometimes teachers are co-authors of research studies (Boutte et al., 2011), and sometimes they are the sole author of the study (Kuby, 2013). However, in this case, 
I am the one who has the authorship on this piece of research. As a result, I aimed to be intentional in presenting my knowledge as my own experience in this research study, making sure to tell my perspective. As researchers, our work-with educators can only become fertile and more substantial if we maintain aims of transparency in owning up to these partial and unfinished views.

I shared my aims with Ms. Rotter and the tensions I often feel about describing and writing about her with others. I asked Ms. Rotter to share her thoughts about working with me, and she wrote:

Working with Oona has taught me so many insightful things about teaching about race, racism, and diverse literature. Students form their own opinions towards different issues. Oona does a great job teaching in my class. When Oona comes in the class she jumps in, and works with me to help with whatever subject I am teaching. After working with Oona, an average read-aloud now goes about 30-45 minutes because of the conversation that takes place with the class. We take all the students' views into consideration and don't let students shy away from the conversation. Even those students that don't speak much normally, get to share different viewpoints. Oona and I allow for all of them to be listened to. I appreciate that in my work with Oona we have allowed students to immerse themselves in the classroom to learn about different races, cultures, discuss customs, reflect on traditions, and acknowledge differences in a positive way. Working with Oona about teaching topics has been positive and engaging for me and my students. 
Ms. Rotter shared the different work we have done together and how she feels that it has enhanced her classroom and her practices as an educator. Michael (2015), who guided much of the way Ms. Rotter and I conceptualized our work together, wrote that inquiries about race in schools "have the potential to either build or erode relationships and trust" (p. 2). We must take steps in research(ing) processes to foster and build relationships of trust with teachers when supporting their teaching of topics of race and racism.

\section{Pedagogical Contributions}

The choices educators make matter. Often, it is the everyday mundane - just as climate, weather- where difficult conversations about race and racism happen. In the small moments, the pauses, the silences. I discuss two pedagogical contributions that have emerged in this study. The first centers on Sharpe's "ordinary notes of care" and how I saw these unfold in Ms. Rotter's classroom. The second is the value of uncertainty that I observed in Ms. Rotter's classroom and how uncertainty assisted the students in Ms. Rotter's classroom with working through difficult ideas and conversations about race and racism, while recognizing that the past is not past.

\section{Fostering "Ordinary Notes of Care"}

Christina Sharpe (2016) throughout In the Wake: On Blackness and Being continuously includes conceptions of care throughout her theorizing. For example, writing about the weather, Sharpe noted, "I wanted to stay in the wake to sound an ordinary note of care. I name it an ordinary note because it takes as weather the contemporary conditions of Black life and death" (2016, p. 132). In Sharpe’s description, care exists as a noun; an entity to be created and nourished as important. MerriamWebster (2019) defines care as "a disquieted state of mixed uncertainty, apprehension, 
and responsibility and painstaking or watchful attention." I was challenged by these notions of care. I've always associated care with a kindness or niceness. Instead, seeing care as attention, uncertainty, and responsibility provokes newness for me.

What does care look like in the wake with young children? One way I saw this care is through the practice of holding each other accountable. In many of the moments I shared in the previous chapter, students disagreed with each other in their conversations about race and racism. For example: Kristoff shared his belief that race was the color of someone's skin and Amari pointed out that sometimes it is not, and in fact there is more to race than just skin color. The disagreement is care towards watchful attention to what might be untrue. Stephanye objects to being called brown, stating that she is Black and should be called as such. Stephanye, challenging and disagreeing with the term Kristoff used for her racial identity, vocalizes an ordinary note of care. This action is responsibility amid apprehension that does indeed take Black life into consideration.

I previously posed the following analytical question: How can educators shift their teaching and learning to curate "ordinary notes of care"? In her writing response to the prompt about whether people should read books about people of different races, Charlie wrote: "Yes! Because we want to have equal rights and treat people equally! People [should] live in peace! Know about the past and make a better future!" Charlie's writing included the equal sign and many exclamation points. Charlie excitedly shared her writing with Ms. Rotter and me, reading and pointing to her words. What sort of "ordinary notes of care" might be present in this exchange? At first glance, I wondered about the language of equal: can equality ever be a reality with our (not past) history? But then I looked deeper and observed Charlie's way of expressing herself - through equal 
signs, elaborately designed exclamation points, and her own style. I was brought back to the classroom lessons I have observed where teachers insist students complete opinion writing within a specific structure. That did not happen here; instead the way that Charlie wanted to express her watchful attention to this issue was recognized and seen as valuable by Ms. Rotter. Charlie was objecting to racism, demonstrating that racism did not allow people to live in peace, fostering an "ordinary note of care." Further, Sharpe (2016) wrote about care in the theoretical concept of the wake:

I want to think 'care' as a problem for thought. I want to think care in the wake as a problem for thinking and of and for Black non/being in the world. Put another way, In the Wake: On Blackness and Being is a work that insists and performs that thinking needs care and that thinking and care need to stay in the wake. (p. 5, emphasis in original)

When I read this quote, I think about the moment when Amari shared with Alexa and I in the interview that Kristoff had talked about separating people with 'the wall' and that it was "too much." I think about this moment often and the violence experienced by Amari and Alexa of hearing a fellow student sharing anti-Black sentiments. Not just for Amari, but I wonder: How often are Black students and other Students of Color experiencing this sort violence and are they provided space to work through it and reject it? What's the alternative, silence or shutting down conversations? Copenhaver-Johnson (2006) informed us that silence still teaches. Do we want racism inherent in such silences to be the message transmitted? As Hartman (2017) stated, in a symposium about the wake, "care is the antidote to violence." 
I hope by providing space for Amari to talk through her classroom experiences, she felt heard and listened to. When I asked them about it, she and Alexa believed that their multiracial identities assisted them with teaching their classmates. Amari and Alexa, in their conversation with me, assumed that some students held anti-Black views. Can we provide Black students and Students of Color "ordinary notes of care" as a place to talk through the antiblackness present in their in-school lives? How can we make sure these ordinary notes of care work towards healing?

\section{Valuing Uncertainty}

As I spent time in Ms. Rotter's classroom and engaged in analysis, I noticed that Ms. Rotter did not directly ask the students about how to solve the problems of racism. She did not ask for answers or hypotheses. Instead, sometimes silences hung in the air, or she responded with "Hmm" or "Ok" or "Thank you for sharing." I learned greatly from watching her allow this uncertainty to dangle within the classroom. I began to recognize the internal pressures I felt inside to know, to understand. Instead, engaging in this work with Ms. Rotter has helped me to slow down and think. I still do not necessarily have an answers to many questions, and that is okay. Discovering answers to persistent questions takes time and is part of my aim when providing unanswered questions. Learning from Ms. Rotter when I read, worked, or taught with the students, I endeavored to mirror her open-ended and uncertain responses. When working with young children, do we provide ourselves and others this slowed down time? I recognize that slowed down time is a privilege and that racism and antiblackness are urgent problems. Although they may initially seem in opposition, I think these things together; how can we urgently attend to the teaching and learning of topics of race and racism, while decelerating solutions? This 
both/and attends to Sharpe's (2016) to become undisciplined, to teach and think about race and racism through differing modes and methods.

What could the practice of urgently pursuing questions while refusing quick answers do to recognize the problems of race and racism? In this dissertation, my process of thinking with theory, presenting analytical questions aims to do just that. In a quote which I have referred to often, including the paragraph above, Sharpe (2016) directed, "We must become undisciplined. The work we do requires new modes and methods of research and teaching; new ways of entering and leaving the archives of slavery" (p. 13). Undisciplined is refusing to do what has already been done and engaging in risky teaching with uncertain outcomes, but that also fosters "ordinary notes of care." I also recognize the tension this creates for teachers who are often expected to know all, be experts in their field, as well as researchers who are often expected to produce definitive knowledge. Yet, as I discussed earlier, we can only claim partial and fractured views and if we own up to our fragmented understandings and perceptions, perhaps we might be able to embrace uncertainty and remain open to being changed by Others.

When Ms. Rotter and I outlined a plan to engage the students in reading and conversation about lynching we thought carefully about this. How can we teach and make sure not to (re)injure the Black students in the class when teaching hard history? Part of it was the preparation involved, such as thinking intentionally about questions/prompts we asked and children's literature we shared. As much as Ms. Rotter and I talked through our intentions and thought of possible questions, there were still many unknowns about what would emerge. We wanted students not to see Black people just as the victims of lynching, but that there was an active perpetrator. In an effort to not cast Black people as 
simply oppressed victims, our choice of reading Strange Fruit was a narrative of a Black woman (Billie Holiday) singing her truth, starting a conversation, and changing relationships with the outcomes of antiblackness (lynching). These are some examples of how early childhood educators can take risks of uncertainty, while fostering ordinary notes of care, and consider the wake in their teaching with young children.

\section{(In)Conclusion}

As I have just discussed, there are many contributions from this dissertation research study. The theoretical contributions demonstrate the value in recognizing more fluid conceptions of the past, present, and future as well as (re)thinking our orientation for ourselves and our students when learning about race and racism. Bringing the theory of the wake into the pedagogical practices in a classroom has been productive and produced new questions, thinking, and knowledge. This is a theory, to my knowledge, that has not yet reached the field of early childhood education. Yet, a limitation of the theory of the wake is recognizing how class and/or gender plays a role in examining how notions of antiblackness unfold in spaces with young children. For example, as I discussed in Chapter 4, RB Elementary draws from some of the highest priced homes in Acacia. How might (re)thinking Amari and Alexa's insights, questions, and contributions with the addition of a class based and/or gendered perspective bring about new understandings of their ways of navigating the wake? How might economic resources act as currency, assisting their naming of anti-Black thinking and actions? How would an analysis which recognizes Amari and Alexa's intersectional identities as biracial girls provide new insights? Bringing a class-based and/or gendered analysis within the theorizing of the wake has generative possibilities. 
Methodological contributions more closely examine how we make inquiry related decisions and choices with young children. Young children's autonomy and agency are important when engaging in race related learning. Additionally, how we work-with teachers matters in the learning of race and racism as well. Are we attentive to their interests, desires, and capabilities? How can we (university researchers) build relationships of trust? The pedagogical contributions focus on a new way of recognizing and fostering care - while residing in the wake and "providing an antidote to violence" (Hartman, 2017). Subsequently, I advocate for pedagogical uncertainty. Racism and antiblackness are difficult and fracturing processes. Taking time to let silence permeate and questions linger have hopeful possibilities as they allow us to travel to ideas yet unknown, considerations we have not yet imagined, and actions we will pursue.

Nevertheless, I deny a clear conclusion. Sharpe states that racism is "the engine that drives the ship of state's national and imperial projects" (2016, p. 3) and yet Alexa wrote that "little people can learn about race." How will we listen to, trust, and include young people in decisions about driving the engine? How might they open up and shift the possibilities of where we may drive? With care, trust, relationships, and uncertainty we can begin to chart a course. 
Appendix A: Children's Literature

Alko, S., \& Qualls, S. (2015). The case for Loving: The fight for interracial marriage. New York, NY: Arthur Levine Books.

Bridges, R., \& Lundell, M. (1999). Through my eyes. New York, NY: Scholastic.

Brown, D., \& Thomson, A. (2015). Who was Malala Yousafzai? New York, NY: Grosset and Dunlap.

Brown, M., \& Palacios, S. (2011). Marisol McDonald doesn’t match/Marisol McDonald no combina. San Francisco, CA: Children’s Book Press.

Campell, N. I., \& LaFave, K. (2008). Shin-chi’s canoe. Toronto, Ontario: Groundwood Books.

Celano, M., Collins, M., Hazzard, A., \& Zivoin, J. (2018). Something happened in our town: A child's story about racial injustice. Washington, DC: Magination Press.

Clark-Robinson, M., \& Morrison, F. (2018). Let the children march. Boston, MA: Houghton Mifflin Harcourt.

Cline-Ransome, L., \& Ransome, J. E. (2012). Words set me free: The story of young Fredrick Douglass. New York, NY: Paula Wiseman Books/ Simon and Schuster.

Coleman, M., \& Geter, T. (1996). White socks only. Chicago, IL: Whitman and Company.

Demsey, K., \& Cooper, F. (2014). Dance like starlight: One ballerina's dream. New York, NY: Philomel Books.

DiPucchio, K., \& Pham, L. (2008). Grace for president. New York, NY: Scholastic. Golio, G., \& Riley-Webb, C. (2017). Strange fruit: Billie Holiday and the power of a protest song. Mineapolis, MN: Millbrook Press. 
Gonzales, M., \& Amini, M. (2017). Yo soy muslim. New York, NY: Simon and Schuster.

Harrison, V. (2017). Little leaders: Bold women in Black history. New York, NY: Little Brown Books for Young Readers.

Higginbotham, A. (2018). Not my idea: A book about whiteness. New York, NY: Dottir Press.

Hooks, G., \& Bootman, C. (2016). Tiny stitches: The life of medical pioneer Vivien Thomas. New York, NY: Lee and Low Books.

Hooks, G., \& Kennedy, K. (2017). If you were a kid during the civil rights movement. New York, NY: Scholastic.

Hudson, W., \& Hudson, C. W. (Eds.). (2018). We rise, we resist, we raise our voices. New York, NY: Crown Books for Young Readers.

Kissinger, K., \& Bohnhoff, C. (2014). All the colors we are: The story of how we get our skin color/Todos los colores de nuestra piel: La historia de por qué tenemos diferentes colores de piel. Redleaf Press.

Latham, I., Waters, C., Qualls, S., \& Alko, S. (2018). Can I touch your hair? Poems of race, mistakes, and friendship. Minneapolis, MN: Carolrhoda Books.

Lé, M., \& Santat, D. (2018). Drawn together. Hyperion Picturebook.

Lester, J., \& Barbour, L. (2008). Let's talk about race. New York, NY: Harper Collins Publishers.

Love, J. (2018). Julián is a mermaid. Somerville, MA: Candlewick Press. Morales, Y. (2018). Dreamers. Neal Porter Books. 
Nelson, K. (2013). Heart and soul: The story of America and the African Americans. New York, NY: Balzar and Bray.

Ramsey, C. A., \& Cooper, F. (2013). Ruth and the green book. New York, NY: Scholastic.

Rappaport, D., \& Collier, B. (2007). Martin's big words: The life of Dr. Martin Luther King, Jr. Hyperion Books.

Redding, L., \& Boyd, A. (2016). Calling the water drum. New York, NY: Lee and Low Books.

Reicherter, D., Hale, C., \& Penh, B. (2018). The Cambodian dancer: Sophany's gift of hope. Tuttle Publishing.

Sanna, F. (2016). The Journey. London, UK: Flying Eye Books.

Shetterly, M. L., \& Freeman, L. (2018). Hidden figures: The true story of four Black women and the space race. New York, NY: Harper Collins.

Spilsbury, L., \& Kai, H. (2018). Racism and intolerance: Children in our world. Hauppage, NY: Barron's.

Tonatiuh, D. (2014). Separate is never equal: Sylvia Mendez and her family's fight for desegregation. New York, NY: Abrams Books for Young Readers.

Tudor, A., \& Tudor, K. (2018). Young water protectors: A story about standing rock. CreateSpace Independent Publishing.

Warren, S., \& Casilla, R. (2012). Dolores Huerta: A hero to migrant workers. Las Vegas, NV: Two Lions Publishing.

Wilson, J., \& Pippins, A. (2018). Young, gifted and Black: Meet 52 Black heroes from past and present. Minneapolis, MN: Wide Eyed. 
Winter, J., \& Ford, A. G. (2010). Barack. Katherine Tegen Books.

Woodson, J., \& Lewis, E. B. (2001). The other side. New York, NY: Putnam Books.

Woodson, J., \& López, R. (2018). The day you begin. New York, NY: Nancy Paulsen. 
Appendix B: Consent Letter and Forms Given to Families in Ms. Rotter's Classroom

November 8, 2018

Dear Parents and Guardians of a student in Ms. Rotter's classroom,

My name is Oona Fontanella-Nothom and I am a doctoral candidate in early childhood education at the University of Missouri in the Department of Learning, Teaching, and Curriculum. I have been an educator for over 15 years, with 14 of them teaching young children and the past three years teaching pre-service teachers in the early childhood and elementary programs in the College of Education at Mizzou. Over the past year, I have Ms. Rotter and I have collaborated together on the sharing of socially and culturally diverse picturebooks in her classroom.

I am writing to ask for your consent in recording video, audio, and/or taking photos of student work as it relates to the sharing and discussing of racially diverse picturebooks in Ms. Rotter's classroom.

Attached to this letter, you will find a detailed explanation of the research being done in the classroom. Please read over the form, and if you feel comfortable consenting to this research, return on the last page to Ms. Rotter as soon as you are able.

Feel free to contact me or Ms. Rotter at any time with questions, concerns, or comments.

Sincerely,

Oona Fontanella-Nothom, M.A.Ed.

Doctoral Candidate

Oona.Fontanella-Nothom@mail.missouri.edu

Cell phone [number redacted] 
Your child is being asked to participate in a research study. This study will explore children's responses to culturally diverse picturebooks.

The picturebook reading that students will be involved with will not take away from the regular curriculum. All students in the classroom, even if they don't have consent to participate in the study, will continue to receive the same instruction from the teacher.

When you are invited to participate in research, you have the right to be informed about the study procedures so that you can decide whether you want to consent to participation. If any aspect of this form is confusing please ask Oona Fontanella-Nothom.

You have the right to know what you and your child will be asked to do so that you can decide whether or not to be in the study. Your child's participation is voluntary. Your child does not have to be in the study if you do not want them to. You may refuse to be in the study and nothing will happen. If you do not want your child to be in the study, you may stop at any time without penalty. Please send written notification to Oona Fontanella-Nothom that you wish to withdraw your child from the study.

\section{Purpose of the study:}

The purpose of this research is to explore children's picture books about racial and cultural diversity with first grade children and explore their responses to literature. This research project, which focuses on reading about diverse families creates spaces for potential conversations around equity and a culture of dignity when all children can see themselves in children's literature and learn about others' cultures.

\section{Length of study:}

This study will take place during this school year in Ms. Rotter's first grade classroom at RB elementary school. Oona Fontanella-Nothom, the university researcher, will be in the classroom 1-2 days each week collecting data and interacting with the teacher and students.

\section{How many people will be a part of the study?}

There is potential for all students in the classroom to be a part of the study.

\section{Types of data collected:}

All observations will occur during regular activities and interactions in the classroom. As a researcher, Oona will be collecting: photographs of classroom interaction and artifacts and audio and video recordings of discussions.

\section{What are the benefits from participating?}

Your child's participation will benefit educators in the following ways:

This research study has the potential to help educators learn more about how young children learn about the world through picture book reading. Additionally, this study is likely to help those in the field of education understand how to successfully engage in conversation of racial and cultural differences with young children. 
Your child's participation will benefit them as a result of having the opportunity to read and explore diverse picture books and be involved in multi-layered conversations about their ideas about picture books.

\section{What are the risks of participating?}

Your child's participation in this study is not expected to cause any risks greater than those encountered in everyday life and normal classroom interactions. There are no foreseeable risks in this study, as students will be interacting with their regular curriculum. You also have the option of not having your child participate in this study, and will not be penalized for your decision.

\section{Confidentiality}

Your child's identity and participation will remain confidential. All students and the school name will be given a pseudonym when research is presented at a conference and/or published in a journal or book. Only general geographic information will be given (for example, mid-western university town). Only Oona, the researcher, will know the identity of participants and have access to the data. All data collected will be stored in a secured location at the university.

\section{What will my child receive for being in the study?}

As the students will not be asked to do anything outside of their regular curriculum, no incentives will be given to students to participate in the study.

\section{Will the researcher tell me if something changes in the study?}

Informed consent is an ongoing process that requires communication between the researcher and participants. You will be informed of any new information during the course of this study that might influence your child's health, welfare, or willingness to be in this study. Additionally, you have the option to receive monthly updates about the study.

\section{Where can I learn more about participating in research?}

The Campus Institutional Review Board offers educational opportunities to research participants, prospective participants, or their communities to enhance their understanding of research involving human participants, the IRB process, the responsibilities of the investigator and the IRB. You may access the Campus IRB website to learn more about the human subject research process at http://www.research.missouri.edu/cirb/index.htm

\section{Who do I contact if I have questions, concerns, or complaints?}

Please contact Oona Fontanella-Nothom if you have questions about the research.

Oona Fontanella-Nothom, M.A.Ed

Doctoral Candidate in Early Childhood Education

Department of Learning, Teaching and Curriculum

College of Education 
University of Missouri

303 Townsend Hall

Columbia, MO 65211

[cell phone number redacted]

orfmc9@missouri.edu

Additionally, you may contact Oona's faculty advisor, Dr. Candace Kuby, at the university with any questions, concerns, or complaints.

Candace R. Kuby, Ph.D.

Associate Professor, Early Childhood Education

Department of Learning, Teaching and Curriculum

College of Education

University of Missouri

303 Townsend Hall

(573) 882-2965

kubyc@missouri.edu

Who do I contact if I have questions about my rights, concerns, complaints or comments about the research?

You may contact the Campus Institutional Review Board if you have questions about your rights, concerns, complaints or comments as a research participant.

You can contact the Campus Institutional Review Board directly by telephone or email to voice or solicit any concerns, questions, input or complaints about the research study.

Campus Institutional Review Board

483 McReynolds Hall

Columbia, MO 65211

573-882-9585

E-Mail: umcresearchcirb@missouri.edu

Website: http://www.research.missouri.edu/cirb/index.htm

Please see next page for signatures. 


\section{SIGNATURE FORM***Please return this form to the classroom*****}

I have read this consent form and my questions have been answered. I know that I can remove my child from the study at any time without any problems.

Please read each statement below and indicate which ones you approve by checking the line next to the statement and then sign at the bottom of the form.

I consent for my child to be a part of the study and give permission for all data photographs, audio files, video recordings, and student made artifacts - to be used for data analysis, publications, and presentations.

I consent for my child to be a part of the study but only wish for the following data sources to be used (check the ones you give permission to be used for analysis, publication and presentations):

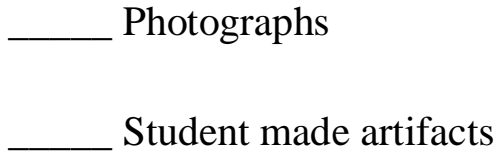

I am willing for my child to be recorded in classroom interactions, but do not wish for the data (recordings) to be used for research purposes.

I am willing to be contacted at a future date if researchers desire to have parental interviews and/or questionnaires related to the study.

I would like to be included on monthly e-mail updates about the status of the research project. Include email address(es) here:

Optional demographic data:

The primary language spoken at our home is:

The race that I identify my child as:

The ethnicity that I identify my child as:

Parent/Guardian(s) Signature

Date

Print Child's Name 


\section{References}

Albon, D., \& Rosen, R. (2014). Negotiating adult-child relationships in early childhood research. New York, NY: Routledge.

Alim, H. S. (2016). Introducing raciolinguistics. In H. S. Alim, J. R. Rickford, \& A. F. Ball (Eds.), Raciolinguistics: How language shapes our ideas about race (pp. 130). New York, NY: Oxford University Press.

Apfelbaum, E. P., Pauker, K., Ambady, N., Sommers, S. R., \& Norton, M. I. (2008). Learning (not) to talk about race: When older children under perform in social categorization. Developmental Psychology, 44(5), 1513-1518.

Baldwin, J. (1963, December 21). A Talk to Teachers (originally published as "The Negro Child - His Self Image"). The Saturday Review. Retrieved from https://curatingtheclassroom.org/2017/05/09/blog-post-title-2/

Bell, D. (1989). And we are not saved: The elusive quest for racial justice. New York, NY: Perseus Books.

Bell, D. (1995). Who's afraid of critical race theory? University of Illinois Law Review, 1995, 893-910.

Beneke, M. R., \& Cheatham, G. A. (2019). Race talk in preschool: Academic readiness and participation in shared book reading. Journal of Early Childhood Literacy, 19(1), 107-133.

Bigler, R.S., \& Liben, L.S. (1993). A cognitive developmental approach to racial stereotyping and reconstructive memory in Euro-American children. Child Development, 64(5), 1507-1518.

Bishop, R. S. (1990). Mirrors, windows, and sliding glass doors. Perspectives, 6(3), ix-xi. 
Bloch, M. N. (2014). Interrogating reconceptualizing early care and education. In M.N. Bloch, B. B. Swadener, \& G. S. Cannella, (Eds.), Reconceptualizing early childhood care and education: A reader (pp. 19-31). New York, NY: Peter Lang.

Bonilla-Silva, E. (2010). Racism without racists: Color-blind racism and racial inequality in contemporary America ( $3^{\text {rd }}$ ed.). Lanham, MD: Rowman and Littlefield.

Botehlo, M. J., \& Rudman, M. K. (2009). Critical multicultural analysis of children's literature. New York, NY: Routledge.

Boutte, G., Johnson, G. L., Wynter-Hoyte, K., \& Uyoata, U. E. (2017). Using African Diaspora literacy to heal and restore the souls of young Black children. International Critical Childhood Policy Studies, 6(1), 66-79.

Boutte, G. S., Lopez-Robertson, J., \& Powers-Costello, E. (2011). Moving beyond colorblindness in early childhood classrooms. Early Childhood Education Journal, 39, 335-342.

Bryan, N. (2018) Shaking the bad boys: Troubling the criminalization of black boys' childhood play, hegemonic white masculinity and femininity, and the school playground-to-prison pipeline. Race Ethnicity and Education. Advance online publication. DOI:10.1080/13613324.2018.1512483

Childers, S. M. (2012). Against simplicity, Against ethics: Analytics of disruption as quasi-. Methodology. Qualitative Inquiry, 18(9), 752-761.

Clark, K., \& Clark, M. (1939). The development of consciousness of self and the emergence of racial identification in Negro preschool children. Journal of Social Psychology, 10, 591-599. 
Clarke, V., \& Watson, D. (2014). Examining whiteness in a children's centre. Contemporary Issues in Early Childhood, 15(1), 69-80.

Cocks, A. J. (2006). The ethical maze: Finding an inclusive path towards gaining children's agreement to research participation. Childhood, 13(2), 247-266.

Copenhaver-Johnson, J. (2006). Talking to children about race: The importance of inviting difficult conversations. Childhood Education, 83(1), 12-22.

Cole, A., \& Knowles, J. G. (2000). Researching teaching: Exploring teacher development through reflexive inquiry. Needham Heights, MA: Allyn and Bacon.

Cradle 2 Grave Program. (n.d.). Retrieved from https://www.cradletograveprogram.com

Crenshaw, K. (1989). Demarginalizing the intersection of race and sex: A Black feminist critique of antidiscrimination doctrine, feminist Theory and antiracist politics. University of Chicago Legal Forum, 1(8), 139-167.

Crenshaw, K., Gotanda, N., Peller, G., \& Thomas, K. (Eds.). (1995). Critical race theory: The key writings that formed the movement. New York, NY: New Press.

Davis, A. Y. (1981). Women, race, and class. New York, NY: Vintage Books.

Davis, A. Y. (2016). Freedom is a constant struggle. Chicago, IL: Haymarket Books. Delgado, R. (1984). The imperial scholar: Reflections on a review of civil rights literature. University of Pennsylvania Law Review, 132, 561-578.

Delgado, R., \& Stefanic, J. (2012). Critical race theory: An introduction. New York: NYU Press.

Derman-Sparks, L. (1989). Anti-bias curriculum: Tools for empowering young children. Washington, D.C.: National Association for the Education of Young Children. 
Derman-Sparks, L., \& Ramsey, P. G. (2011). What if all the kids are white? Anti-bias multicultural education with young children and families (2nd ed.). New York, NY: Teachers College Press.

DiAngelo, R. (2018). White fragility: Why it's so hard for white people to talk about racism. Boston, MA: Beacon Press.

Dillard, C. (2019, March 27). Hate at school: February 2019. Retrieved April 3, 2019, from https://www.tolerance.org/magazine/hate-at-school-february-2019

Dockett, S., \& Perry, B. (2007). Trusting children's accounts in research. Journal of Early Childhood Research, 5(1), 47-63.

Dolezal, R. (2015, June 16). Rachel Dolezal breaks her silence: 'I identify as black.' Retrieved from https://www.today.com/video/rachel-dolezal-breaks-her-silence-iidentify-as-black-465269315945

Douglass, F. (1995). The narrative of the life of Fredrick Douglass. Dover Publications.

Dumas, M. J. (2016). Against the dark: Antiblackness in educational policy and discourse. Theory Into Practice, 55, 11-19.

Dumas, M. J., \& Nelson, J. D. (2016). (Re)Imagining Black boyhood: Toward a critical framework for educational research. Harvard Educational Review, 86(1), 27-47.

Fass, P. (2007). Children of a new world. New York, NY: NYU Press.

Frankenberg, R. (1993). The social construction of whiteness: White women, race matters. Minneapolis, MN: University of Minnesota.

Freire, P. (1970/2000). Pedagogy of the oppressed, 30th anniversary edition. New York, NY: Continuum. 
Garlen, J. C. (2018). Interrogating innocence: "Childhood" as exclusionary social practice. Childhood. Advance online publication. DOI: $10.1177 / 0907568218811484$

Goodman, M. (1964). Race awareness in young children. New York, NY: Collier.

Guinier, L. (2004). From racial liberalism to racial literacy: Brown v. board of education and the interest-divergence dilemma. Journal of American History, 91(1), 92-118.

Hancock, T. S., \& Fontanella-Nothom, O. (accepted). Becoming with/in excess(es) and mess(es): Pedagogies of sustainment (POSt). Qualitative Inquiry.

Harris, C. I. (1993). Whiteness as property. Harvard Law Review, 106(8), 1707-1791.

Hartman, S. (2007). Lose your mother: Journey along the Atlantic slave route. New York, NY: Farrar, Straus, and Giroux.

Hartman, S. (2017). In the wake: A salon in honor of Christina Sharpe. Retrieved from https://www.facebook.com/BCRW.Feminism/posts/care-is-the-antidote-toviolence-saidiya-hartman-powerful-conversation-with-chri/10154481676477297/

Hibbard, L. (2012, March 5). Jada Williams, student, allegedly harassed for awardwinning essay comparing school to modern slavery. Retrieved from https://www.huffpost.com/entry/jada-williams-student-allegedly-harassed-foressay_n_1321926

hooks, b. (1994). Teaching to transgress: Education as the practice of freedom. New York, NY: Routledge.

Husband, T. (2010). He's too young to learn about that stuff: Anti-racist pedagogy and early childhood social studies. Social Studies Research \& Practice, 5(2), 61-75. 
Husband, T. (2012). “I don't see color”: Challenging assumptions about discussing race with young children. Early Childhood Education Journal, 39(6), 365-371.

Husband, T. (2016). But I don't see color: The perils, practices, and possibilities of antiracist education. Rotterdam, NL: Sense Publishers.

Husband, T. (2018). Using multicultural picturebooks to promote racial justice in urban early childhood literacy classrooms. Urban Education. Advance online publication. DOI:10.1177/0042085918805145

Jackson, A. Y., \& Mazzei, L. A. (2012). Thinking with theory in qualitative research: Viewing data across multiple perspectives (1st ed.). New York, NY: Routledge.

Jackson, A. Y., \& Mazzei, L. A. (2017). Thinking with theory: A new analytic for qualitative inquiry. In N. K. Denzin \& Y. S. Lincoln (Eds.), The sage handbook of qualitative research (5th ed., pp. 718-737). Thousand Oaks, CA: Sage.

Janks, H. (2010). Language and power. New York, NY: Routledge.

Jenkins, E. C. \& Austin, M. C. (1987). Literature for children about Asian and Asian Americans. New York, NY: Greenwood Press.

Jordan, P., \& Hernandez-Reif, M. (2009). Re-examination of young children's racial attitudes and skin tone preferences. Journal of Black Psychology, 35(3), 388-403

Kai, M. (2019, January 11). In another case of dreadlock discrimination, Texas elementary school insists 1 st grader cut his locs. Retrieved from: https://theglowup.theroot.com/in-another-case-of-dreadlock-discrimination-texaselem-1831684144

Katz, P. A. (1973). Stimulus predifferentiation and modification of children's racial attitudes. Child Development, 44(2), 232-237. 
Katz, P. A. (1987). Developmental and social processes in ethnic attitudes and self identification. In J. S. Phinney (Ed.), Children ethnic socialization: Pluralism and development (pp. 92-100). Thousand Oaks, CA: Sage.

Killen, M., Margie, N., \& Sinno, S. (2006). Morality in the context of intergroup relationships. In M. Killen \& J. Smetana (Eds.), Handbook of moral development (pp. 155-185). Mahwah, NJ: Lawrence Erlbaum.

King, L. J. (2016). Teaching Black history as a racial literacy project. Race Ethnicity and Education, 19(6), 1303-1318.

Kuby, C. R. (2013). Critical literacy in the early childhood classroom: Unpacking histories, unlearning privilege. New York, NY: Teachers College Press.

Kuntz, A. (2015). The responsible methodologist: Inquiry, truth-telling, and social justice. Walnut Creek, CA: Left Coast Press.

Labadie, M., Mosley, M. M., \& Rogers, M. (2012). Opening spaces for critical literacy: Introducing books to young readers. The Reading Teacher, 66(2), 117-127.

Ladson-Billings, G., \& Tate, W. F. (1995). Toward a critical race theory of education. Teachers College Record, 97(1), 47-68.

Lasker, B. (1929). Race attitudes and children. New York, NY: Henry Holt.

Lee, C. J. (1995). Navigating the typology of race. In K. Crenshaw, N. Gotanda, G. Peller, K. Thomas (Eds.), Critical race theory: The key writings that formed the movement (pp. 441-448). New York, NY: The New Press.

Lenz-Taguchi, H. (2006) Reconceptualizing early childhood education: challenging taken-for-granted ideas. In J. Einarsdottir \& J. Wagner (Eds.), Nordic childhoods and early education: Philosophy, research, policy and practice in Denmark, 
Finland, Iceland, Norway, and Sweden (pp. 257-287). Greenwich, CT:

Information Age Publishing.

Lenz Taguchi, H. L., \& St. Pierre, E. A. (2017). Using Concept as Method in Educational and Social Science Inquiry. Qualitative Inquiry, 23(9), 643-648.

Leonardo, Z. (2009). Race, whiteness, and education. New York, NY: Routledge.

Leonardo, Z. (2013). Race frameworks: A multidimensional theory of racism and education. New York, NY: Teachers College Press.

Leonardo, Z. (2016, April). The "new eugenics" and education [Discussant]. Paper presented at the meeting of the American Educational Research Association, Washington D.C.

Leong, N. (2013). Racial capitalism. Harvard Law Review, 126(8), 2153-2225.

Levy, S., West, T., Ramirez, L., \& Pachankis, J. (2004). Racial and ethnic prejudice among children. In J. Chin (Ed.), The psychology of prejudice and discrimination: Racism in America (pp. 37-60). Westport, CT: Greenwood.

Lewison, M., Leland, C., Flint, A. S., \& Möller, K. J. (2002). Dangerous discourses: Controversial books to support engagement, diversity, and democracy. The New Advocate, 15(3), 215-226.

Lipsitz, G. (2006). The possessive investment in whiteness: How white people profit from identity politics (2nd ed.). Philadelphia, PA: Temple University.

Lorber, J. (1994). Paradoxes of gender. New Haven, CT: Yale University Press.

Lorde, A. (1984/2007). Sister outsider. Trumansburg, NY: Crossing Press.

MacNaughton, G., \& Davis, K. (2009). Discourses of "race" in early childhood: From cognition to power. In G. MacNaughton \& K. Davis (Eds.), "Race” and early 
childhood education: An international approach to identity, politics, and pedagogy (pp. 17-30). New York, NY: Palgrave Macmillan.

Matsuda, M. (1991). Voices of America: Accent, antidiscrimination law, and jurisprudence for the last reconstruction. Yale Law Journal, 100, 1329-1407.

Medina, B., \& Frank, T. (2019, April 17). TSA agents say they're not discriminating against black women, but their body scanners might be. Retrieved April 20, 2019 from: https://www.propublica.org/article/tsa-not-discriminating-against-blackwomen-but-their-body-scanners-might-be

Michael, A. (2015). Raising race questions: Whiteness and inquiry in education. New York, NY: Teachers College Press.

Morrison, T. (1993). Novelist Toni Morrison looks back on her youth and family and presents her newest book, "Jazz." Interview by C. Rose [Television broadcast]. Retrieved from https://charlierose.com/videos/18778

Nash, K., Howard, J., Miller, E., Boutte, G., Johnson, G., \& Reid, L. (2018). Critical racial literacy in homes, schools, and communities: Propositions for early childhood contexts. Contemporary Issues in Early Childhood, 19(3), 256-273.

Orr, J. (1997). The same but different: Classroom-based collaborative research and the work of classrooms. In H. Christensen, L. Goulet, C. Krentz, \& M. Maeers (Eds.), Recreating relationships: Collaboration and Educational Reform (pp. 247-262). Albany, NY: SUNY Press.

Pacini-Ketchabaw, V. (2007). Child care and multiculturalism: A site of governance by marked by flexibility and openness. Contemporary Issues in Early Childhood, $8(3), 222-232$. 
Patel, L. (2016). Decolonizing educational research: From ownership to answerability. New York, NY: Routledge.

Reason, P., \& Bradbury, H. (2006). Handbook of action research. Thousand Oaks, CA: Sage.

Richardson, L., \& St. Pierre, E. A. (2005). Writing: A method of inquiry. In N. K. Denzin \& Y. S. Lincoln (Eds.), The Sage handbook of qualitative research (pp. 959-978). Thousand Oaks, CA: Sage.

Robinson, K. H., \& Jones Díaz, C. J. (2006). Diversity and difference in early childhood education: Issues for theory and practice. London: Open University Press.

Roediger, D. (1991). The wages of whiteness. New York, NY: Verso.

Rogers, R., \& Mosley, M. (2006). Racial literacy in a second-grade classroom: Critical race theory, whiteness Studies, and literacy Research. Reading Research Quarterly, 41(4), 462-495.

Rosenblatt, L. M. (1978). The reader, the text, and the poem: The transactional theory of the literary work. Carbondale, IL: Southern Illinois University Press.

Rosenblatt, L. M. (1982). The literary transaction: Evocation and response. Theory into Practice, 21(4), 268-277.

Rubin, J. C. (2018). Rethinking literacy and responsibility: A diffractive engagement with posthumanist education and Jain nonviolence. Literacy Research: Theory, Method, and Practice, 67, 327-342.

Sacchetti, M. (2018, December 28). Official: Guatemalan boy who died in U.S. custody tested positive for influenza B, final cause of death remains under investigation. Retrieved from https://www.washingtonpost.com/local/immigration/father- 
whose-son-died-in-custody-knew-bringing-him-would-ease-entry-intous/2018/12/27/4c210bfc-0a1d-11e9-85b6-

41c0fe0c5b8f_story.html?utm_term=.3d0b7f6fac5e

Sealey-Ruiz, Y. (2011). Learning to talk and write about race: Developing racial literacy in a college English classroom. English Quarterly, 42(1-2), 24-42.

Sharpe, C. (2016). The wake: On blackness and being. Durham, NC: Duke University Press.

Sipe, L. R. (1998). How picture books work: A semiotically framed theory of textpicture relationships. Children's Literature in Education, 29(2), 97- 108.

Sipe, L. R. (2008). Young children's visual meaning-making in response to picturebooks. In J. Flood, S. Brice Heath \& D. Lapp (Eds.), Handbook of research in teaching literacy through the visual and communicative arts vol. 2 (pp. 381-392). Mahwah, NJ: Lawrence Erlbaum.

Solórzano, D. G., \& Delgado Bernal, D. (2001). Examining transformational resistance through a critical race and LatCrit theory framework: Chicana and Chicano students in an urban context. Urban Education, 36, 308-342.

Souto-Manning, M. (2013). Multicultural teaching in the early childhood education: Approaches, strategies, and tools preschool-2nd grade. New York, NY: Teachers College Press.

Spivak, G. C. (2014). Readings. New York, NY: Seagull Books.

St. Pierre, E. A. (2017, April). Post qualitative inquiry in the ontological turn [Lecture]. Paper presented at the meeting of the American Educational Research Association, San Antonio, TX. 
Stevenson, H. (2014). Promoting racial literacy in schools: Differences that make a difference. New York, NY: Teachers College Press.

Tallbear, K. (2013). Native American DNA. Minneapolis, MN: University of Minnesota Press.

Tatum, B. (2017). Why are all the black kids sitting together in the cafeteria? And other conversations about race ( $2^{\text {nd }}$ ed.). New York, NY: Basic Books.

Taylor, K. (2013). The political economy of racism. Socialism 2013. Lecture retrieved from https://wearemany.org/a/2013/06/political-economy-of-racism

Thompson, A. (2003). Tiffany, friend of people of color: White investments in antiracism. International Journal of Qualitative Studies in Education, 16(1), 7-29.

TOLO (n.d.). Peter Tolkin + Sarah Lorenzen Architecture Art/Furniture Projects. Retrieved from http://toloarchitecture.com/pdfs/TOLO_Website_Art\%20Furniture.pdf

Tuck, E., \& McKenzie, M. (2015). Place in research: Theory, methodology, and methods. New York, NY: Routledge.

Tuck, E., \& Yang, K. W. (2018). Introduction: Born under the rising sun of justice. In E. Tuck \& K. W. Yang (Eds.), Toward what Justice? Describing diverse dreams of justice in education (pp. 1-17). New York, NY: Routledge.

Twine, F. W. (2011). A white side of Black Britain: Interracial literacy and racial literacy. Durham, NC: Duke University Press.

Van Ausdale, D. (2004). Children. In E. Cashmere (Ed.), Encyclopedia of race and ethnic studies (pp. 78-81). New York, NY: Taylor and Francis. 
Van Ausdale, D., \& Feagin, J. R. (2001). The first $r$ : How children learn race and racism. Lanham, MD: Rowman \& Littlefield.

Vasquez, V. (2004). Negotiating critical literacies with young children. Mahwah, NJ: Erlbaum.

Weheliye, A. G. (2014). Habeas viscus: Racializing assemblages, biopolitics, and black feminist theories of the human. Durham, NC: Duke University Press.

Wilderson, F. B. (2010). Red, white, and black: Cinema and the structure of U.S. antagonisms. Durham, NC: Duke University Press.

Williams, L. R., \& Norton, N. E. L. (2008). Thought provoking moments in teaching young children. In C. Genishi \& A. L. Goodwin (Eds.), Diversities in early childhood education (pp. 103-118). New York, NY: Routledge.

Wood, S., \& Jocius, R. (2013). Combating “I hate this stupid book!” Black males and critical literacy. The Reading Teacher, 66(8), 661-669.

Woodhead, M. \& Faulkner, D. (2008). Subjects, objects or participants? Dilemmas of psychological research with children. In P. Christensen \& A. James (Eds.), Research with children: Perspectives and practices (2nd ed., pp. 10-39). London, UK: Falmer Press. 
Oona Fontanella-Nothom was born on a warm evening on September 6, 1980 in Manhattan, New York at New York Hospital. Her father often mentioned understanding her tenacity for life early on, when upon holding her for the first time, she grabbed his finger and locked eyes with him. Oona discovered a love for reading at a young age, and books encouraged her imagination and allowed her to explore, question, and connect with a world beyond her own. Raised in a house where music was always playing and living in a place "where the cement grows" developed her curiosity and interest in the diversity of the world. As a teacher of young children, Oona discovered her passion and forged a commitment to making the world a better place. Driven by persistent questions about children's abilities to wrestle with issues of justice and equity, Oona pursued a master's degree where she discovered that she enjoyed engaging with a thing called research. Unbeknownst to her, these experiences, interests, and questions converged and she found herself pursuing a Ph.D. in Learning, Teaching, and Curriculum with an emphasis in early childhood education. 